Linköping University Medical Dissertations No. 1590

\title{
Neurotoxic side effects and impact on daily life in patients with colorectal cancer with adjuvant oxaliplatin-based chemotherapy
}

\author{
Jenny Drott
}

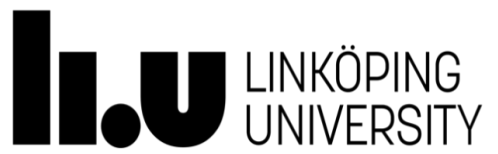

Department of Medical and Health Sciences

Linköping University, Sweden

Linköping 2018 
() Jenny Drott, 2018

Cover picture: M. Drott

Published article has been reprinted with the permission of the copyright holder.

Printed in Sweden by LiU-Tryck, Linköping, Sweden, 2018

ISBN 978-91-7685-442-6

ISSN $0345-0082$ 
To my family

Jens, Max and My

Life can only be understood backwards;

but it must be lived forwards.

Søren Kierkegaard 



\section{CONTENTS}

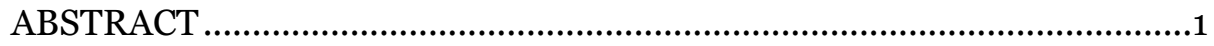

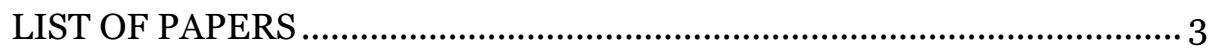

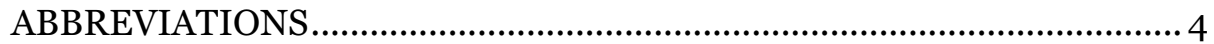

INTRODUCTION ………………………………................................... 5

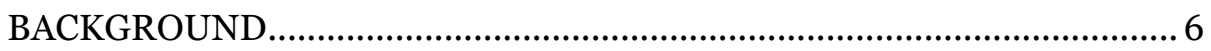

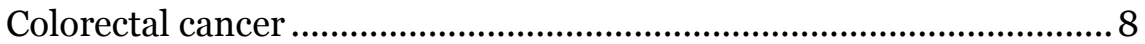

Colorectal cancer treatments ............................................................. 9

Chemotherapy-induced neurotoxic side effects ................................... 10

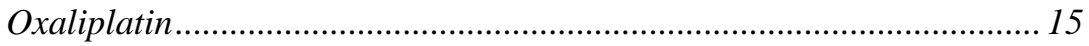

Oxaliplatin-induced neurotoxic side effects............................................ 17

Use of mobile phone technology in cancer care …………………….....20

THEORETICAL FRAMEWORK.............................................................. 21

Self-care deficit nursing theory ............................................................. 21

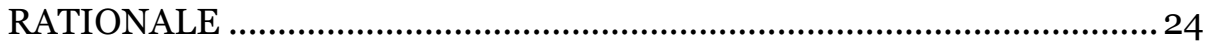

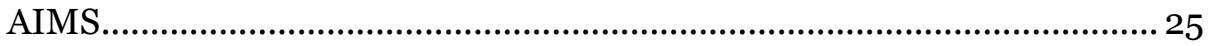

Specific aims ………........................................................................ 25

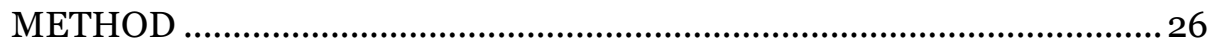

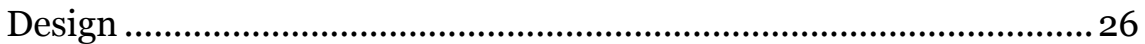

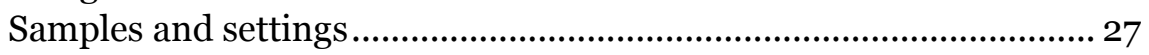

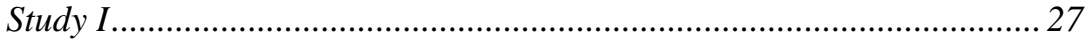

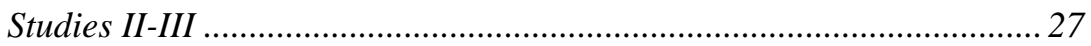

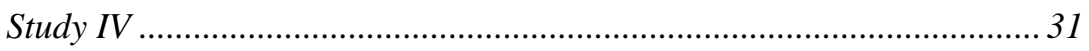

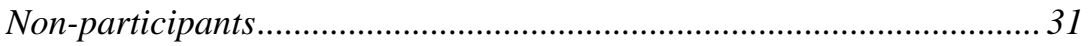

Data collection .................................................................................. 35

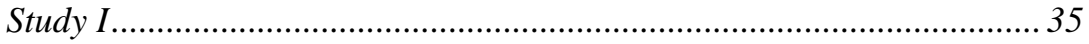

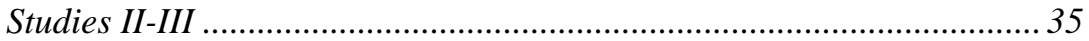

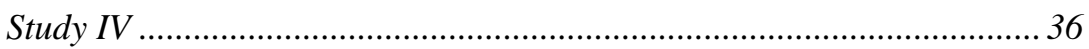


Description of the Oxaliplatin-associated Neurotoxicity Questionnaire

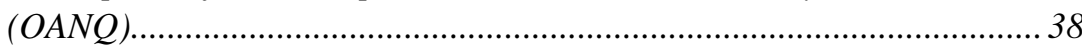

The mobile phone-based system …………………………………........ 40

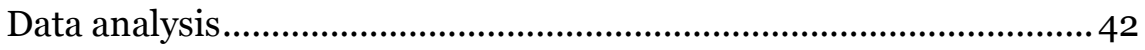

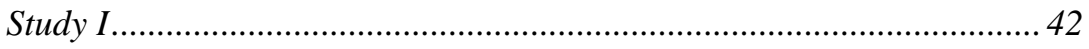

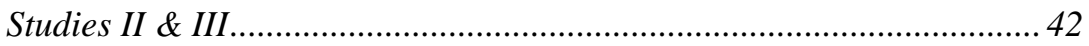

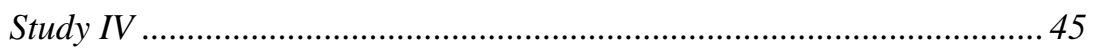

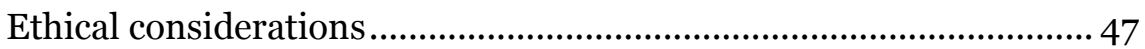

Trustworthiness, validity and reliability ……………….......................48

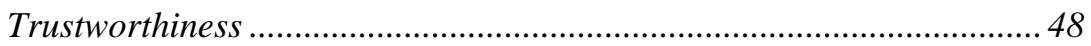

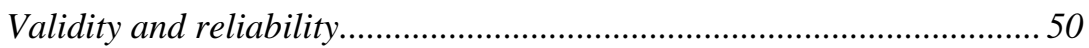

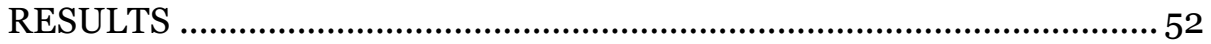

Documentation of neurotoxicity in medical records........................... 52

Experiences of neurotoxic side effects and impact on daily life ......... 54 Real-time longitudinal patient-reported neurotoxicity, and impact on daily activities .......................................................................................... 57

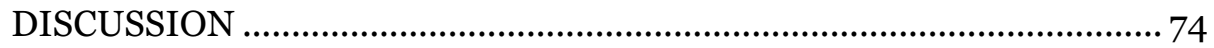

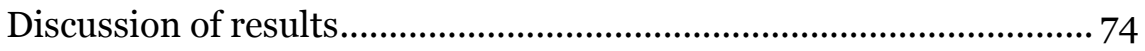

Patient perspectives on neurotoxic side effects and impact on daily life 74 Neurotoxic side effects and self-care .................................................... 79

Methodological considerations .............................................................. 84

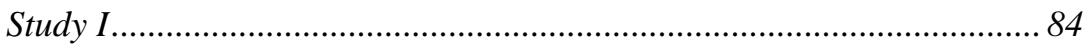

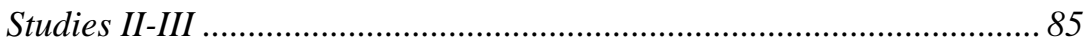

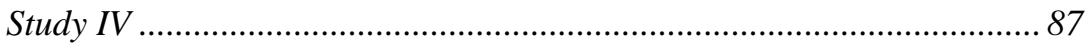

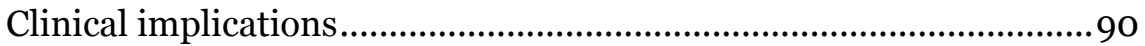

Future research .................................................................................90

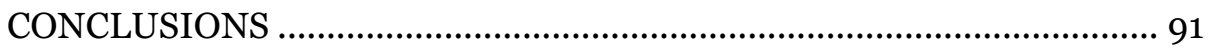

SVENSK SAMMANFATTNING …......................................................... 92

ACKNOWLEDGEMENTS ....................................................................94

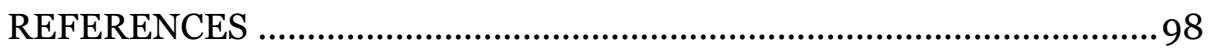




\section{ABSTRACT}

Introduction: Colorectal cancer (CRC) is one of the most common cancers globally. Chemotherapeutic drugs are frequently used in postoperative treatment. The platinum compound oxaliplatin (OXA) is an option for adjuvant treatment of patients with resected CRC, and has been shown to improve survival. OXA-induced neurotoxic side effects are common (e.g. sensitivity to cold, numbness). Neurotoxicity can interfere with the patient's daily living and affect ability to carry out activities. Because there is no evidence for effective treatment in terms of eliminating neurotoxic side effects, the most successful approaches include early identification, reduction of dose and interruption of treatment. Current research has identified a need for patient-oriented evidence in terms of long-term follow-up of neurotoxicity.

Aim: The overall aim of this thesis was to explore OXA-induced neurotoxic side effects in patients with colorectal cancer, and the influence on patients' daily lives during and post OXA treatment.

Methods: The thesis is based on four studies, and includes an analysis of medical records, as well as prospective quantitative and qualitative approaches with longitudinal data collection through a mobile phone-based system. The studies were performed at oncology departments in four hospitals in Sweden. Inclusion criteria were that patients should be at least 18 years of age, and should have been treated with chemotherapy, including OXA (FOLFOX, XELOX), in an adjuvant setting for CRC stages II-III. Study I had a retrospective design, and data involved $(n=61)$ medical records. A structured protocol was used to evaluate the documentation of patients' neurotoxic side effects. In studies II and III, ten patients were recruited using a strategy of purposeful and consecutive selection according to the inclusion criteria, where OXA-related neurotoxic side effects were assessed. A total of 10 interviews were carried out when neurotoxic side effects appeared (II), and after completed OXA treatment (3, 6 and 12 month's follow-up) 25 repeated interviews were conducted (III). The prospective longitudinal study IV aimed to identify and assess patient-reported outcomes in terms of neurotoxic side effects, and their impact on patients' daily activities $(n=46)$. An Oxaliplatin-associated Neurotoxicity Questionnaire (OANQ) was administered in real time to indicate patientreported outcomes. In total, 370 questionnaire responses were available for analysis.

Results: The results from the retrospective study (I) showed that a free description of the degree of neurotoxic side effects was given in the patients' medical records. No formal assessment had been used in the documentation. The findings of the two qualitative studies contribute knowledge about how patients endure neurotoxic side effects early in the treatment phase, and how they learn to live with neurotoxicity in the long-term perspective. Patients coped with their side effects by developing different self-care strategies to restore normality in their daily lives (II-III). Neurotoxic side effects interferes with the patient's daily activities in a variety of ways. These side effects change in terms of their character and their location in the body over time. The most frequent side effects during treatment were cold-precipitated tingling in the upper extremities and in the mouth/throat. At the end of treatment, neurotoxicity in the lower extremities was considered high and 
interfered with the patients' daily activities. The results show significant differences between baseline data, and nine of the patients had not returned to baseline after one year (IV).

Conclusion: Neurotoxic side effects affect patients' daily activities in different ways, with an impact on their physical, psychological, emotional and social life. Patients endured and coped with their side effects in different ways involving self-care strategies to restore normality. The patients' daily lives were affected by numbness and tingling in the legs and tingling in upper extremity, and they had learned to live with these side effects. The neurotoxic side effects changed character and localisation over time. These results should be taken into account when patients are informed about treatment, and in the dialogue about the benefits and risks.

Keywords: Cancer care, Cancer nursing, Colorectal cancer, Neurotoxicity, Neuropathy, Oxaliplatin, Chemotherapy, Patient-reported outcomes, Health, Qualitative study, Longitudinal study, mHealth 


\section{LIST OF PAPERS}

I. Drott J, Starkhammar H, Börjeson S, Berterö C. Oxaliplatin induced neurotoxicity among patients with colorectal cancer: documentation in medical records - a pilot study. Open Journal of Nursing 2014 (4), 265-274.

II. Drott J, Starkhammar H, Kjellgren K, Berterö C. People with colorectal cancer endure neurotoxic side effects early in the oxaliplatin treatment period - a qualitative study. Accepted for publication in Oncology Nursing Forum.

III. Drott J, Starkhammar H, Kjellgren K, Berterö C. The trajectory of neurotoxic side effects' impact on daily life: a qualitative study. Supportive Care in Cancer 2016 (24), 3455-3461.

IV. Drott J, Fomichov V, Starkhammar H, Börjeson S, Kjellgren K, Berterö C. Oxaliplatin induced neurotoxic side effects and their impact on daily activities: a longitudinal study among patients with colorectal cancer. Resubmitted.

Published papers have been reprinted with permission from the publisher. 


\section{ABBREVIATIONS}

\begin{tabular}{|c|c|}
\hline ADL & Activities of Daily Living \\
\hline CIPN & Chemotherapy-induced Peripheral Neuropathy \\
\hline \multirow[t]{2}{*}{ CIPNAT } & Chemotherapy-induced Peripheral Neuropathy Assessment \\
\hline & Tool \\
\hline CQ & Circadian Questions \\
\hline CRC & Colorectal cancer \\
\hline CTC & Common Toxicity Criteria \\
\hline CTCAE & Common Terminology Criteria for Adverse Events \\
\hline ePRO & Electronic Patient-reported Outcomes \\
\hline \multirow[t]{3}{*}{ EORTC QLQ-CIPN20 } & European Organization for Research Treatment in Cancer \\
\hline & Quality of Life - Chemotherapy-induced Peripheral Neurop- \\
\hline & 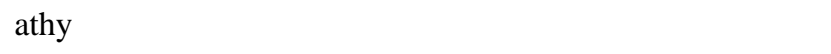 \\
\hline \multirow[t]{2}{*}{ FACT/GOG-NTX } & Functional Assessment of Cancer Therapy/Gynaecologic \\
\hline & Oncology Group Neurotoxicity \\
\hline \multirow[t]{2}{*}{$\mathrm{ICF}$} & International Classification of Functioning, Disability and \\
\hline & Health \\
\hline mHealth & Mobile Health \\
\hline OANQ & Oxaliplatin-associated Neurotoxicity Questionnaire \\
\hline OXA & Oxaliplatin \\
\hline PNQ & Patient Neuropathy Questionnaire \\
\hline PRO & Patient-reported Outcomes \\
\hline PROM & Patient-reported Outcomes Measurement \\
\hline RCT & Randomised controlled trials \\
\hline TNM & Tumour Nodes Metastasis \\
\hline WHO & World Health Organization \\
\hline
\end{tabular}




\section{INTRODUCTION}

Every human being strives to be healthy. When diseases such as cancer occur, people try to find cures for the disease and to relieve symptoms and side effects. Healthcare professionals are responsible for supporting and promoting health. In my clinical experience as a nurse in cancer care, the focus is often on supporting the patients in adapting to their situation in different ways. Maintaining daily activities that healthy people view as obvious can often be a challenge after a cancer diagnosis and cancer treatments. This thesis was initiated since neurotoxicity was raised as a problematic side effect by the patients in previous studies conducted by my research team (Börjeson et al. 2012, Pettersson et al. 2014).

Colorectal cancer (CRC) is one of the most common cancers globally. Chemotherapeutic drugs are frequently used in postoperative treatment of patients with $\mathrm{CRC}$. The platinum agent oxaliplatin (OXA) is a common choice for adjuvant treatment of patients with resected CRC. OXA has been shown to improve survival, and these patients have a long life expectancy (André et al. 2009, De Gramont et al. 2007, Seretny et al. 2014).

Lack of evidence for the effectiveness of treatment of neurotoxic side effects, means there are no gold standards in terms of how to care for these patients (Hershman et al. 2014, Smith et al. 2014). The most successful approaches to eliminating or reducing chronic neurotoxic side effects include early identification, reduction of dosage and interruption of OXA treatment (Bakogeorgos and Georgoulias 2017). Current research and recommendations indicate a need for high-quality, patient-oriented evidence in terms of longterm follow-up of neurotoxicity. This should focus on underestimated side effects and the need for assessments in terms of function (Majithia et al. 2016, Park et al. 2013). The main aim of this thesis is to explore and improve knowledge of the phenomenon known as neurotoxic side effects and its impact on daily life, with a view to improving care for these patients over time. 


\section{BACKGROUND}

A diagnosis of colorectal cancer (CRC) is a stressful life event. CRC significantly affects many aspects and stress factors in a person's life. Normal daily life is affected in terms of periods in hospital, including surgical and oncological treatments, and these influence health in different ways. A patient's individual experience of health is often related to changes in his or her life situation. This is a personal experience, and the resulting challenges for daily activities are personal to the specific situation and the specific context. A loss of independence in daily life affects perceived health, and a person's role changes from being a healthy individual to being a patient (Baier et al. 2016, Catt et al. 2017, Jagger et al. 2001).

According to the World Health Organization (WHO), health is a multidimensional concept defined as "a state of complete physical, mental and social well-being, and not merely the absence of disease and disability" (WHO 1948). Outcomes include physical, psychological and social aspects of health. Measurements of health are widely used to describe the impact of disease from the patient's perspective.

CRC influences health in different ways, and it is common to experience different symptoms and side effects during treatment, such as pain, fatigue, changes in bowel habits, nausea, sleeping problems, anxiety, depression and neurotoxicity (Hung et al. 2013, Pettersson et al. 2014, Zhang et al. 2015, Walling et al. 2015). Symptom burden is common as a result of both the disease and treatments given to cure or prolong life (Røhrl et al. 2016).

OXA-induced neurotoxic side effects are a result of treatment. OXA-induced neurotoxic side effects are common, and have two different manifestations: acute and chronic. Acute side effects can occur immediately, within hours or days after infusion (cold-related paraesthesia, dysesthesia). They are usually resolved within a week and can disappear for the next cycle. On the other hand, they can become chronic (paraesthesia, numbness), leading to functional deficits in the longer perspective (Padman et al. 2015). Common neurotoxic side effects include sensitivity to the cold, numbness and tingling in the hands and feet (Park et al. 2013, Vatandoust et al. 2014, Verstappen et al. 2003). However, the incidence of both acute and chronic neurotoxic side effects impacts patients' health-related quality of life (Stefansson et al. 2016, Tofthagen et al. 2013a). This thesis focuses on patients' perceptions and patient-reported outcomes of neurotoxic side effects. 
Two narratives from two patients living with CRC and with OXA-induced neurotoxic side effects aimed to illustrate the challenges and also the distress the patients struggled with in everyday life.

Everything started with fatigue and diffuse abdominal pain, which proved to be colon cancer. I had surgery in the summer and began chemotherapy in the autumn of the same year. I am living with my husband and small children in a house with three floors. I am bothered by severe neurotoxic side effects, mostly sensitivity to cold. Daily life is characterised by fatigue, and organising everyday life to prevent exposure to cold. The children follow each other to school, because it is not possible for me to go outside in cold weather. All beverages are heated in the kettle, or must stay at room temperature for a long time. I am bothered by constant thirst and it is difficult to drink enough fluids. Preparing food from the refrigerator and freezer is not possible. I need support from my family members. The children help each other when my husband is working. The laundry room is designated to my grandmother, because the cellar floor is so cold that it is not possible to go down there without severe discomfort. When the treatment is over, we have plans for a holiday to a warm country. But before that, my only desire is to be able to go outside and enjoy the children's outdoor activities. (Female, 45 years old)

I had changes in bowel habits and bloody diarrhoea, and was diagnosed with colon cancer. I had surgery in the autumn and started chemotherapy in the winter of the same year. I am living with my wife and retired recently. During chemotherapy, I had mostly coldrelated side effects in my face, so that I was unable to go out with the dog. My wife reduced her work hours to help. I struggle, and have a lot of forms of treatment. Side effects in my hands and feet started after the last treatment. I then had difficulties with fine-motor activities (fastening buttons), and my wife had to help me. I also have numbness and a loss of sensation in my legs, which makes it difficult to walk. I avoid walking nowadays, and am afraid of falling. I'm unsure on uneven surfaces. I hope these side effects will get better as the days go on, but I feel that they have become worse and worse. (Male, 66 years old) 


\section{Colorectal cancer}

CRC is a threat to the health of many people around the world, and has one of the highest incidences of malignancy internationally. The incidence varies greatly between different parts of the world. The highest incidence is seen in Australia, New Zealand and Western Europe, while Africa has the lowest incidence (WHO World Cancer Report 2014, WHO Globocan 2012).

In Sweden, 6000 people are diagnosed with CRC each year, about 4000 of whom are diagnosed with colon cancer and 2000 with rectal cancer. The number of persons diagnosed with CRC (incidence) has increased, and the mortality have decreased during the last decades. The relative 5-year survival rate has improved for both colon and rectal cancer during the last decades. Data from 2008 to 2016 show approximately $70 \%$ survive for 5 years, unlike from 1998 to 2002 when 5-year survival was below 60\%. The ageadjusted incidence of colon cancer in Sweden has gradually increased in recent decades, in contrast to rectal cancer where the incidence is almost unchanged (National Board of Health and Welfare, Statistics on Cancer Incidence 2016).

CRC starts to grow into the wall of the colon or rectum. It starts in the innermost layer (mucosa) and can grow through other layers over time. Most forms of CRC are adenocarcinomas, and these types of cancer start in cells that make mucus. Symptoms might not appear immediately. Common symptoms may include changes in bowel habits, such as diarrhoea and obstipation. Rectal bleeding, blood in the stool, abdominal pain, fatigue and loss of weight are also common symptoms. Most CRC is due to lifestyle factors and old age (mean age 70 years, $5 \%$ under 50 years), but can also be a result of genetic disorders (fewer than $5 \%$ of cases). The majority of CRC cases involve no genetic risk. Risk factors include existing inflammatory bowel diseases, diet, smoking, obesity and inactivity. Factors involving diet which increase the risk of CRC include alcohol and red or processed meat (Swedish colorectal cancer registry, National Cancer Institute 2017, Swedish Cancer Society 2018). Colorectal screening, using faecal occult blood tests or colonoscopy, are recommended in terms of improving cancer-related survival by diagnosing the disease at an earlier stage (Vermeer et al. 2017). 


\section{Colorectal cancer treatments}

Surgery is the backbone of CRC treatment. The results of surgery vary depending on the patient's general condition and comorbidity, as well as how widespread the cancer is and where it is situated in the intestine. TNM (Tumour Nodes Metastasis) classification and stage grouping (WHO 2000) are presented below:

\section{$\underline{\text { Stage Grouping }}$}

Stage I: T1, N0, M0 and T2, N0, M0

Stage II: T3, N0, M0 and T4, N0, M0

Stage III: Any T, N1, M0 and Any T, N2, M0

Stage IV: Any T, Any N, M1

(T- Primary tumour, T1 Tumour invades submucosa, T2 Tumour invades muscularis propria, T3 Tumour invades through muscularis propria into subserosa or into non-peritonealised pericolic or perirectal tissues, T4 Tumour directly invades other organs or structures and/or perforates visceral peritoneum, N-Regional Lymph Nodes; N0 No regional lymph node metastasis, N1 Metastasis in one to three regional lymph nodes, N2 Metastasis in four or more regional lymph nodes, M Distant Metastasis, M0 No distant metastasis, M1 Distant metastasis)

In addition to the above tumour-stage division, the outcome also depends on if the tumour invades the vessels, and perineal tumours represent negative prognostic factors. Acute surgery is also a negative prognostic factor. The risk of mortality, complications and the need for ostomy as a result of the surgery can vary from low to high. At stages I and II, the tumour is restricted to the intestine and most patients are cured. At stage III, survival 5 years after diagnosis is approximately $70 \%$, and at stage IV fewer than $20 \%$ of patients survive after 5 years (Swedish colorectal cancer registry).

To reduce the risk of recurrence, many patients receive postoperative chemotherapy with one or two drugs, starting within 8 weeks after surgery. Risk of relapse is reduced by up to $30 \%$ compared to surgery alone (Andre et al. 2009, Schmoll et al. 2012, Schmoll et al. 2015). For patients undergoing radical surgery for non-metastatic rectal cancer, a metaanalysis with twenty-one RCTs, showed a reduction in the risk of disease recurrence by $25 \%$ among patients undergoing adjuvant chemotherapy as compared to those with no postoperative chemotherapy (Petersen et al. 2012). 
Of all patients treated for CRC in stages II and III in Sweden between 2009 and 2014, more than 25\% received adjuvant chemotherapy (Swedish colorectal cancer registry). Most patients have chemotherapy for 6 months, but the optimal duration of adjuvant chemotherapies can be challenging to define (André et al. 2009, Des Guetz et al. 2010, Haller et al. 2005, Haller et al. 2011, Yothers et al. 2011).

The effect of adjuvant chemotherapy is to prevent the recurrence of cancer (Breugom et al. 2015, Ewertz et al. 2015, Jonker et al. 2011, Schmoll et al. 2012). There must be a balance between the positive effect of chemotherapy and the perceived negative side effects, which is a great challenge for healthcare professionals in dialogue with patients.

\section{Chemotherapy-induced neurotoxic side effects}

Chemotherapy-induced neurotoxic side effects are common in anticancer treatment and are associated with some of the most commonly used chemotherapeutic drugs. Treatment with taxanes, vinca alkaloids and platinum agents is often associated with neurotoxicity (Miltenburg and Boogerd 2014). The incidence of chemotherapy-induced neurotoxic side effects varies in the literature (Argyriou et al. 2014, Cavaletti et al. 2010, Ewertz et al. 2015, Ferrier et al. 2013, Grisold et al. 2012), and the degree of neurotoxic side effects depends on the chemotherapeutic drugs of choice, as well as the combinations used (Park et al. 2013). Chemotherapeutic drugs, dose intensity, cumulative dose, duration of treatment and existing neuropathy affect the risk and incidence of chemotherapy-induced neurotoxic side effects (Flatters et al. 2017, Grothey 2003, Park et al. 2013, Seretny et al. 2014, Velasco et al. 2014).

A meta-analysis (including data from 4179 patients across different cancer types and chemotherapy), showed a high overall prevalence of chemotherapy-induced neurotoxic side effects, $60 \%$ after three months and $30 \%$ after six months post chemotherapy. The prevalence of neurotoxicity falls over time and approximately one-third of patients can expect to have chronic neurotoxicity six months or more post chemotherapy. Twelve of the thirty-one studies, included patients with CRC and oxaliplatin treatment (Seretny et al. 2014). 
Side effects are defined as harmful and unwanted effects of a drug or chemical which occur along with the desired effect (Rang 2015), and side effects caused by chemotherapy have consequences which are perceived by patients. Chemotherapy-induced neurotoxic side effects are likely to have negative associations with health-related quality of life (Iconomou et al. 2004, Mols et al. 2014, Mols et al. 2015).

Previous studies have shown that severe neurotoxic side effects affect the patient's life, and are strongly associated with depression and problems with reduced quality of sleep (Hong et al. 2014, Tofthagen et al. 2013a).

A systematic review, which aimed to identify and synthesise all qualitative research studies on experience of chemotherapy-induced neurotoxic side effects, published between 2005 and 2015, included only five American studies. The studies included adult patients with cancer who reported chemotherapy-induced neurotoxicity, regardless of cancer diagnosis, stage of cancer and goal of treatment. Studies were excluded if they failed to reach the adapted quality assessment criteria or used a quantitative approach and did not provide descriptions of patient experiences (Tanay et al. 2017). The synthesis indicated a lack of qualitative evidence about experience of chemotherapy-induced neurotoxic side effects, and also a need for further studies outside the United States. Three of the five studies in the review, included patients with CRC (Table 1). The two other studies, included patients with breast cancer (not presented in Table 1). 
Table 1. An overview of qualitative studies from 2005-2015.

\begin{tabular}{|c|c|c|c|c|c|c|}
\hline Study & Design & Method & $\mathbf{N}$ & Sampling & $\begin{array}{l}\text { Patient } \\
\text { Characteristics }\end{array}$ & Time point \\
\hline $\begin{array}{l}\text { Bakitas } \\
2007 \\
\text { USA }\end{array}$ & $\begin{array}{l}\text { Qualitative, } \\
\text { Phenomenology, } \\
\text { semi-structured } \\
\text { interviews }\end{array}$ & $\begin{array}{l}\text { Interpretative } \\
\text { descriptive } \\
\text { approach }\end{array}$ & 28 & Convenience & $\begin{array}{l}\text { Colon, ovarian, haema- } \\
\text { tological and other } \\
\text { cancers } \\
46-81 \text { years } \\
\text { Curative goal of } \\
\text { treatment }\end{array}$ & $\begin{array}{l}\text { 3-198 months } \\
\text { after } \\
\text { diagnosis }\end{array}$ \\
\hline $\begin{array}{l}\text { Tofthagen } \\
2010^{\mathrm{a}} \\
\text { USA }\end{array}$ & $\begin{array}{l}\text { Qualitative, } \\
\text { case study }\end{array}$ & Case report & 1 & Convenience & $\begin{array}{l}\text { Colon cancer } \\
72 \text { years } \\
\text { Curative goal of } \\
\text { treatment }\end{array}$ & $\begin{array}{l}4 \text { years after } \\
\text { treatment }\end{array}$ \\
\hline $\begin{array}{l}\text { Tofthagen } \\
2010^{\mathrm{b}} \\
\text { USA }\end{array}$ & $\begin{array}{l}\text { Qualitative, } \\
\text { semi-structured } \\
\text { interviews }\end{array}$ & $\begin{array}{l}\text { Descriptive, } \\
\text { ethnographic } \\
\text { approach }\end{array}$ & 14 & Convenience & $\begin{array}{l}\text { Colorectal, breast, lung, } \\
\text { multiple myeloma and } \\
\text { cholangiocarcinoma } \\
\text { cancer } \\
42-84 \text { years } \\
\text { Curative and palliative } \\
\text { goal of treatment }\end{array}$ & $\begin{array}{l}\text { During treat- } \\
\text { ment to within } 6 \\
\text { months of } \\
\text { having com- } \\
\text { pleted treatment }\end{array}$ \\
\hline
\end{tabular}

Further research is required which focuses on patients' experiences and perception of chemotherapy-induced neurotoxic side effects, in order to improve supportive care for these patients. Early assessment and detection of neurotoxic side effects is important in terms of reducing and eliminating chronic neurotoxic side effects later on. Patient-reported outcomes and assessments are important in terms of obtaining patients' views of their situation without interpreting their responses (Cappelleri et al. 2014, Visovsky et al. 2008). 
There are a number of established scales for assessing and grading chemotherapy-induced neurotoxic side effects. Some of these are developed for patient-reported assessments and some for professionals (see Table 2). Patient-reported assessments for chemotherapy-induced neurotoxic side effects focus on functional impairments in daily activity or the effect on quality of life.

Early detection of neurotoxicity is important for early symptom management, and there are a number of tools for assessing neurotoxicity (Table 2). CTCAE assessments capture the severity of chemotherapy-induced neurotoxic side effects from an objective point of view, and are often used in clinical trials (Cavaletti et al. 2010, Cavaletti et al. 2013, National Cancer Institute 2009). In general, clinical assessment leads to a subjective type of grading and considerable inter-rater variability (Alberti et al. 2014). Patientreporting assessments for chemotherapy-induced neurotoxic side effects focus on functional impairments in daily activity or the effect on quality of life (Huang et al. 2007, Leonard et al. 2005, Tofthagen et al. 2011a).

Reviews indicate the importance of patient-reported questionnaires in terms of capturing patients' perceptions of neurotoxicity and severity as a result of healthcare professionals underestimating severity (Brewer et al. 2016, Cavaletti et al. 2010, Haryani et al. 2017, Le-Rademacher et al. 2017, Postma et al. 1998). In 2005, Leonard et al. developed a specific questionnaire to capture OXA-induced neurotoxic side effects which interfere with daily activities. 
Table 2. Assessment tools for chemotherapy-induced neurotoxic side effects

\begin{tabular}{|c|c|c|}
\hline & Assessment tool & Description \\
\hline \multirow[t]{4}{*}{$\begin{array}{l}\text { Physician/healthcare professional } \\
\underline{\text {-based assessments }}\end{array}$} & CTCAE $^{1}$ & $\begin{array}{l}\text { Neuropathy graded on scale and inhi- } \\
\text { bition of ADL }\end{array}$ \\
\hline & WHO scale ${ }^{2}$ & $\begin{array}{l}\text { Neuropathy graded on scale of 1-4 } \\
\text { and inhibition of ADL }\end{array}$ \\
\hline & Ajani scale ${ }^{3}$ & $\begin{array}{l}\text { Neuropathy grade associated with } \\
\text { morbidity, guidance on future therapy } \\
\text { and functional capacity }\end{array}$ \\
\hline & $\begin{array}{l}\text { Total neuropathy } \\
\text { scale (TNS) }{ }^{4}\end{array}$ & $\begin{array}{l}\text { Evaluation of perception of vibration, } \\
\text { neurophysiological examination }\end{array}$ \\
\hline \multirow[t]{5}{*}{$\underline{\text { Patient-reported assessments }}$} & $\begin{array}{l}\text { FACT/GOG- } \\
\text { NTX }^{5}\end{array}$ & 11-item subscale of FACT/GOG \\
\hline & $\begin{array}{l}\text { EORTC QLQ- } \\
\text { CIPN20 }\end{array}$ & 20-item subscale of EORTC QLQ \\
\hline & $\mathrm{PNQ}^{7}$ & 2-item questionnaire \\
\hline & CIPNAT $^{8}$ & $\begin{array}{l}\text { 50-item questionnaire, interference } \\
\text { with activity }\end{array}$ \\
\hline & $\begin{array}{l}\text { OANQ } \\
\text { (Leonard } \\
\text { questionnaire) }^{9}\end{array}$ & $\begin{array}{l}\text { 29-item questionnaire, upper and } \\
\text { lower extremities and face, effect on } \\
\text { daily activities }\end{array}$ \\
\hline
\end{tabular}

1. CTCAE- Common Terminology Criteria for Adverse Events (Trotti et al. 2003); ${ }^{2}$ WHO- World Health Organization (Miller et al. 1981); ${ }^{3 \cdot}$ Ajani scale (Ajani et al. 1990); ${ }^{4}$ Total neuropathy scale (Cavaletti et al. 2003); ${ }^{5}$ FACT/GOG-NTX- Functional Assessment of Cancer Therapy/Gynaecologic Oncology Group Neurotoxicity (Huang et al. 2007); 6. EORTC QLQ-CIPN20- European Organization for Research Treatment in Cancer Quality of Life - Chemotherapy Induced Peripheral Neuropathy (Postma et al. 2005);

7. PNQ- Patient Neuropathy Questionnaire (Shimozuma et al. 2009); ${ }^{8}$. CIPNAT- Chemotherapy-induced Peripheral Neuropathy Assessment Tool (Tofthagen et al. 2011b); 9. OANQ- Oxaliplatin-associated Neurotoxicity Questionnaire (Leonard et al. 2005). 


\section{Oxaliplatin}

For the past 50 years, a cornerstone in the treatment of CRC has been chemotherapy consisting of 5-FU in combination with leucovorin, a regime with relatively low toxicity (Gustavsson et al. 2015). Of all patients treated with surgery for CRC in stages II and III in 2014 in Sweden, about 25\% received adjuvant chemotherapy. Half of them received adjuvant chemotherapy with OXA. Approximately 400 patients a year received postoperative adjuvant chemotherapy (CRC in stages II and III) with oxaliplatin (OXA) in Sweden (National Quality Report from the Swedish Colorectal Cancer Registry 2015).

The platinum compound OXA is a widely-used drug which has proved effective in treating different gastrointestinal tumours, mainly CRC. OXA was first successfully used for metastatic CRC, and nowadays it is an option in adjuvant treatments for patients with resected CRC (André et al. 2004, André et al. 2009, Ducreux et al. 2011, de Gramont et al. 2000, Haller et al. 2011).

A combination of different chemotherapeutic agents which improve the anti-tumour effects of the treatment are common in patients with CRC (Bujko et al. 2015, Jonker et al. 2011). OXA is one of these drugs, and is usually combined with 5-fluorouracil (5-FU) and folinic acid/leucovorin (FOLFOX), or with capecitabine (XELOX) and administration of intravenous infusion of OXA is given every two or three weeks (Cassidy et al. 2004, de Gramont et al. 1997, de Gramont et al. 2000, Land et al. 2007).

Six months of adjuvant chemotherapy is the current standard of care worldwide for patients with stage III colon cancer, based on results from large clinical trials (André et al. 2004, Haller et al. 2011, Kuebler et al. 2007, Schmoll et al. 2012). Survival in patients with CRC can be increased by about $25 \%$ when OXA is added to the treatment (André et al. 2009, Park et al. 2013, Sereno et al. 2014). 
The International Duration Evaluation of Adjuvant therapy (IDEA) collaboration was established to analyse a number of trials worldwide which investigated whether 3-month adjuvant OXA-based chemotherapy was superior to the current standard 6-month treatment for patients with stage III colon cancer. The primary endpoint involved 3 years of disease-free survival. A major aim of the IDEA collaboration was also to mitigate potential long-term OXA-induced neurotoxic side effects by reducing the duration of treatment (André et al. 2013). OXA is known to be highly neurotoxic. Neurotoxic side effects occur in the majority of patients given the treatment, and may lead to a long-term burden for the patients (Argyriou et al. 2010, Argyriou et al. 2014, Baek et al. 2010, Beijers et al. 2014b, Beijers et al. 2015, Grisold et al. 2012, Kerckhove et al. 2017). 


\section{Oxaliplatin-induced neurotoxic side effects}

The term 'neurotoxic side effects' is used in this frame, other terms also exist in the scientific literature (e.g. neurotoxicity, neuropathy and peripheral neuropathy, peripheral nervous system diseases) and are used synonymously. Chemotherapy-induced peripheral neuropathy (CIPN) is also used as an umbrella term internationally. The expression 'side effects' is often used in terms of patient-reported outcomes measurement (PROM) (Stefanovic et al. 2017).

OXA-induced neurotoxic side effects can take either an acute or a chronic form. The chronic form is often delayed. The acute form usually starts within hours or days after the infusion. If the side effects are severe, prolonging the time of infusion can help mitigate them. This acute form of neurotoxic side effect is usually reversible, and is often resolved in days or weeks after the treatment. Sometimes side effects are completely resolved before the next cycle of treatment. The longer the patient's overall treatment, the more common it is for the side effects to occur earlier, last longer or never be resolved (Grenon and Chan 2009, Grisold et al. 2012, Velasco et al. 2014, Wolf et al. 2008). Acute OXA-induced neurotoxic side effects have been shown to predict chronic side effects (Argyriou et al. 2014, Attal et al. 2009, Pulvers and Marx 2017). Chronic side effects (>14 days) is usually characterized by paraesthesia and dysesthesias and may include deficits in proprioception that can interfere with patients daily activities (Tofthagen 2012).

Neurotoxic side effects are the result of a drug's ability to cause a consistent pattern of neural dysfunction or changes in the structure of the nervous system. The neural dysfunction can occur either in the central nervous system, the sensory organs or the peripheral system (Cavaletti and Marmiroli 2015). The peripheral system is the part of the nervous system outside the brain and spinal cord. Most OXA-neurotoxicity results in loss of sensitivity. Neural dysfunction in motor neurons results in muscle weakness (Argyriou et al. 2014, Beijers et al. 2014a, Kerckhove et al. 2017). 
The compromised nerve function seen after neurotoxic side effects seems to depend mainly on structural changes in the myelin sheaths and the number of functional axons. Decreased blood flow and inflammatory processes may contribute to nerve destruction involving multiple sensory changes, including the development of mechanical allodynia. Light pressure, which would normally be perceived as harmless, causes pain. Cold temperatures evoke a painful sensation. The precise pathobiology of OXA-induced neurotoxicity is still to be fully explained. Recent research implicates mitochondrial dysfunction as well as oxidative stress (Han and Smith 2013). Side effects directly after OXA treatment have been reported to involve oxalate-induced dysfunction in voltage-gated $\mathrm{Na}^{+}$ channels, through an oxalate effect on calcium and magnesium ions (Kiernan and Krishnan 2006, Krishnan et al. 2005).

Common OXA-induced neurotoxic side effects include cold sensitivity, numbness and tingling in the hands and feet, pain and changes in fine-motor ability. Tingling in the hands and feet often occur early on (Cavaletti and Marmiroli 2015, Han and Smith 2013). Sensitivity to cold is especially common, and the majority of patients receiving the treatment report this side effect (Park et al. 2013).

The identification of risk factors for neurotoxicity is important. It has been shown that the chronic form of OXA-induced neurotoxic side effects is closely related to high cumulative doses (Beijers et al. 2014b, Kidwell et al. 2012, Park et al. 2013, Velasco et al. 2014) and $>6$ cycles of OXA (Vincenzi et al. 2013). A cumulative dose of $780-850 \mathrm{mg} / \mathrm{m}^{2}$ is a risk factor and a predictor of chronic OXA-induced neurotoxic side effects (André et al. 2009, Grothey 2003). Suspected reported risk factors such as a patient's age (>65 years), alcohol consumption and earlier co-morbidities (e.g. diabetes, vitamin $\mathrm{B}_{12}$ deficiency) may increase the risk of neurotoxic side effects (Vincenzi et al. 2013). Smoking, decreased creatinine clearance, pre-existing neuropathy and sex (female), are also suspected risk factors (Bakogeorgos and Georgoulias 2017, Seretny et al. 2014). 


\section{Prevention of neurotoxic side effects}

Several studies with different study design have investigated different strategies for preventing, eliminating or reducing OXA-induced neurotoxic side effects (Albers et al. 2014, Avan et al. 2015, Gewandter et al. 2017, Grisold et al. 2012, Han et al. 2016, Hoff et al. 2012, Wolf et al. 2008). Some studies have investigated the effect of giving the patient calcium and magnesium before administering OXA (Grothey et al. 2006, Jordan et al. 2016, Wen et al. 2013). Tests have investigated the effects of treatment with gabapentin and heating OXA before administration, but none had significant results (Cathomas et al. 2010, Mitchell et al. 2006). Gabapentin is a drug used in epilepsy and in treatment of neuropathic pain. It has an effect on damaged nerves, but has not been shown to reduce the incidence or severity of OXA-induced neurotoxicity (Mitchell et al. 2006). A placebocontrolled randomised phase II study explored the preventive effects of calmangafodipir (protecting cells from oxidative stress), and the trial show indications that calmangafodipir prevents the development of acute and delayed OXA-induced neurotoxicity (Glimelius et al. 2018).

The American Society of Clinical Oncology (ASCO) guidelines state that there are no existing agents to prevent chemotherapy-induced neurotoxicity. For managing existing neurotoxic side effects, duloxetine (a serotonin/norepinephrine inhibitor) has shown some positive effects on pain and has also reduced tingling and numbness (Hershman et al. 2014, Smith et al. 2013, Smith et al. 2017, Wolf et al. 2008). Complementary and alternative medicines have also been evaluated, but there is no evidence that they are effective. Although a number of interventions have been tested in terms of reducing OXA-induced neurotoxic side effects, none of them can be recommended for clinical use (Bakogeorgos and Georgoulias 2017, Cheng et al. 2015, Majithia et al. 2016). 


\section{Use of mobile phone technology in cancer care}

New possibilities for interventions to monitor symptoms with mobile-phone technology may be the future. The increased number of mobile-phone users across the world facilitates improved communication between patients and healthcare professionals in cancer care, and creates a supportive environment (Blake 2008, Gurol-Urganci et al. 2013, Klasnja and Pratt 2012, Krishna et al. 2009, McCann et al. 2009, Sundberg et al. 2015). Mobile-phone technology has been shown to have an impact on how patients understand their disease and its treatment. Mobile Health (mHealth), i.e. medical and public health practice supported by mobile devices such as mobile phones has also been used by healthcare professionals for monitoring symptoms of chronic diseases other than cancer (WHO 2011).

Patients with cancer discharged from hospital have positive experiences of reporting side effects and symptoms using mobile-phone technology systems (Drott et al. 2016, Mirkovic et al. 2014). Healthcare professionals have also experienced benefits, since technology allows them to provide early interventions to patients during chemotherapy treatment (McCann et al. 2009). Patient-reported outcomes (PRO) and electronic Patientreported Outcomes (ePRO) are designed to capture patients' perspectives on their situation exactly as they perceive them, without interpreting their responses. ePRO using mobile-phone technology makes early detection of OXA-induced neurotoxic side effects possible. The use of mobile-phone technology is useful throughout the cancer-care process.

Because there is no generally accepted treatment for OXA-induced neurotoxicity, it is important to identify these patients early in order to reduce the risk of their developing chronic neurotoxic side effects (Padman et al. 2015). Patient-reported assessments in real time using mobile phones have been evaluated as a suitable way of following side effects and the progression of symptoms (Hallberg et al. 2014). Screening side effects and symptoms with mobile-phone technology solutions may help identify patients who need further evaluation or healthcare intervention to improve their health (Gustavell et al. 2018, Langius-Eklof et al. 2017, Maher 2013). 


\section{THEORETICAL FRAMEWORK}

A cancer diagnosis, with its accompanying chemotherapy treatment, can significantly affect patients' overall health. The person's role changes from being a healthy person to a patient. Normal daily activities are affected through periods in hospital, including surgical and oncological treatments, and this influences health in different ways.

\section{Self-care deficit nursing theory}

The theoretical framework in this thesis is Orem's self-care deficit nursing theory. Orem defines health as living with structural and functional wholeness and soundness. Orem (1995) introduced patient-related concepts to self-care. These include self-care agency, which is the capacity of individuals to care for themselves, self-care demand, which involves the actions required to meet a person's self-care needs, and self-care deficit, which occurs when people can no longer meet their self-care needs and require nursing care. Health is seen in relation to self-care deficits. Orem suggests that self-care agency and self-care behaviour can be influenced by a wide range of factors, which can include age, gender, culture, environment, family and the healthcare system. It is necessary to know about the patients environmental situations, and the patients should not be isolated from their context and environments. Orem states that environment features are continuously and interactive in the specific time-place context. Environmental condition can affect lives in different ways, both positively and negatively (Orem 2001).

Within the framework of Orem's self-care deficit nursing theory, the patients' health is explained as a basic conditioning factor and affects the self-care agency and self-care demands. Self-care activities are practices that a person initiates and performs on their own to maintain health. According to the universal self-care demands defined by Orem; air, water, food, activity, rest and social activities can be influenced in different ways to promote health and normality (Orem 2001). 
These universal self-care requisites include essential physical, psychological, social and spiritual aspects of life. Each part is important and fundamental to the process of human life. Requisites for self-care depend on the ability to meet self-care demands, and a selfcare deficit involves a loss of self-care requisites (Orem 2001).

Self-care can be seen as a balance between many factors, including the need for self-care and the ability to satisfy self-care demands. The balance between abilities and demands is central. The human tendency is to be normal and to take action to maintain health. The balance and relations between self-care demands and patients' ability to care for themselves, both with and without support, can be a helpful consideration in nursing and caring. OXA-induced neurotoxic side effects can affect experiences of health in patients (Figure 1).

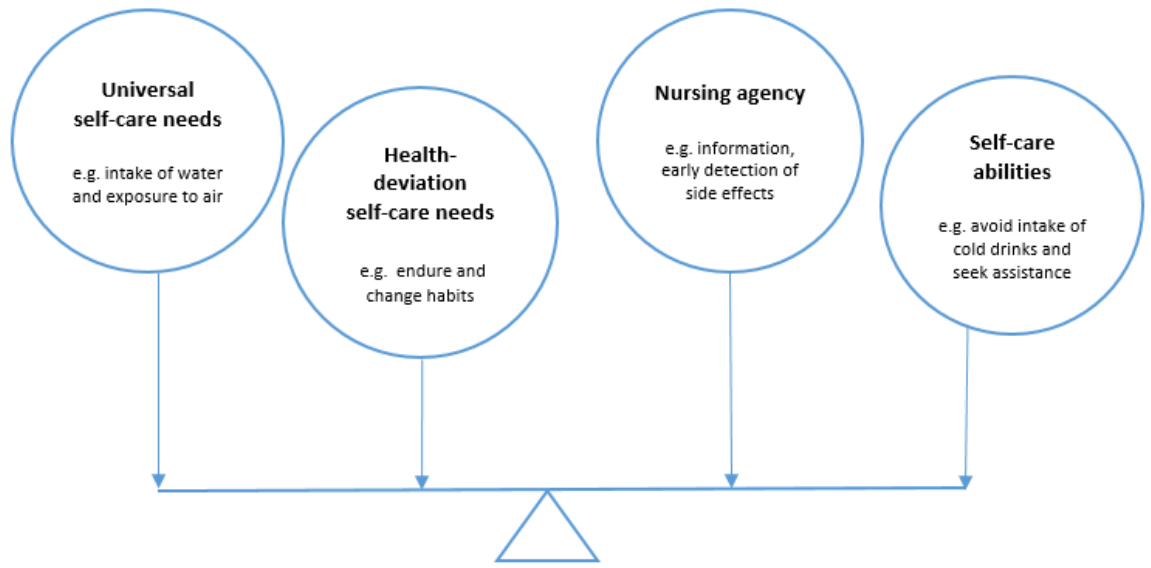

Figure 1. Experience of health in a patient with OXA-induced neurotoxic side effects, showing universal self-care needs, self-care needs in terms of health deviation, self-care abilities and nursing support. Figure inspired by Orem (2001). 
The ability to balance needs is central, both at the conceptual level and in the care of patients. The nurse's responsibility is to support patients in promoting self-care agency to maintain health. Orem stresses the importance of preventive health care and that primary prevention involves meeting universal self-care requisites effectively. Secondary prevention involves interventions and early detection of side effects, while tertiary prevention occurs when rehabilitation takes place. Orem considers that there are different types of nursing system, which are wholly or partly compensatory, or supportive-educative. A wholly compensatory nursing system is required when nurses need to assume a compensatory role to support the patient, if patients are unable to meet universal self-care needs on their own (Orem 2001).

Partly compensatory nursing does not require the same intensity as wholly compensatory nursing, but nurses still take action, and patients participate in their own decision-making, nursing activity and care. The supportive-educative nursing system is more applicable in patients who have the ability to care for themselves, and who can adapt to situations but need nursing support. Nursing support in cancer care includes communication to help patients make decisions. All these nursing systems are dynamic and may change over time. They may also overlap (Orem 2001). 


\section{RATIONALE}

Postoperative adjuvant treatment with OXA has been shown to improve survival. However, the incidence of neurotoxic side effects can be a problematic factor and affect the patient's daily life. A lack of evidence for preventive options and effective treatment means that there is no gold standard to follow, and long-term patient follow-up is problematic. The most successful approaches for eliminating chronic neurotoxic side effects include early identification, reduction of dose and interrupting OXA treatment. Current research has indicated a need for patient-oriented evidence in terms of long-term followup of neurotoxicity. It will therefore be important to investigate real-time longitudinal patient outcomes, as well as patients' perceptions of neurotoxic side effects and the impact on their daily life. The main aim of this thesis is to explore this phenomenon in these patients over time. 


\section{AIMS}

The overall aim of this thesis is to explore OXA-induced neurotoxic side effects in patients with colorectal cancer, and the influence on patients' daily lives during and post OXA treatment.

\section{Specific aims}

- To identify and explore the neurotoxic side effects documented in medical records of patients with CRC treated with oxaliplatin-based adjuvant chemotherapy.

- To identify and describe people' with CRC experiences of neurotoxic side effects early in the oxaliplatin treatment period, and how neurotoxicity affects their daily lives.

- To explore the experiences of oxaliplatin-induced neurotoxic side effects among patients' with CRC and how these side effects influenced their daily lives over time.

- To identify and assess patient-reported OXA-induced neurotoxic side effects and their impact on the patient's daily activities, during and after chemotherapy. 


\section{METHOD}

\section{Design}

To fulfil the aim of this thesis, different research methods have been used. These include retrospective analysis of medical records, and descriptive prospective quantitative and qualitative approaches involving longitudinal data collection. The design was descriptive and interpretive. A comprehensive view of the four studies in this thesis is shown in Table 3.

Table 3. Overview of the design, methods and analysis in the four studies included in the thesis

\begin{tabular}{|c|c|c|c|c|}
\hline & Study I & Study II & Study III & Study IV \\
\hline Design & $\begin{array}{l}\text { Retrospective } \\
\text { analysis of medi- } \\
\text { cal records }\end{array}$ & $\begin{array}{l}\text { Qualitative interview } \\
\text { study }\end{array}$ & $\begin{array}{l}\text { Prospective qualita- } \\
\text { tive longitudinal in- } \\
\text { terview study }\end{array}$ & $\begin{array}{l}\text { Prospective quantitative } \\
\text { longitudinal study }\end{array}$ \\
\hline $\begin{array}{l}\text { Sample } \\
(\mathrm{n}=\text { number })\end{array}$ & $\begin{array}{l}\mathrm{n}=61 \text { medical } \\
\text { records }\end{array}$ & $\mathrm{n}=10$ patients & $\begin{array}{l}\mathrm{n}=10 \text { patients, } \\
\text { Total of } 25 \text { repeated } \\
\text { interviews }\end{array}$ & $\begin{array}{l}\mathrm{n}=46 \text { patients, } \\
\text { Repeated assessment in } \\
\text { total of } 370 \text { question- } \\
\text { naires }\end{array}$ \\
\hline Data collection & $\begin{array}{l}\text { Retrospective } \\
\text { scrutiny of medi- } \\
\text { cal records using } \\
\text { a protocol }\end{array}$ & $\begin{array}{l}\text { Qualitative inter- } \\
\text { views early in the } \\
\text { chemotherapy period } \\
\text { at the onset of neuro- } \\
\text { toxic side effects }\end{array}$ & $\begin{array}{l}\text { Repeated qualitative } \\
\text { interviews at the end } \\
\text { of OXA treatment, } \\
\text { and } 3,6 \text { and } 12 \\
\text { months post OXA } \\
\text { treatment }\end{array}$ & $\begin{array}{l}\text { Questionnaire: repeated } \\
\text { individualised OANQ* } \\
\text { in a mobile phone-based } \\
\text { system during OXA } \\
\text { treatment and } 3,6,9 \text { and } \\
12 \text { months post treatment }\end{array}$ \\
\hline Time period & $\begin{array}{l}\text { Patients treated } \\
2009-2010\end{array}$ & 2013-2014 & 2013- 2015 & 2013-2016 \\
\hline Data analysis & $\begin{array}{l}\text { Summative con- } \\
\text { tent analysis } \\
\text { Descriptive \& in- } \\
\text { terpretive }\end{array}$ & $\begin{array}{l}\text { Thematic analysis } \\
\text { Interpretive }\end{array}$ & $\begin{array}{l}\text { Thematic analysis } \\
\text { Interpretive }\end{array}$ & $\begin{array}{l}\text { Descriptive statistics, } \\
\text { two-sided z-test and t- } \\
\text { test, nonparametric Wil- } \\
\text { coxon signed-rank test, } \\
\text { McNemar's test, Mixed } \\
\text { effect model }\end{array}$ \\
\hline
\end{tabular}

*OANQ - Oxaliplatin-associated Neurotoxicity Questionnaire 


\section{Samples and settings}

The studies were performed in four oncology departments at four hospitals - two university-based and two regional - in the south of Sweden. During the recruitment period for studies II-IV, parallel studies were recruiting in the same patient population. There were study stop periods in two hospitals from May to August 2014-2016 due to staff shortages in the clinics.

\section{Study I}

In study I, the sample consisted of medical records. The records were collected from patients with a history of stage II-III CRC treated between 2009 and 2010 with OXA in an adjuvant setting at a university hospital in the south of Sweden. Inclusion criteria were that the patients in the medical records were at least 18 years of age, had been treated with 5-fluorouracil (5-FU), folinic acid (leucovorin) and capecitabine (FOLFOX, XELOX) in combination with OXA in an adjuvant setting for stage II-III CRC, and had no neurotoxicity before OXA treatment started. Exclusion criteria involved palliative treatment and known metastasis. Out of the 180 eligible medical records, 61 fulfilled the inclusion criteria. The medical records included documentation from all professionals in different clinical contexts. The data corpus amounted to 347 pages.

\section{Studies II-III}

In study II the patients were recruited using a purposeful and consecutive selection strategy at the onset of OXA-related neurotoxic side effects. The first ten patients who consented to the quantitative study IV and assessment of neurotoxic side effects were interviewed. The patients in studies II and III was also included in study IV. The OXA-related neurotoxic side effects were assessed in real time (Figure 2) using a mobile phone-based system. Inclusion criteria involved patients at least 18 years of age who had been treated with 5-fluorouracil (5-FU), folinic acid (leucovorin) and capecitabine (FOLFOX, XELOX) in combination with OXA postoperatively in an adjuvant setting for stages IIIII of CRC. They had to be able to speak and understand the Swedish language, have no history of neurotoxicity and be able to answer circadian questionnaires on a mobile phone to detect neurotoxic side effects. 
The majority of patients who were included answered using their own mobile phone, but a few patients borrowed one during the study period in order to participate. All of the patients included had existing OXA-induced neurotoxic side effects (purposeful selection).

Patients with reduced cognitive function, recognised earlier neurotoxic side effects and problems speaking and understanding Swedish were excluded. Patients in study III had the same inclusion criteria as in study II, but they were followed with repeated face to face interviews. The patients were contacted for face to face interviews when they reported any grade of neurotoxic side effect on the web-based graph according to the study design.

Patients who self-reported neurotoxic side effects using a mobile phone were followed for 1 year post OXA treatment, and assessed for neurotoxicity and impact on daily life. Interviews were conducted after they had completed OXA treatment, and 3, 6 and 12 months after the treatment. One patient's identification of neurotoxic side effects on a web-based graph is illustrated in Figure 2, and is supplemented by follow-up interviews with the same patient. 

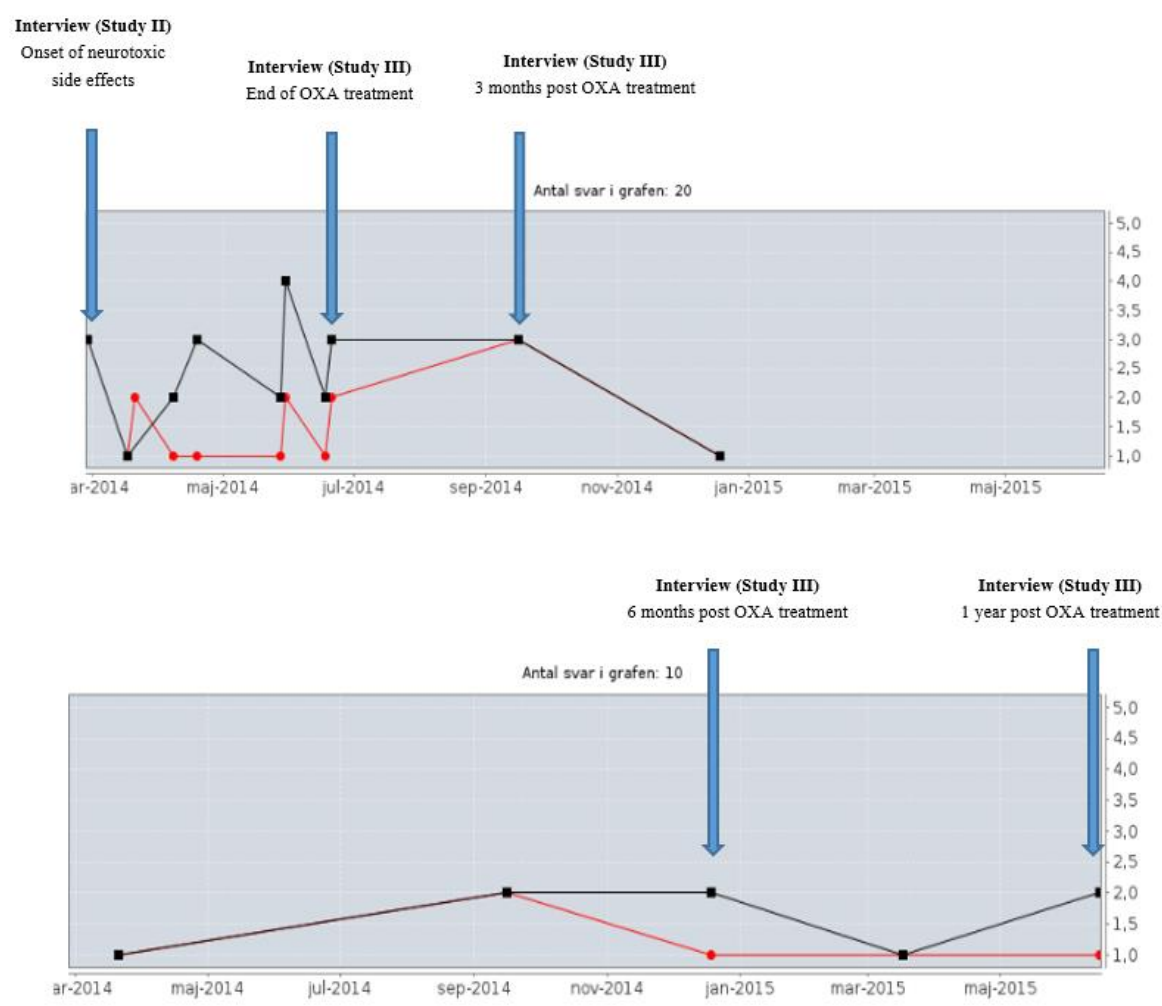

Figure 2. Web-based graphs from one patient, illustrating two questions: "Do you have burning pain and discomfort with cold?" and "Do you have numbness?" (Oxaliplatin-associated Neurotoxicity Questionnaire). They show self-reported neurotoxic side effects on a scale of 1.0-5.0 (black lines), and the patient's self-graded impact of neurotoxicity on daily activities on a scale of 1.0-5.0 (red lines). Answers were only visualized in the graphs when the patients had neurotoxic side effects over 1.0. The patients were recruited for interviews when neurotoxic side effects appeared, at the end of treatment and after 3, 6 and 12 months (reproduced with permission from 21st Century Mobile AB). 
The sample involved ten patients with reported neurotoxic side effects, and they were interviewed repeatedly. Drop-outs during the study period are presented in Figure 3.

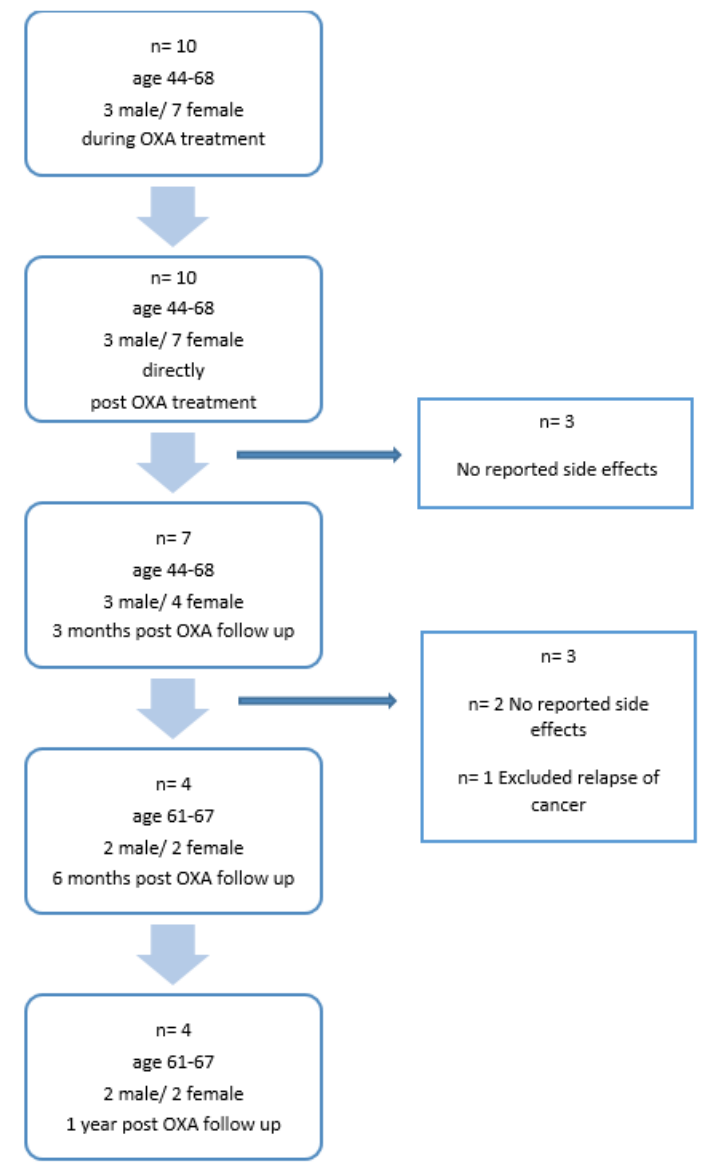

Figure 3. Flow chart of follow-up interviews with ten patients with neurotoxic side effects. Patients with no side effects at the time of the interview were excluded (purposeful selection), but the web-based graphs from the self-reported side effects were observed over the whole study period. A patient whose cancer returned, and who reported severe neurotoxic side effects and influence on daily activities, was excluded from participation due to health condition. 


\section{Study IV}

In this prospective longitudinal study, patients were recruited by being assessed for eligibility according to the inclusion criteria by the physician who was responsible for them. The inclusion criteria were: patients had to be at least 18 years of age, able to speak and understand Swedish, and have been treated with 5-fluorouracil (5-FU), folinic acid (leucovorin) and capecitabine in combination with OXA (FOLFOX, XELOX) postoperatively in an adjuvant setting for stages II-III CRC. None of the included patients had received any chemotherapy treatment previously and none of them had chemotherapy-induced neurotoxic side effects. Patients with reduced cognitive function were excluded from the study. A total of 96 patients were assessed for eligibility during the recruitment period (Figure 4).

\section{Non-participants}

Studies I-III adopted a purposeful and consecutive selection strategy according to the inclusion criteria, and an analysis of non-participants was not appropriate. Figure 4 provides an overview of, and information on progress through the different phases of studies IIIV. It maps out the number of patients assessed for eligibility, patients who were included and excluded, and the reasons for exclusion (Figure 4). 


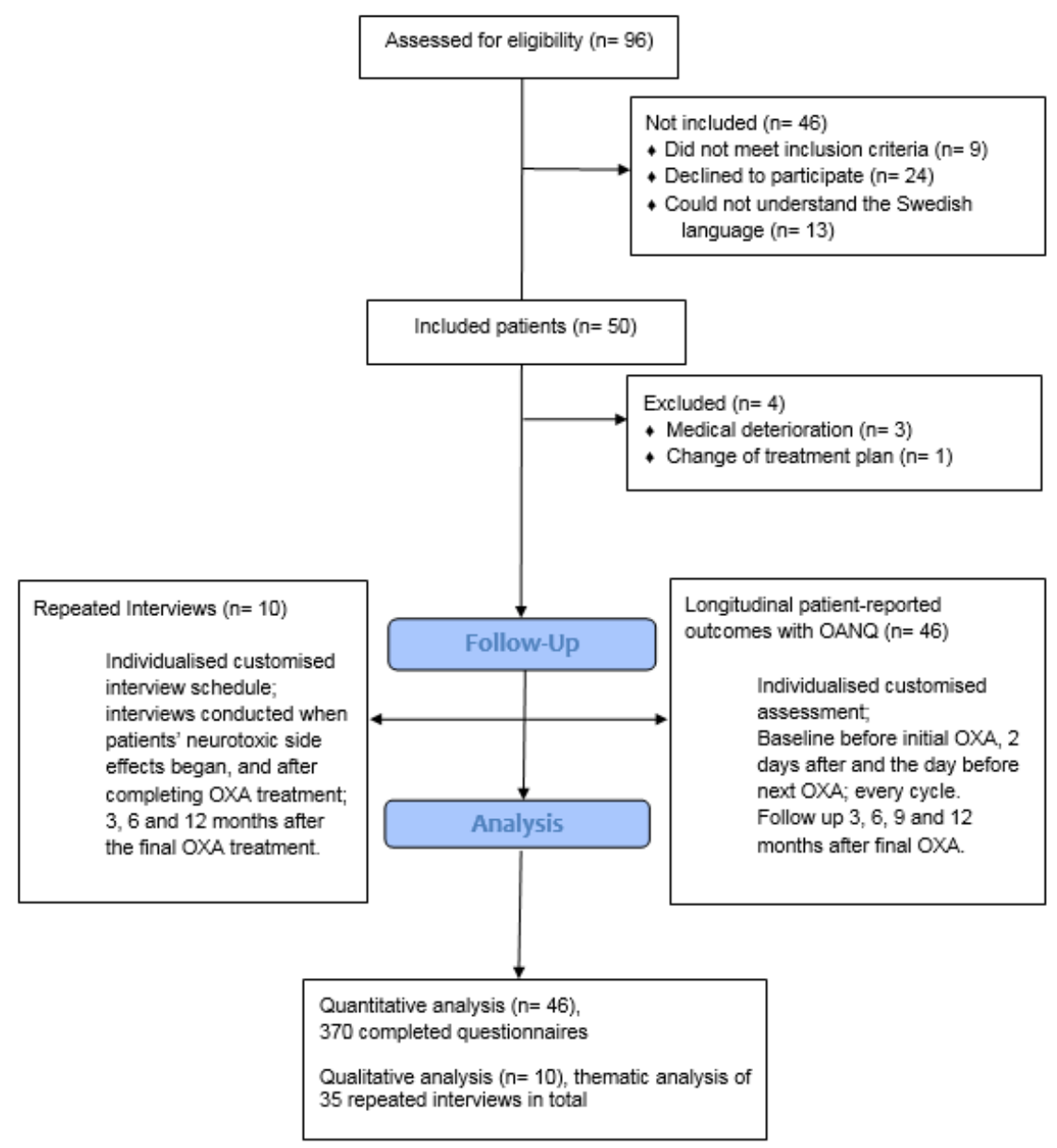

Figure 4. Flow diagram, studies II-IV 
An overview of the patients' clinical characteristics, social status, educational level and occupation is shown in Tables 4 and 5. In terms of earlier self-reported diseases (studies II-IV) at baseline, 39\% had hypertension and 7\% gout, depression or epilepsy. None had potentially neurotoxic drugs at baseline assessment.

Table 4. Demographic and clinical characteristics of patients in studies I-IV.

\begin{tabular}{|c|c|c|c|c|}
\hline & Study I & Study II & Study III & Study IV \\
\hline $\begin{array}{l}\text { Sample } \\
(\mathrm{n}=\text { number) }\end{array}$ & $\mathrm{n}=61$ & $\mathrm{n}=10$ & $\mathrm{n}=10$ & $\mathrm{n}=46$ \\
\hline Age (years) range (mean) & $37-80(64)$ & $44-68(61)$ & $44-68(61)$ & $31-75(61)$ \\
\hline \multicolumn{5}{|l|}{ Gender, n (\%) } \\
\hline Male & $35(57)$ & $3(30)$ & $3(30)$ & $28(61)$ \\
\hline Female & $26(43)$ & $7(70)$ & $7(70)$ & $18(39)$ \\
\hline \multicolumn{5}{|l|}{$\begin{array}{l}\text { Type of malignancy, } \mathbf{n} \\
(\%)\end{array}$} \\
\hline Colon & $45(74)$ & $9(90)$ & $9(90)$ & $40(87)$ \\
\hline Rectum & $15(25)$ & $1(10)$ & $1(10)$ & $6(13)$ \\
\hline Colon \& Rectum & $1(1)$ & - & - & - \\
\hline \multicolumn{5}{|l|}{ Chemotherapy, n (\%) } \\
\hline FOLFOX $^{\mathrm{a}}$ & $8(13)$ & $1(10)$ & $1(10)$ & $7(15)$ \\
\hline XELOX $^{\mathrm{b}}$ & $53(87)$ & $9(90)$ & $9(90)$ & $39(85)$ \\
\hline $\begin{array}{l}\text { Oxaliplatin } \mathrm{mg} / \mathrm{m}^{2} \\
\mathrm{~min} / \max \text { (mean) } \\
\text { Total dose }\end{array}$ & $120-2940(1060)$ & $175-520(214)$ & $175-1500(791)$ & $120-2428(925)$ \\
\hline $\begin{array}{l}\text { Number of OXA treat- } \\
\text { ments, mean }\end{array}$ & 5.4 & 1.5 & 4.6 & 5 \\
\hline
\end{tabular}

${ }^{\mathrm{a}}$ Fluorouracil + leucovorin + oxaliplatin, ${ }^{\mathrm{b}}$ Capecitabine + oxaliplatin 
Table 5. Social status, educational level and occupational information on patients in studies II-IV.

\begin{tabular}{|c|c|c|c|}
\hline & Study II & Study III & Study IV \\
\hline $\begin{array}{l}\text { Sample } \\
\qquad(\mathrm{n}=\text { number })\end{array}$ & $\mathrm{n}=10$ & $\mathrm{n}=10$ & $\mathrm{n}=46$ \\
\hline \multicolumn{4}{|l|}{ Social status, $\mathbf{n}(\%)$} \\
\hline Living alone & $2(20)$ & $2(20)$ & $6(13)$ \\
\hline Living with life partner & $8(80)$ & $8(80)$ & $33(72)$ \\
\hline $\begin{array}{l}\text { Partner and children at home, } \\
<21 \text { years }\end{array}$ & $2(20)$ & $2(20)$ & $7(15)$ \\
\hline \multicolumn{4}{|l|}{ Educational level, n (\%) } \\
\hline Lower than high school & $2(20)$ & $2(20)$ & $5(11)$ \\
\hline High school or college & $5(50)$ & $5(50)$ & $26(57)$ \\
\hline University & $3(30)$ & $3(30)$ & $14(30)$ \\
\hline \multicolumn{4}{|l|}{ Occupation } \\
\hline Employed full time & 1 & 1 & $4(9)$ \\
\hline Employed part time & 2 & 2 & $2(4)$ \\
\hline Retired & 3 & 3 & $19(41)$ \\
\hline Early retired/Disabled & - & - & $2(4)$ \\
\hline Sick leave full time & 3 & 3 & $14(30)$ \\
\hline Unemployed & - & - & $1(2)$ \\
\hline $\begin{array}{l}\text { Employed part time and sick } \\
\text { leave part time }\end{array}$ & 1 & 1 & $2(4)$ \\
\hline No answer & - & - & $2(4)$ \\
\hline
\end{tabular}




\section{Data collection}

\section{Study I}

Data from patients' medical records were collected in the oncology department and coded with a number from 1 to 61 . The protocol was tested on five medical records, and in all of them the protocol captured the documented text of the patients' neurotoxic side effects. They were therefore included in the analysis. All documentation in each medical record was read twice. A predetermined protocol was developed from the questionnaire to assess the documentation of patients' neurotoxic side effects (Leonard et al. 2005). Every specific neurotoxic side effect in the record was counted, and the number of side effects was noted in the protocol. Each sentence that included neurotoxic side effects in some way was manually documented verbatim in the protocol. The content in the medical records involving neurotoxic side effects was counted, sorted and categorised according to the protocol.

\section{Studies II-III}

The qualitative studies II-III collected data through single and repeated face to face interviews with ten patients. To identify suitable patients, the researcher screened patients' answers on neurotoxic side effects in the web-based graphs (Figure 2). The patients were contacted by telephone when neurotoxic side effects were assessed for the first time during treatment, and an interview meeting was booked at a patient-appropriate location. The majority of the interviews were carried out in the patient's home. In study II they were interviewed at the onset of the side effects (study II).

Patients showing persistent neurotoxicity on the web-based graphs at the end of OXA treatment were interviewed repeatedly (study III). The interviews were conducted after final OXA treatment, and three months, six months and one year post treatment (when side effects persisted). A total of 35 interviews were completed in the qualitative studies II-III (see Figure 3). An interview guide was used to define the areas to be explored as well as the neurotoxic side effects and how they affect daily life (study II+III). The guide also allowed both the interviewer and interviewee to diverge from the main topics to pursue an idea or statement in more detail (Patton 2015). 
Before each interview began, small talk was conducted to create a relaxed atmosphere. Each interview began with an introductory question inviting the patients to talk about their neurotoxic side effects and how these affected their daily life (study II+III). Probing questions such as "Please tell me more" or "Could you explain?" were used throughout the interviews. All patients knew the various questions they would receive regarding neurotoxic side effects from the questionnaire (OANQ). The interviews were recorded digitally and transcribed verbatim. The data corpus amounted to 105 pages in study II and 226 pages in study III.

\section{Study IV}

The quantitative data for this study comprise patients' self-reported data obtained via a mobile phone-based system. The physician responsible for the patient assessed him or her and decided whether he/she was able to participate in the study. Nurses initiated the transfer of the questionnaire to each patient's mobile phone. A specially developed calendar function in the mobile phone-based system was used to fill in the specific dates for sending back the questionnaires. The calendar was adapted for each patient, and the OANQ questionnaire was sent out to them in order to obtain individual, customised assessments according to the study design (Figure 5). The patients had 24 hours to answer the questionnaire, and a reminder to answer was sent at $4 \mathrm{pm}$. 
Figure 5 provides an overview of the different phases of data collection in studies II-IV during and post OXA-based chemotherapy.

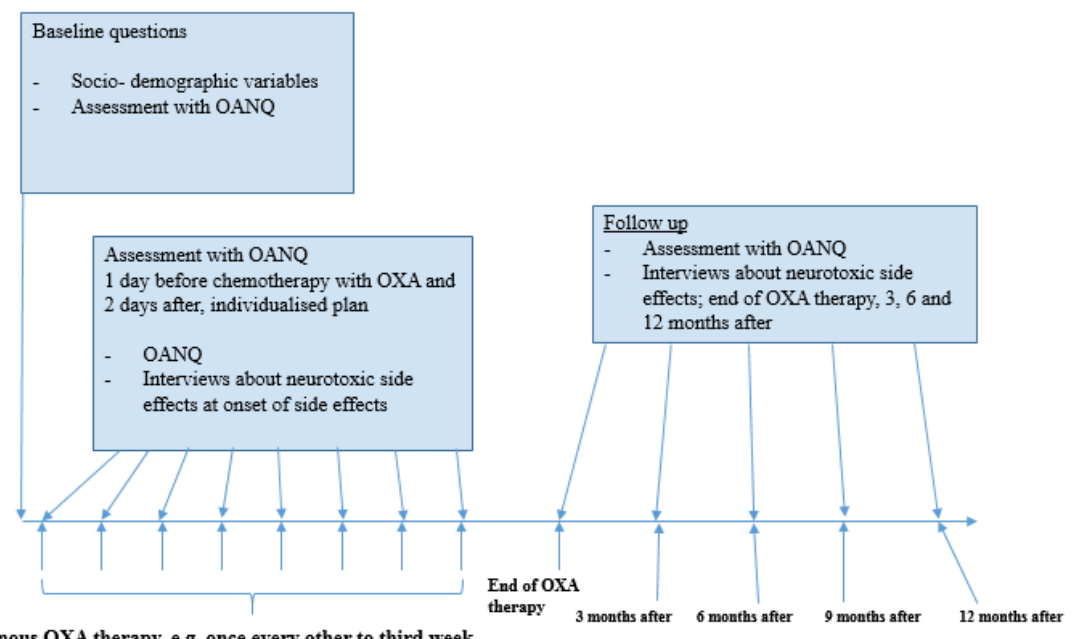

Cycles of intravenous OXA therapy, e.g. once every other to third week

Figure 5. Data collection during and post Oxaliplatin-based chemotherapy, studies II-IV. Individualised, self-reported assessments of neurotoxic side effects using the OANQ (Oxaliplatin-associated Neurotoxicity Questionnaire) in a mobile phone-based system. Patients were recruited to interviews when neurotoxic side effects began, at the end of treatment and after 3, 6 and 12 months. 


\section{Description of the Oxaliplatin-associated Neurotoxicity Ques- tionnaire (OANQ)}

To measure the frequency, severity and distress of neurotoxic side effects, a 29-item questionnaire was used. The questionnaire was developed by Leonard et al. The OANQ was developed to assess neurotoxic side effects both during and after OXA treatment (Leonard et al. 2005). Patients first indicated whether they had the specific side effect, answering yes or no. If they answered yes, they graded the side effects on a five-point scale ranging from $1=$ "hardly any" to $5=$ "very much". They then graded the impact of the neurotoxic side effects on their daily activities, where $1=$ "hardly bothered at all" and 5= "extremely bothered". The questionnaire was divided into three sections corresponding to location of the side effect: upper extremities (10 items), lower extremities (9 items) and the face/mouth area (10 items).

Questions from the three body locations and sections:

\section{Upper extremity}

Tingling? (pins and needles)

Numbness?

Difficulty telling the difference between rough and smooth surfaces?

Difficulty feeling hot things?

Difficulty feeling cold things?

A greater than normal sense of touch? (i.e. putting on gloves)

Burning pain or discomfort without cold?

Burning pain or discomfort with cold?

Difficulty identifying objects in your hand? (i.e. coin)

Involuntary hand movements?

\section{Lower extremity}

Tingling? (pins and needles)

Numbness?

Difficulty telling the difference between rough and smooth surfaces?

Difficulty feeling hot things?

Difficulty feeling cold things?

A greater than normal sense of touch? (i.e. discomfort with socks)

Burning pain or discomfort without cold?

Burning pain or discomfort with cold?

Legs feel heavy? 


\section{Facial/Oral}

Jaw pain?

Eyelids drooping?

Throat discomfort?

Ear pain?

Tingling in mouth?

Difficulty with speech?

Burning or discomfort with your eyes?

Loss of any vision?

Feeling shock/pain down back?

Problems with breathing?

The OANQ was originally constructed from observational studies, experiences in clinical practice and interviews with patients undergoing chemotherapy treatment with OXA. The questionnaire was not given an official name by the authors (Leonard et al. 2005), and therefore it has different names in the various trials. For example, it has been known as the Chemotherapy-induced Neurotoxicity Questionnaire (CINQ), the Oxaliplatin-associated Neuropathy Questionnaire and in some trials "The Leonard Scale Questionnaire". All refer to the original article by Leonard et al. (Leonard et al. 2005). In this thesis, the questionnaire is referred to as the Oxaliplatin-associated Neurotoxicity Questionnaire (OANQ).

The original OANQ in English was translated into Swedish in three stages by researchers. Firstly, a native translator translated all items into Swedish. Secondly, this version was checked by the authors and was then independently back translated into English by a native-speaking translator. Thirdly, the original and back-translated version was compared for equivalence. The translation and back translation of the OANQ were equivalent to the original, and no cultural dilemmas could be found (Acquadro 2012, Acquadro 2009, Brislin 1970). The Swedish version of the OANQ was tested for language and understanding by five patients who were not included in the study, and no language changes was made. The Swedish version of the OANQ was administered through a mobile phonebased system (Drott et al. 2016, Gustafsson et al. 2016). 


\section{The mobile phone-based system}

To measure the severity and distress of neurotoxic side effects, the OANQ (Leonard et al. 2005) was used both during and post OXA treatment on a mobile phone-based system. The OANQ was adjusted to fit this system (Drott et al. 2016, Gustafsson et al. 2016). During the adjustment process, some of the items/questions were condensed to fit also the mobile version for JAVA ME phones (maximum characters), but this did not interfere with the content of the questions in the questionnaire. The questions were sent to the patients as data traffic (not SMS).

The mobile phone-based system CQ (Circadian Questions) developed by $21^{\text {st }}$ Century Mobile, Stockholm, Sweden (http://www.cqmobil.se) was used. The system is interactive, with a secure login-restricted and web-based feedback module. The collected data were transferred to a secure database as data traffic (not SMS) via the internet. The accessibility and usability of the OANQ in the mobile-phone system was evaluated, and patients found the questions relevant and easy to understand (Drott et al. 2016).

Neurotoxic side effects were assessed in real time and not retrospectively. The answers from the patients were sent directly via their mobile phone to the mobile phone-based system database, and presented as graphs on a website (see Figure 2). The self-reported side effects were immediately accessible to authorized healthcare professionals and the research team. Support with technical issues was made available both to patients and healthcare professionals.

A study procedure was established which included instructions for research nurses and nurses in general on how to use the mobile phone-based system. When the nurses initiated the transfer of the questionnaire to an individual's mobile phone, they used a calendar function to fill in the specific dates. The dates in the calendar function were set according to each patient's specific OXA chemotherapy regime, and the questionnaire was sent out to the patient to obtain individual, customized assessments. 
The patients received written, platform-specific information from the nurses explaining how to install the system on their mobile phones (platform-independent system compatible with JAVA ME phones, iPhone, Android, iPad and Windows Phone). A majority of patients used their own mobile phones, and a few patients used a mobile phone provided by the research team. Start screens appeared on the mobile phone initially, before the patient received the questions. Examples of start screens are presented in Figure 6. The start screens included information about installation of the mobile phone-based system CQ, acceptance of the Patient Data Act and the questionnaire. Patients indicated in the questionnaire whether they had the specific side effect. If not, they clicked next. If they had side effects, they graded them on a five-point scale ranging from $1=$ "hardly any" to $5=$ "very much". They then graded the impact on their daily activities, where 1= "hardly bothered at all" and 5= "extremely bothered".

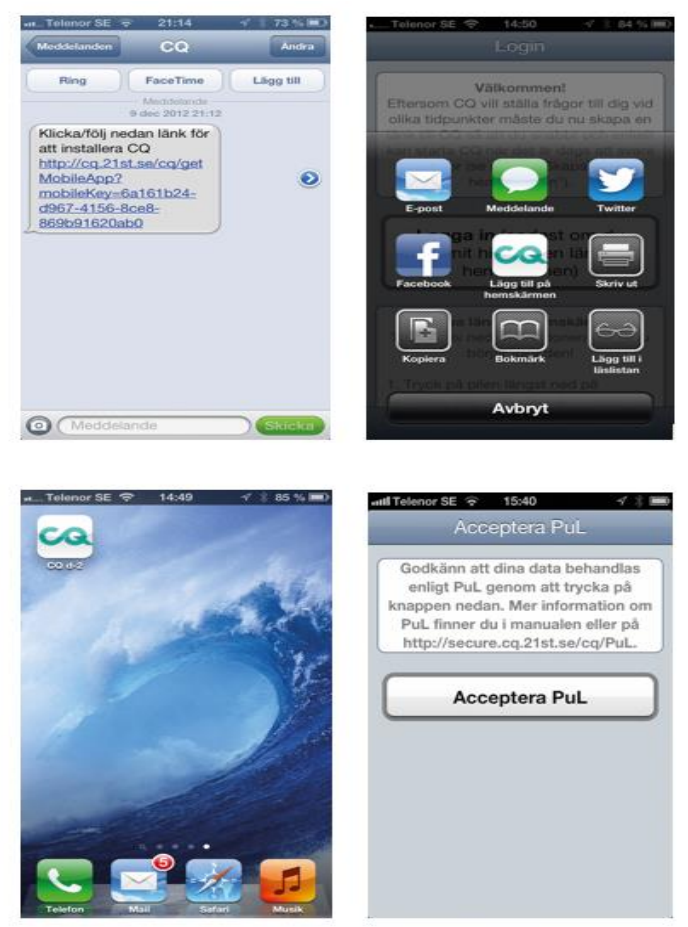

Figure 6. Examples of four start screens in a mobile phone. The start screens included information about installations of the mobile phone-based system CQ and acceptance of Patient Data Act (Swedish PuL) (reproduced with permission from 21st Century Mobile AB). 


\section{Data analysis}

\section{Study I}

Summative content analysis

A summative content analysis was used to identify and quantify words and content in the medical record text, in order to understand the content (Hsieh and Shannon 2005). Quantification is an attempt to explore how words are used. A summative approach to qualitative content analysis goes beyond word counts to include latent content analysis and interpretation. The focus is on discovering underlying meanings in the text. In this study, the text from the medical records was scrutinised from the point at which the patient started adjuvant chemotherapy, including OXA, and continued during and after OXA treatment. The content of the records was counted, sorted and categorised according to the protocol. The expressions which had been counted were analysed with descriptive statistics, count frequencies, mean (SD), median (range), percent and standard deviation. The verbatim statements were grouped, and the categories were analysed and interpreted to understand the meaning of each category (Hsieh and Shannon 2005).

\section{Studies II \& III}

\section{Thematic analysis}

The data were analysed thematically according to Braun and Clarke (2006, 2013). Thematic analysis is a flexible qualitative method, and can be applied across a range of epistemological approaches. The method is used for identifying, analysing and reporting themes from data. Interpretive levels are used to identify underlying ideas and assumptions.

The analysis followed five steps: 1) Familiarisation with the data, 2) Generating initial codes, 3) Searching for themes, 4) Reviewing themes, 5) Defining and naming themes.

Verbatim transcripts of the interviews were processed, and initial thoughts and ideas were noted. The transcribed data were read and re-read several times to enable the researchers to familiarise themselves with them (step 1). 
Codes were identified involving features of the data considered pertinent to the research question and the aim. Examples of codes in study II; "Not possible to drink cold beverages", "Difficult to prepare cold food to my family", "One strategy is to avoid triggers to prevent neurotoxicity" and "I change my routines and habits to avoid the side effects". The codes were used to ensure the data were arranged in a coherent pattern and were considered in relation to the data set as a whole. The whole data set was given equal attention, so that full consideration could be given to repeated patterns within the data (step 2).

These larger sections of data consisted of combinations of different codes which could be similar or were considered to involve the same aspect of the data. All initial codes relevant to the research question were incorporated into a theme (steps 3-5). The main theme in study II, "Endure neurotoxic side effects" included for example the codes "Avoid triggers (cold temperatures)", "Using family members as assistants" and "Change routines to avoid the neurotoxic side effects".

To help generate themes, a separate thematic map was made for each patient at each time point, and a comprehensive map was later produced for all patients who were included at each time point. The analysis was conducted in Swedish and translated into English at the point of presenting the findings and quotes. In order to increase the trustworthiness of the findings, the analysis was subjected to peer-debriefing within the research team (Nowell et al. 2017). 
Examples of thematic maps is presented in Figure 7.

A)

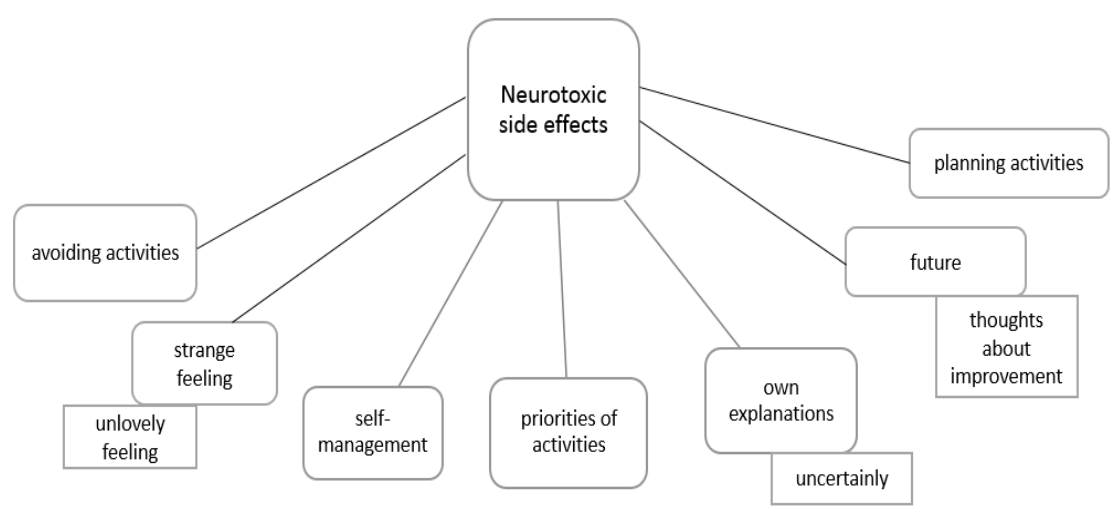

B)

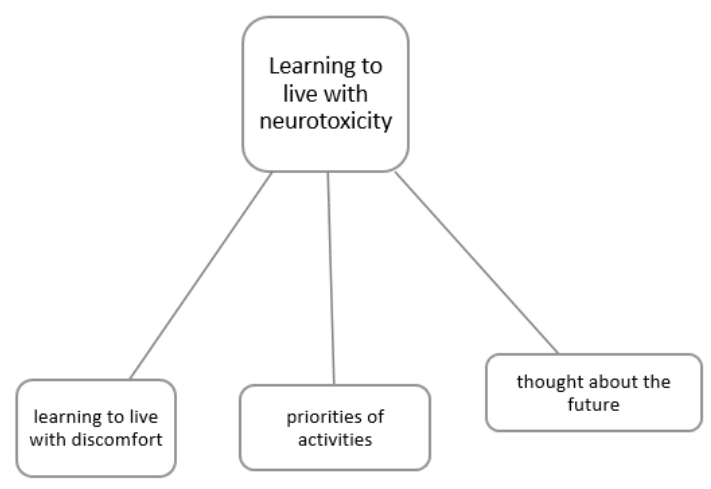

Figure 7. Example of an initial thematic map from 3-month interview data from one patient (A) and a final thematic map from 1-year interview data (B) (study III). 


\section{Study IV}

\section{Statistical analysis}

Data from the patient-reported OANQ were analysed statistically as shown below.

Descriptive statistics for the patient information at baseline were performed as means and standard deviations (SD), medians and ranges or proportions. Differences between patients who were included and those who were not (non-participants/ declined to participate) were tested with a two-sided z-test. Differences between the mean ages were analysed with a two-sided t-test. Since the study was not hypothesis-driven, no power calculation was made (Polit and Beck 2016).

Neurotoxic side effects and impact on daily activities were graded for each item of the OANQ as a percentage over time. With a dichotomisation of the grading of side effects, the presence or not of neurotoxicity was analysed for each item. Differences among time points were tested with the non-parametric McNemar's test. Since there was a need for a continuous and summarised measurement to perform aggregated longitudinal analysis, a Neurotoxicity Index was calculated by combining the grades for severity of side effects and their effect on daily activities. The following formula was developed for this purpose:

$$
\sum_{\text {item } 1}^{\text {item } 29}(\text { side effect grade } *(\text { effect on daily activities grade }+1))
$$

The Neurotoxicity Index has the potential to measure range from 0 up to the highest score 870 . The index is presented as a mean with a $95 \%$ confidence interval (CI) for the total population and for each gender.

Differences between time points Cycle 1, day-1 before OXA treatment, Cycle 5, day-2 (mean of OXA treatment length) and follow-ups post treatment (at 3, 6, 9 and 12 months) were assessed with the non-parametric Wilcoxon signed-rank test. Differences in the Neurotoxicity Index between genders at each time point were tested with a twosided t-test, with p-values adjusted with the Bonferroni method. 
For the purpose of this longitudinal design with unbalanced data a linear mixed effect model for repeated measures with a first-order autoregressive covariance matrix was fitted. The Neurotoxicity Index is presented as mean with a $95 \%$ CI adjusted for covariates, gender, age and OXA dose as fixed effects and the patients as random effects.

The OXA dose entered was the average delivered dose until each specific time point and an interaction term (age*OXA dose) was added to the model due to the correlation between this two variables. The Akaike Information Criterion (AIC) was used to select the final model (Brown and Prescott 2006, Elashoff et al. 2017, Fitzmaurice et al. 2011).

Due to the small sample in time points Cycle 7, day before (day -1) to Cycle 11, two days (d2) after OXA treatment, those were excluded in some figures. All tests used a significance level of $p<0.05$. The analyses were performed in IBM SPSS Statistics 22. 


\section{Ethical considerations}

Ethical approval was obtained from the Regional Ethical Review Board (record no: 2011/308-31, 2012/301-31, 2014/144-32, 2014/431-32), and the studies were conducted in agreement with the Declaration of Helsinki (World Medical Association 2013). All patients provided oral and written informed consent. The physician responsible for each patient assessed their state of health and decided if they were fit to participate in the study. The patients were given written and oral information about the study during their initial visit for planning treatment, so that they had time to think about it and decide whether they wished to participate in the project. The patients were later contacted by a research nurse or other nurse who provided further information and obtained informed consent. They were also informed that they could decline to participate or withdraw from the study at any time without explanation or consequences for their future care. This is especially important when patients with cancer are included in scientific studies, since vulnerable patients have a right to privacy in a critical period of their life. On the other hand, these studies are important in terms of improving knowledge about neurotoxic side effects and their consequences for daily life.

In study I, all the data were collected from patients' medical records, so this did not directly intrude on any patient's private sphere. Nevertheless, it is important to secure ethical permission (record no: 2011/308-31) and to management data collection securely. All data were collected in a room at the hospital. A special login for quality development purposes was used in the electronic medical record system. The medical records never left the hospital, and nothing was copied. The data were transferred to the study-specific protocol, and were coded in order to protect each patient's identity; no patients could be identified in the protocol. The protocols were stored in a separate and secure location. All data from all studies (I-IV) were treated confidentially.

Careful consideration was given to choosing the questionnaire and limiting items/questions. Another aspect to be considered is that participation in these studies could cause patients to experience discomfort. This is a vulnerable patient group to study, and questionnaires and interviews can affect the patients emotionally. Data collection through repeated questionnaires using a mobile phone system and repeated face-to-face interviews could be perceived as burdensome for the patients. 
The patient in study III, whose cancer returned reported severe neurotoxic side effects and influence on daily activities. After discussion with the patient, responsible health care professionals and with MD in the research team, the patient was excluded from study participation due to the patients' health condition.

It is important to be sensitive to the patient's private sphere and integrity (Council of Europe 1997, Council for International Organizations of Medical Sciences 2002). Arrangements for contact and support were made if the patients required it. There were also possible benefits in that the patients included in the study had the opportunity to talk about their experiences and situation during the interviews. This may have been therapeutic in terms of someone showing interest in their side effects and their life situation. The interviewer did not actively participate in the patients' ordinary care. The number of patients in the qualitative studies was low, and therefore extra consideration was taken to protect their identities.

\section{Trustworthiness, validity and reliability}

\section{Trustworthiness}

Lincoln and Guba (1985) suggested four criteria for establishing trustworthiness in qualitative studies: credibility, dependability, confirmability and transferability. In the qualitative studies (I-III), patients were chosen using a purposive and consecutive sampling strategy, aimed at gathering a multiplicity of experiences to enhance credibility (internal validity). Credibility refers to the extent to which the findings of a study are true, and whether they accurately reflect the aim of the research and reality in general throughout the research process. A deeper understanding of personal situations in their context over time may contribute to credibility in these longitudinal qualitative studies. Interaction between the researcher and the patients over time helps build a trusting relationship (Lincoln and Guba 1985). The procedure to conduct the thematic analysis aims to meet the trustworthiness criteria outlined by Lincoln and Guba were following a six-phased method (Nowell et al. 2017). The six phases establishing trustworthiness during each phase of thematic analysis is a reflective process over time and moving back and forward between phases. 
Dependability (reliability) refers to the stability of data, the extent to which it is true and represents the reality of the patients and whether the findings are consistent. Dependability is strengthened by using triangulation and peer-debriefing. Confirmability (objectivity) means that the findings are not an outcome of the subjectivity or bias of the researcher, and quotations were used in the findings to illustrate the patients' actual words.

The researcher's pre-understanding involved experience with patients with cancer in the gastrointestinal tract in an inpatient setting. The majority of the interviews were conducted in the patients' homes. The researcher had no caring relationship with the patients in the qualitative studies, but had relatively long clinical experience as a nurse in cancer care, as well as experience of communication with patients with cancer.

The various steps in the research process are carefully described to make the research confirmable and to provide an audit trail (Lincoln and Guba, 1985). More than one researcher was involved in the analysis during the initial stage and throughout the process, a procedure which is known as researcher triangulation (Nowell et al. 2017). In order to make the findings more trustworthy, the analysis was subjected to peer debriefing and was continuously scrutinised by the research team (Lincoln and Guba 1985, Patton 2015).

Transferability (external validity) involves the extent to which findings can be transferred into other similar contexts, as noted by Lincoln and Guba (1985). To make these studies more transferable, descriptive information was presented about the participating patients (sampling) and settings involved. This makes it possible for the reader to evaluate and apply the results to other contexts or patient groups. 


\section{Validity and reliability}

The OANQ was constructed from experiences in clinical practice, interviews and observational studies. The above-mentioned method used to elaborate the questionnaire indicates strong content validity (Mokkink et al. 2010). Reliability were tested using the Swedish version of the OANQ. A test-retest of the Swedish version of the OANQ was performed via the mobile-phone based system to evaluate the reliability (Gustafsson et al. 2016).

The test-retest reliability of the OANQ was assessed using paired samples t-test, intraclass correlation (ICC) and weighted kappa. A paired samples t-test did not reveal any significant differences for the three domains between the two tests. ICC for side effects show that $69 \%$ indicates excellent reproducibility, $24 \%$ fair to good reproducibility, and $7 \%$ poor reproducibility. ICC for items on daily activities; $83 \%$ indicates excellent reproducibility, $10 \%$ fair to good reproducibility, and $7 \%$ poor reproducibility (Gustafsson et al. 2016).

To estimate reproducibility by quantifying the concordance of the same subject for repeated measures, weighted kappa was used and showed overall feasibility. Weighted kappa for side effect items; 59\% almost perfect agreement, 28\% substantial agreement, $10 \%$ moderate agreement, and 3\% fair agreement. Weighted kappa for effect on daily activities items; $52 \%$ almost perfect agreement, 38\% substantial agreement, $7 \%$ moderate agreement, and 3\% fair agreement (Gustafsson et al. 2016).

Cronbach's alpha was calculated to evaluate the internal consistency. Internal consistency indicated that the questionnaire in total had good reliability, test $1=\alpha>0,929$ and test $2=$ $\alpha>0,935$. Cronbach's alpha for each body locations (domains) were lower than in total. For example, the domain upper extremity (items $1-10$ ) test $1=\alpha>0,854$ and test $2=\alpha$ $>0,851$ (Gustafsson et al. 2016). Cronbach's alpha for all items was $\alpha>0.9$ and corresponded with the well-known problem with multi-item scales (Polit 2014). OANQ can contribute to the monitoring and follow-up of OXA treatment administered via a patientreported mobile-phone system, but further psychometric testing is needed. 
Validity testing of the paper version of the OANQ was evaluated earlier using comparative analysis with FACT/GOG Ntx, and both instruments assessed similar constructs. Pearson's correlation analysis was carried out, and showed a significant correlation between the FACT/GOG and the OANQ $(-0.73 ; p<0.001)$, and between the Ntx-subscale and the OANQ $(-0.84 ; p<0.001)$, indicating a significant negative impact of patient-reported neurotoxic side effects on daily activities and quality of life. This showed that both instruments were assessing a similar construct (Driessen et al. 2012). 


\section{RESULTS}

The studies are presented in chronological order and summarised at the end of this results section.

\section{Documentation of neurotoxicity in medical records}

In study I, the patients in the reviewed medical records were aged between 37-80 years (median 64). Of the identified patients, 35 were men (57\%) and 45 patients (74\%) had colon cancer, 15 (25\%) had rectum cancer and one patient had both colon and rectum cancer. Doses of OXA were between 120-2940 mg/m² (median $1080 \mathrm{mg} / \mathrm{m}^{2}$ ). The mean number of OXA treatments was 5.43 ( $\mathrm{SD} \pm 2.36$ ).

The three most common side effects identified in the medical records were cold sensitivity, tingling in the hands, and numbness in the hands. Cold sensitivity was the most repeated term in the medical records (Table 6). It was described as a problem with cold in general or in specific areas, such as the mouth, throat, face, hands and feet, and was documented in 39 of the 61 medical records of participating patients. No documentation on sensitivity to cold was found after OXA treatment was completed. Forty-nine patients $(80 \%)$ had documented neurotoxic side effects during chemotherapy, and 21 patients $(35 \%)$ had neurotoxicity documented in their medical records after OXA treatment was completed. Seventeen (28\%) patients had reduced OXA dose because of troublesome neurotoxic side effects.

Table 6. Number of patients with neurotoxicity and frequency of words in medical records $(\mathrm{n}=61)$.

\begin{tabular}{|c|c|c|}
\hline Neurotoxic side effects & No of patients & Frequency of words \\
\hline Cold sensitivity & $39(64 \%)$ & 110 \\
\hline Tingling in hands & $38(62 \%)$ & 88 \\
\hline Numbness in hands & $21(34 \%)$ & 70 \\
\hline Numbness in feet & $20(33 \%)$ & 53 \\
\hline Tingling in feet & $17(28 \%)$ & 40 \\
\hline Muscle cramps & $9(15 \%)$ & 18 \\
\hline Taste changes & $9(15 \%)$ & 10 \\
\hline Muscle weakness & $7(11 \%)$ & 9 \\
\hline Balance problems & $7(11 \%)$ & 7 \\
\hline Dysphagia & $4(6 \%)$ & 4 \\
\hline Nerve pain & $3(5 \%)$ & 4 \\
\hline Breathing difficulties & $3(5 \%)$ & 3 \\
\hline
\end{tabular}


The verbatim statements from the patients' medical records were clustered and analysed. Analysed both in terms of description and interpretation to understand the meaning of categories. Three categories were identified in the qualitative interpretive part; acute neurotoxicity, chronic neurotoxicity and degree of neurotoxicity.

Acute neurotoxicity included mostly side effects documented half an hour to an hour after the start of infusion. Cold sensitivity was the most common documented side effect (Table 6). It was repeated 110 times in the records under on-going treatment. No documentation was found about cold sensitivity after OXA treatment was completed.

Chronic neurotoxicity included documented text after completed OXA treatment. Numbness in the hands and feet, clumsiness, and some sensory disturbance were common. Side effects were documented a long time after OXA treatment was completed, and sometimes the delay was up to one year or more after the treatment. In the analysis these side effects were interpreted as chronic neurotoxicity. In the records, chronic neurotoxicity was often documented in association with a patient's well-being. This way of pointing out patients' wellbeing and adding the neurotoxic problem was interpreted and understood as minimization of chronic neurotoxicity.

In the category, degree of neurotoxicity, a subjective judgement by the health professionals was documented in the medical records. Free descriptions were used such as: some, little, much better and a lot of neurotoxic side effects. No formal measurement of the degree of neurotoxicity was documented by the healthcare professionals. 


\section{Experiences of neurotoxic side effects and impact on daily life}

The two qualitative studies (studies II and III) contribute to knowledge about how patients endure neurotoxic side effects early in the treatment phase, and how they learn to live with neurotoxicity in the long term. Patients endure and manage their side effects in different ways, involving self-care strategies to restore normality in their daily lives. All patients stated that the cancer itself, as well as the treatment, had an impact on them and their life situation. They were living with a life-threatening disease, and were also trying to manage the side effects of treatment. They were all therefore coping with side effects and at the same time hoping to be cured.

In study II, the aspect foremost in the patients' minds at the beginning of treatment was survival, and patients were therefore prepared to endure severe neurotoxic side effects. They coped with the neurotoxicity, but at the same time were trying to maintain a positive attitude and think about the future. Early in the treatment period the most common neurotoxic side effects were sensitivity to the cold and tingling in the hands, feet and face. Daily activity and social life were affected by these side effects. In study II, one main theme were identified. The main theme was "Endure neurotoxic side effects".

Sensitivity to cold affected daily life in different ways and situations, and it was common to adapt in different ways. The cold climate outside meant that patients did not go outdoors. They had to adapt to handling cold food and beverages, and contact with the freezer or refrigerator. The patients needed to find different ways of performing these tasks. Sometimes the best way involved planning, or modifying and changing habits. One frequently used strategy was to accept help from family members, partners and friends, who were used as assistants.

To continue activities as usual, patients needed to plan carefully. Another strategy was to change routines they had had for many years, and develop new ones. Changed habits and lifestyle affected patients emotionally, and feelings of sadness were common. 
However, the patients adapted to the situation with coping strategies. They did not consider their side effects severe, but they were distressed about the way the neurotoxicity barrier affected their ability to carry out daily activities. The main results showed that at the beginning of the treatment phase they endured the neurotoxic side effects in expectation of a cure (study II). The analysis of the post-treatment interviews (study III) resulted in four themes. The themes, presented in chronological order in Figure 8, illustrate the trajectory of side effects and their impact on the patients' daily lives.
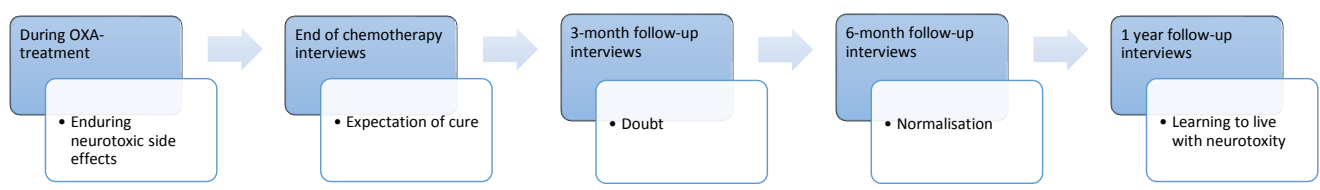

Figure 8. The themes illustrate the trajectory of neurotoxic side effects

When the chemotherapy was over, the patients' minds focused on being cured. The treatment was hard, but they managed it because they trusted the healthcare service and believed in a cure. They still had neurotoxic side effects but they hoped these would disappear. The patients had thought it would take some time. They looked forward to being healthy again and living a normal life. The patients had expectations of a cure and were living in the hope that this difficult situation would come to an end.

Three months after they had finished the OXA treatment, the patients had doubts. There was a sense of feeling unsure about the neurotoxic side effects and the prognosis of these symptoms. The patients had doubts about their ability to manage the side effects and about their future. Different strategies were used to manage the situation. The patients experienced a strange feeling in their bodies and reprioritised or avoided activities as a result of the side effects.

"I should start walking and exercising again, but I haven't been able to. I have some kind of imbalance and feel insecure" 
After six months, the patients started to adapt to the neurotoxic side effects. They had their own intellectual argument for persuading themselves to live a normal life even though they still had symptoms. They were grateful to be alive, and also grateful that some of the side effects had disappeared. The patients had made a number of adaptations to manage their life situation, and had also conditioned themselves to live with neurotoxicity. Despite this neurotoxicity in their daily lives, they argued that their life situation had normalised. Adjusting and reprioritising activities made the patients act normally, as they usually did. Sometimes adjustments were not enough, and then they just ignored the symptom.

"I feel the symptoms all the time, I try not to think about it"

After a year the patients had learned to live with neurotoxicity. They had learned to ignore the side effects and accept the feelings of distress. They avoided activities and this made them sad. They had learned to live with neurotoxicity, but if the symptoms worsened, they would be hard to manage.

"You learn to live with this unpleasant feeling in the hand and feet, I mean that I could have been dead today”

They thought about the future and about the possible relapse of the cancer. They had learned to stand the neurotoxic side effects, but if they would be worse, that would be hard to take.

"I don't want the symptoms to increase. I can stand them as they are today, but if the symptoms should be worsen, it would be hard"

The patients pointed out that they didn't have the same energy as before the chemotherapy. The neurotoxic side effects decreased their energy. 


\section{Real-time longitudinal patient-reported neurotoxicity, and impact on daily activities}

All patients in study IV reported multifactorial neurotoxic side effects during the 227 cycles (1-11 cycles, mean 5 cycles) with OXA. The total dose of OXA they received varied between $120-2428 \mathrm{mg} / \mathrm{m}^{2}$ (mean $925 \mathrm{mg} / \mathrm{m}^{2}$ ) and the mean dose for each chemotherapy cycle was $185 \mathrm{mg} / \mathrm{dose}\left(75-293 \mathrm{mg} / \mathrm{m}^{2}\right)$.

Patients withdrew from the study at different time points: two died, nine discontinued because of their state of health and three had technical/practical problems. The response rate during the OXA treatment (cycle 1-11) was 76\%, during the follow-up period $55 \%$, and $70 \%$ in total. Post treatment, the number of returned questionnaires after three months was $20(56 \%)$, after six months $20(61 \%)$, after nine months $20(61 \%)$ and after 12 months $13(41 \%)$. In terms of returned questionnaires, the range was 1-26 and the mean 8/patient. No internal data were missing (Figure 9).

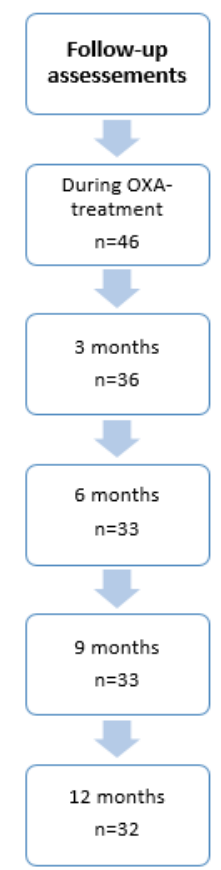

Figure 9. Number of patients at different time points. 
The dose of OXA varied between 1-11 cycles, and also the number of patients (Table 7).

Table 7. Dose of Oxaliplatin, $\mathrm{mg} / \mathrm{m}^{2} /$ cycle.

\begin{tabular}{|c|c|c|c|c|c|}
\hline Cycle & Mean & $\begin{array}{l}\text { Standard } \\
\text { Deviation }\end{array}$ & Minimum & Maximum & No of patients \\
\hline 1 & 214 & 54 & 120 & 292 & 46 \\
\hline 2 & 204 & 55 & 110 & 292 & 39 \\
\hline 3 & 182 & 61 & 90 & 292 & 37 \\
\hline 4 & 178 & 59 & 90 & 292 & 32 \\
\hline 5 & 175 & 51 & 90 & 270 & 28 \\
\hline 6 & 169 & 55 & 80 & 270 & 25 \\
\hline 7 & 159 & 43 & 90 & 240 & 9 \\
\hline 8 & 132 & 46 & 75 & 170 & 5 \\
\hline 9 & 97 & 26 & 75 & 125 & 3 \\
\hline 10 & 93 & 25 & 75 & 110 & 2 \\
\hline 11 & 75 & . & 75 & 75 & 1 \\
\hline
\end{tabular}

No statistical differences were found in age or gender between the participating patients and the patients who declined to participate in the study. The 46 patients who were not included (assessed for eligibility) were between 43 and 75 years of age (mean 61), and 29 were men $(63 \%)$.

All patients in the study reported neurotoxicity. A majority of the patients reported coldprecipitated tingling, burning pain or discomfort, and throat discomfort during OXA treatment. Oral/facial neurotoxic side effects were frequently reported during OXA treatment, but decreased after the treatment. Some of the face-related side effects, such as problems with eyelids or pain in the ears, remained relatively unchanged throughout the study period. 
Tingling in the upper extremities was reported by the majority during treatment, and significant differences were found between baseline and 3, 9 and 12 months follow-ups. Half of the patients had difficulties perceiving differences between rough and smooth surfaces and significant differences were found between baseline and 9 months follow-up. One year after treatment, numbness in the lower extremities were significant different from baseline. Differences between some of the time points for each item are presented in Table 8.

Table 8. Patient-reported neurotoxicity differences between time-points for each item.

\begin{tabular}{|c|c|c|c|c|c|c|c|c|c|c|c|c|c|c|c|c|c|c|c|c|}
\hline & C1, d-1 (Baseline) & \multicolumn{3}{|c|}{$\mathrm{C} 5, \mathrm{~d} 2$} & \multicolumn{4}{|c|}{3 months follow-up } & \multicolumn{4}{|c|}{6 months follow-up } & \multicolumn{4}{|c|}{9 months follow-up } & \multicolumn{4}{|c|}{12 months follow-up } \\
\hline & $\%$ & $n$ & $\%$ & $\begin{array}{l}P_{\text {Base- }} \\
C 5, \mathrm{~d} 2\end{array}$ & $n$ & $\%$ & $\begin{array}{l}P_{\text {Base- }} \\
3 \text { mon }\end{array}$ & $\begin{array}{c}P_{C 5, d 2-} \\
3 \text { mon }\end{array}$ & $n$ & $\%$ & $\begin{array}{l}P_{\text {Base- }} \\
6 \text { mon }\end{array}$ & $\begin{array}{c}P_{C 5, d 2-} \\
\text { 6mon }\end{array}$ & $n$ & $\%$ & $\begin{array}{l}P_{\text {Base. }} \\
9 \text { mon }\end{array}$ & $\begin{array}{l}P_{C 5, d 2-} \\
\text { 9mon }\end{array}$ & $n$ & $\%$ & $\begin{array}{l}P_{\text {Base. }} \\
12 \text { mon }\end{array}$ & $\begin{array}{l}P_{C 5,02} \\
12 \text { mon }\end{array}$ \\
\hline \multicolumn{21}{|l|}{ Upper Extremity } \\
\hline Tingling (Pins and needles) & 0 & 16 & 88 & 0,004 & 20 & 70 & 0,016 & 0,500 & 20 & 55 & 0,063 & 1,000 & 20 & 55 & 0,016 & 0,625 & 13 & 54 & 0,031 & 1,000 \\
\hline Numbness & 0 & 16 & 50 & 0,063 & 20 & 65 & 0,031 & 0,063 & 20 & 35 & 0,125 & 1,000 & 20 & 45 & 0,063 & 1,000 & 13 & 38 & 0,125 & 1,000 \\
\hline Difficulty telling the difference between rough and smooth surf & 0 & 16 & 38 & 0,250 & 20 & 55 & 0,031 & 0,219 & 20 & 35 & 0,250 & 1,000 & 20 & 55 & 0,016 & 0,687 & 13 & 31 & 0,250 & 1,000 \\
\hline \begin{tabular}{|l|l|} 
Difficulty feeling hot things \\
\end{tabular} & 0 & 16 & 19 & 1,000 & 20 & 35 & 0,063 & 0,125 & 20 & 25 & 0,250 & 1,000 & 20 & 45 & 0,031 & 0,250 & 13 & 38 & 0,125 & 1,000 \\
\hline Difficulty feeling cold things & 0 & 16 & 56 & 0,125 & 20 & 40 & 0,031 & 1,000 & 20 & 40 & 0,250 & 0,625 & 20 & 45 & 0,031 & 0,687 & 13 & 38 & 0,125 & 0,250 \\
\hline A greater than normal sense of touch (i.e., putting on gloves) & 0 & 16 & 44 & 0,063 & 20 & 30 & 0,125 & 0,500 & 20 & 20 & 0,500 & 0,500 & 20 & 45 & 0,031 & 1,000 & 13 & 31 & 0,250 & 1,000 \\
\hline Burning poin or discomfort without cold & 0 & 16 & 38 & 0,125 & 20 & 20 & 0,500 & 1,000 & 20 & 20 & 0,500 & 0,500 & 20 & 35 & 0,125 & 0,625 & 13 & 23 & 0,500 & 1,000 \\
\hline Burning poin or discomfort with cold & 0 & 16 & 75 & 0,008 & 20 & 30 & 0,250 & 0,500 & 20 & 35 & 0,250 & 0,125 & 20 & 30 & 0,125 & 0,063 & 13 & 31 & 0,250 & 0,250 \\
\hline Difficulty identifying objects in your hand (i.e., coin) & 0 & 16 & 19 & 1,000 & 20 & 30 & 0,500 & 0,125 & 20 & 25 & 0,500 & 1,000 & 20 & 35 & 0,063 & 0,500 & 13 & 23 & 0,500 & 1,000 \\
\hline Involuntary hand movements & 0 & 16 & 56 & 0,031 & 20 & 25 & 0,500 & 1,000 & 20 & 25 & 0,500 & 0,125 & 20 & 30 & 0,250 & 0,625 & 13 & 8 & 1,000 & 1,000 \\
\hline \multicolumn{21}{|l|}{ Lower Extremity } \\
\hline Tingling (pins and needles) & 0 & 16 & 44 & 0,063 & 20 & 80 & 0,008 & 0,031 & 20 & 45 & 0,125 & 0,625 & 20 & 60 & 0,016 & 0,063 & 13 & 62 & 0,063 & 0,500 \\
\hline \begin{tabular}{l|l} 
Numbness & \\
\end{tabular} & 0 & 16 & 44 & 0,125 & 20 & 80 & 0,008 & 0,125 & 20 & 55 & 0,063 & 0,250 & 20 & 60 & 0,031 & 0,375 & 13 & 69 & 0,031 & 0,500 \\
\hline Difficulty telling the difference between rough and smooth surf & 0 & 16 & 19 & 1,000 & 20 & 45 & 0,063 & 0,031 & 20 & 40 & 0,125 & 0,125 & 20 & 55 & 0,016 & 0,031 & 13 & 46 & 0,250 & 0,250 \\
\hline \begin{tabular}{|l|l|} 
Difficulty feeling hot things \\
\end{tabular} & 0 & 16 & 19 & 1,000 & 20 & 35 & 0,125 & 0,250 & 20 & 25 & 0,250 & 1,000 & 20 & 50 & 0,031 & 0,125 & 13 & 38 & 0,500 & 0,500 \\
\hline Difficulty feeling cold things & 0 & 16 & 44 & 0,125 & 20 & 35 & 0,250 & 0,500 & 20 & 30 & 0,250 & 1,000 & 20 & 45 & 0,031 & 1,000 & 13 & 46 & 0,250 & 1,000 \\
\hline A greater than normal sense of touch (i.e., discomfort with sor & 0 & 16 & 31 & 0,250 & 20 & 55 & 0,031 & 0,031 & 20 & 40 & 0,250 & 0,500 & 20 & 50 & 0,016 & 0,250 & 13 & 46 & 0,125 & 1,000 \\
\hline \begin{tabular}{|l|l|} 
Burning poin or discomfort without cold \\
\end{tabular} & 0 & 16 & 25 & 0,500 & 20 & 40 & 0,125 & 0,063 & 20 & 25 & 0,250 & 1,000 & 20 & 40 & 0,031 & 0,500 & 13 & 46 & 0,125 & 0,500 \\
\hline Burning poin or discomfort with cold & 0 & 16 & 56 & 0,031 & 20 & 30 & 0,250 & 1,000 & 20 & 35 & 0,125 & 0,500 & 20 & 45 & 0,016 & 1,000 & 13 & 46 & 0,125 & 1,000 \\
\hline Legs feel heavy & 0 & 16 & 69 & 0,031 & 20 & 50 & 0,125 & 1,000 & 20 & 55 & 0,063 & 1,000 & 20 & 50 & 0,063 & 1,000 & 13 & 31 & 0,250 & 0,500 \\
\hline \multicolumn{21}{|l|}{ Facial/Oral } \\
\hline Jaw pain & 0 & 16 & 69 & 0,016 & 20 & 5 & 1,000 & 0,125 & 20 & 10 & 1,000 & 0,063 & 20 & 20 & 0,500 & 0,031 & 13 & 8 & 1,000 & 0,500 \\
\hline Eyelids drooping & 0 & 16 & 38 & 0,125 & 20 & 15 & 1,000 & 1,000 & 20 & 20 & 0,500 & 0,500 & 20 & 25 & 0,500 & 0,500 & 13 & 0 & & 1,000 \\
\hline Throot discomfort & 0 & 16 & 88 & 0,004 & 20 & 10 & 1,000 & 0,031 & 20 & 10 & 1,000 & 0,016 & 20 & 25 & 0,500 & 0,008 & 13 & 8 & 1,000 & 0,125 \\
\hline Eor pain & 0 & 16 & 25 & 0,500 & 20 & 20 & 0,500 & 1,000 & 20 & 10 & 1,000 & 1,000 & 20 & 15 & 1,000 & 0,500 & 13 & 0 & & 1,000 \\
\hline Tingling in mouth & 0 & 16 & 75 & 0,016 & 20 & 20 & 0,500 & 0,031 & 20 & 15 & 1,000 & 0,016 & 20 & 15 & 1,000 & 0,008 & 13 & 8 & 1,000 & 0,250 \\
\hline Difficulty with speech & 0 & 16 & 56 & 0,031 & 20 & 15 & 0,500 & 0,250 & 20 & 10 & 1,000 & 0,125 & 20 & 20 & 1,000 & 0,031 & 13 & 8 & 1,000 & 1,000 \\
\hline Burning or discomfort with your eyes & 0 & 16 & 44 & 0,125 & 20 & 15 & 0,500 & 1,000 & 20 & 20 & 1,000 & 0,125 & 20 & 15 & 1,000 & 0,125 & 13 & 15 & 1,000 & 1,000 \\
\hline Loss of any vision & 0 & 16 & 56 & 0,063 & 20 & 30 & 0,250 & 1,000 & 20 & 30 & 0,250 & 1,000 & 20 & 20 & 0,500 & 0,375 & 13 & 8 & 1,000 & 0,500 \\
\hline Feeling shock/pain down back & 0 & 16 & 31 & 0,500 & 20 & 20 & 1,000 & 1,000 & 20 & 30 & 0,500 & 1,000 & 20 & 20 & 1,000 & 1,000 & 13 & 31 & 0,500 & 1,000 \\
\hline Problems with breathing & 0 & 16 & 38 & 0,250 & 20 & 15 & 0,500 & 0,500 & 20 & 15 & 0,500 & 1,000 & 20 & 15 & 1,000 & 0,250 & 13 & 15 & 1,000 & 1,000 \\
\hline
\end{tabular}

Abbreviations: Time-points; C1, d-1 =Cycle 1, day before OXA treatment, C5, d2= Cycle 5, 2 days after OXA treatment, $\%=$ percentage of patients with neurotoxicity, $P=\mathrm{p}$-value. $p<0.05$ was considered significant. 
Differences between the time points Cycle 1 day 2, Cycle 2 day 2 and 12 months followup were also tested for each item. Between Cycle 1 day 2 and Cycle 2 day 2 the result show significant differences in the item "tingling in upper extremity" $(p=0,031)$ and between Cycle 1 day 2 and 12 months follow-up in the item "jaw pain" ( $p=0,031)$.

Between Cycle 2 day 2 and 12 months follow-up the results show significant differences in the items "throat discomfort" $(p=0,004)$ and "tingling in mouth" $(p=0,031)$.

The patients reported impact on daily activities due to the neurotoxic side effects. In the long-term perspective, side effects in the lower extremities were reported as having influence on patients' daily activities. The results show significant differences between baseline data, and nine of the patients had not returned to baseline after one year. The nine patients who still reported neurotoxicity and effect on daily activities were between 54 and 68 years of age (mean $65, \mathrm{SD} \pm 4)$. Seven of them were men $(78 \%)$.

The four patients who did not report side effects after one year were all females (61-69 years, mean 64).

Figure 10 a-c presents the progression of symptom severity of neurotoxic side effects and their impact on the patients' daily activities for each item in the OANQ. Three body locations are presented (Figure $10 \mathrm{a}-\mathrm{c}$ ). 

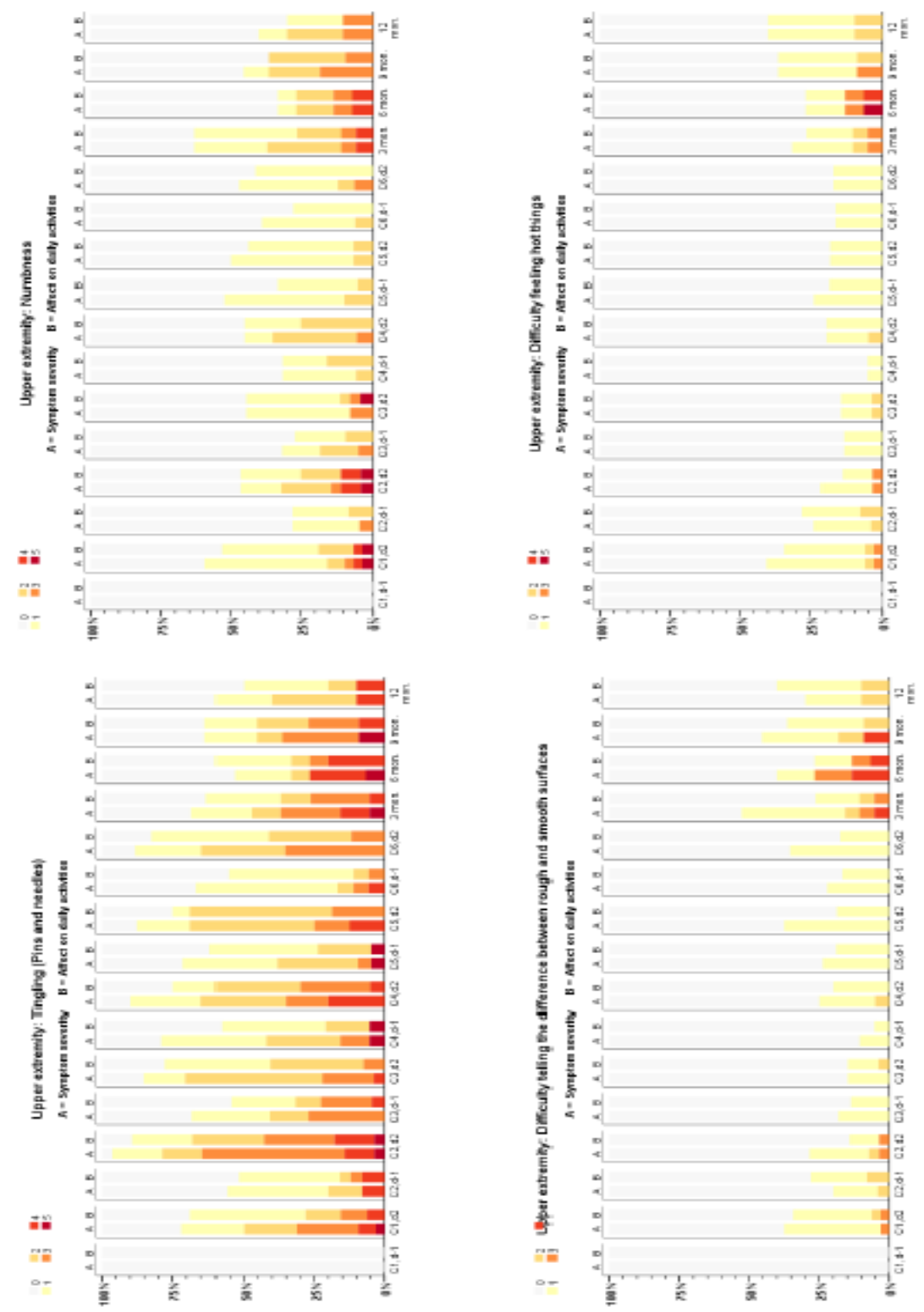

Figure 10a. Patient-reported neurotoxic side effects and impact on daily activities in upper extremity (arms $\&$ hands) items. Graded as follows: $0=$ "No side effect", $1=$ "Hardly any" and 5= "Very much". Impact on daily activities: $0=$ "No effects", $1=$ "Hardly bothered at all" and 5= "Extremely bothered". Time axis: cycle number (C No.), day before OXA treatment (d-1) and 2 days (d2) post OXA treatment. 

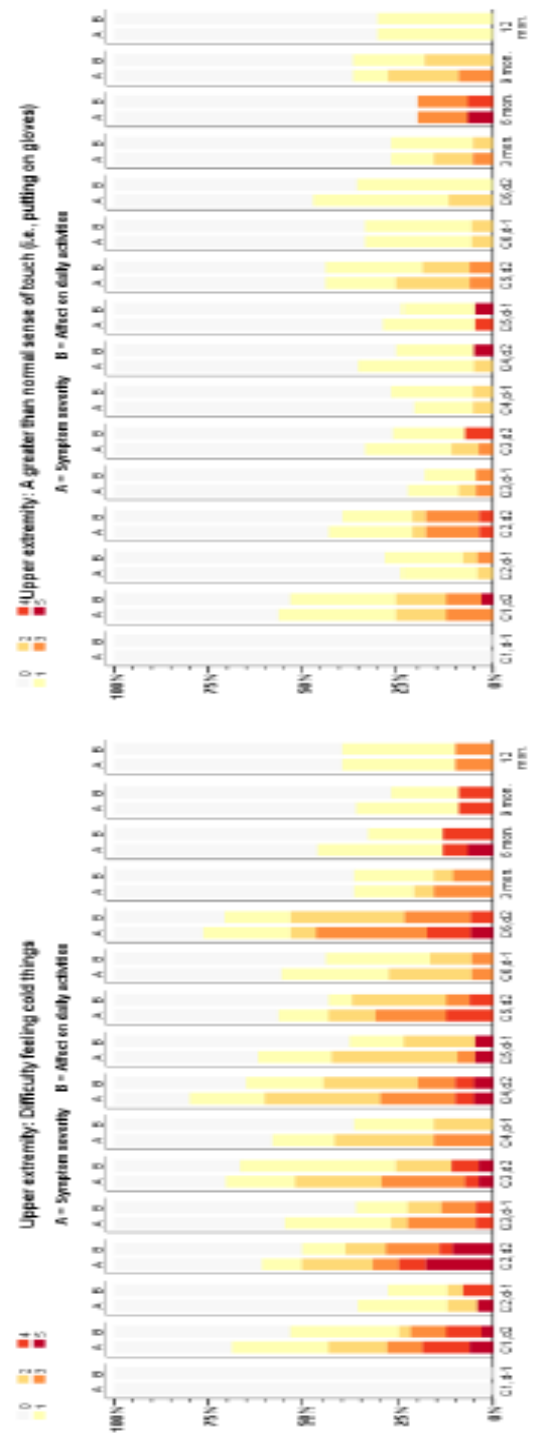

Figure 10 a. Patient-reported neurotoxic side effects and impact on daily activities in upper extremity (arms $\&$ hands) items. Graded as follows: $0=$ "No side effect", $1=$ "Hardly any" and 5= "Very much". Impact on daily activities: $0=$ "No effects", $1=$ "Hardly bothered at all" and $5=$ "Extremely bothered". Time axis: cycle number (C No.), day before OXA treatment (d-1) and 2 days (d2) post OXA treatment. 

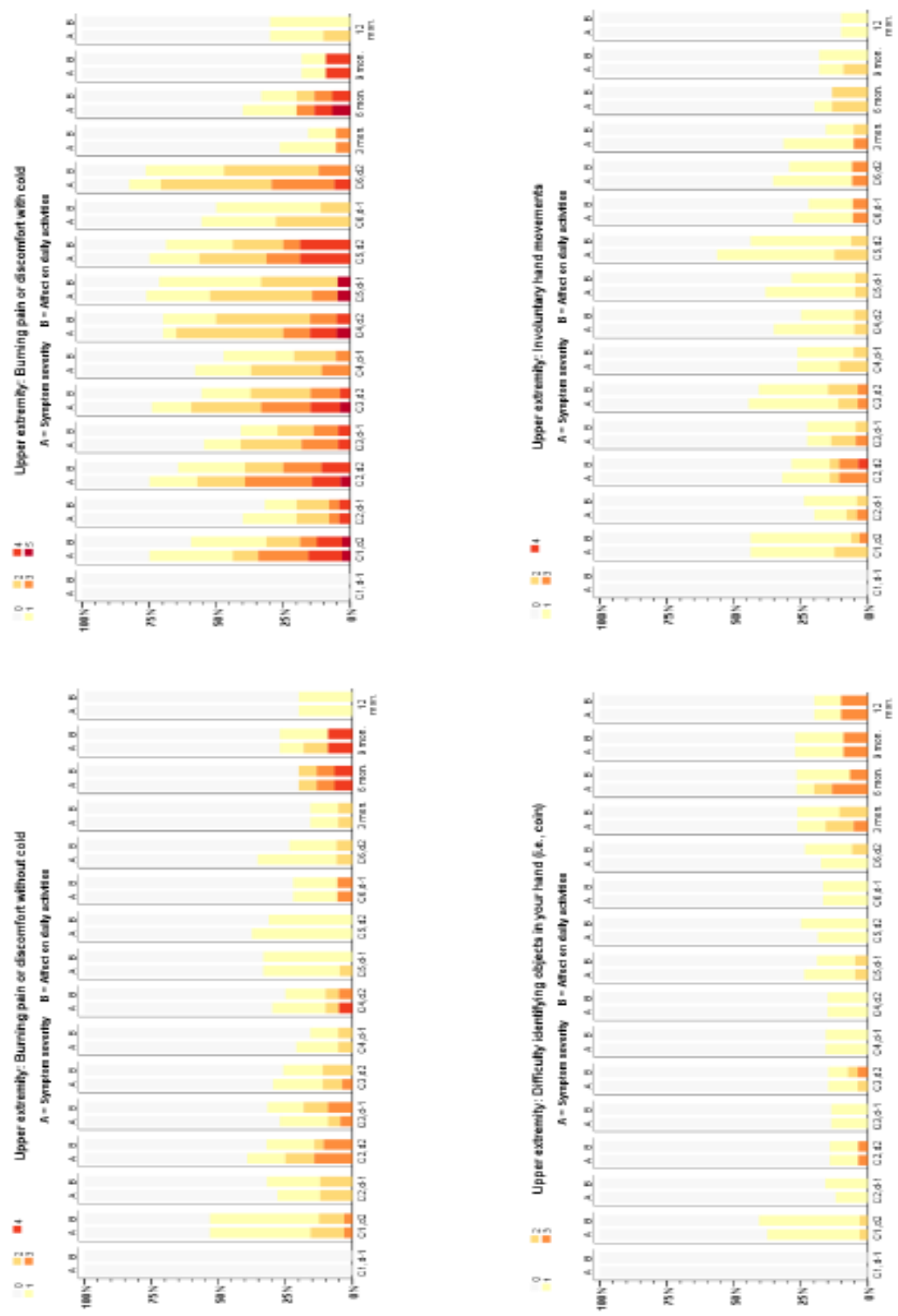

Figure 10 a. Patient-reported neurotoxic side effects and impact on daily activities in upper extremity (arms $\&$ hands) items. Graded as follows: $0=$ "No side effect", 1= "Hardly any" and 5= "Very much". Impact on daily activities: $0=$ "No effects", $1=$ "Hardly bothered at all" and 5= "Extremely bothered". Time axis: cycle number (C No.), day before OXA treatment (d-1) and 2 days (d2) post OXA treatment. 

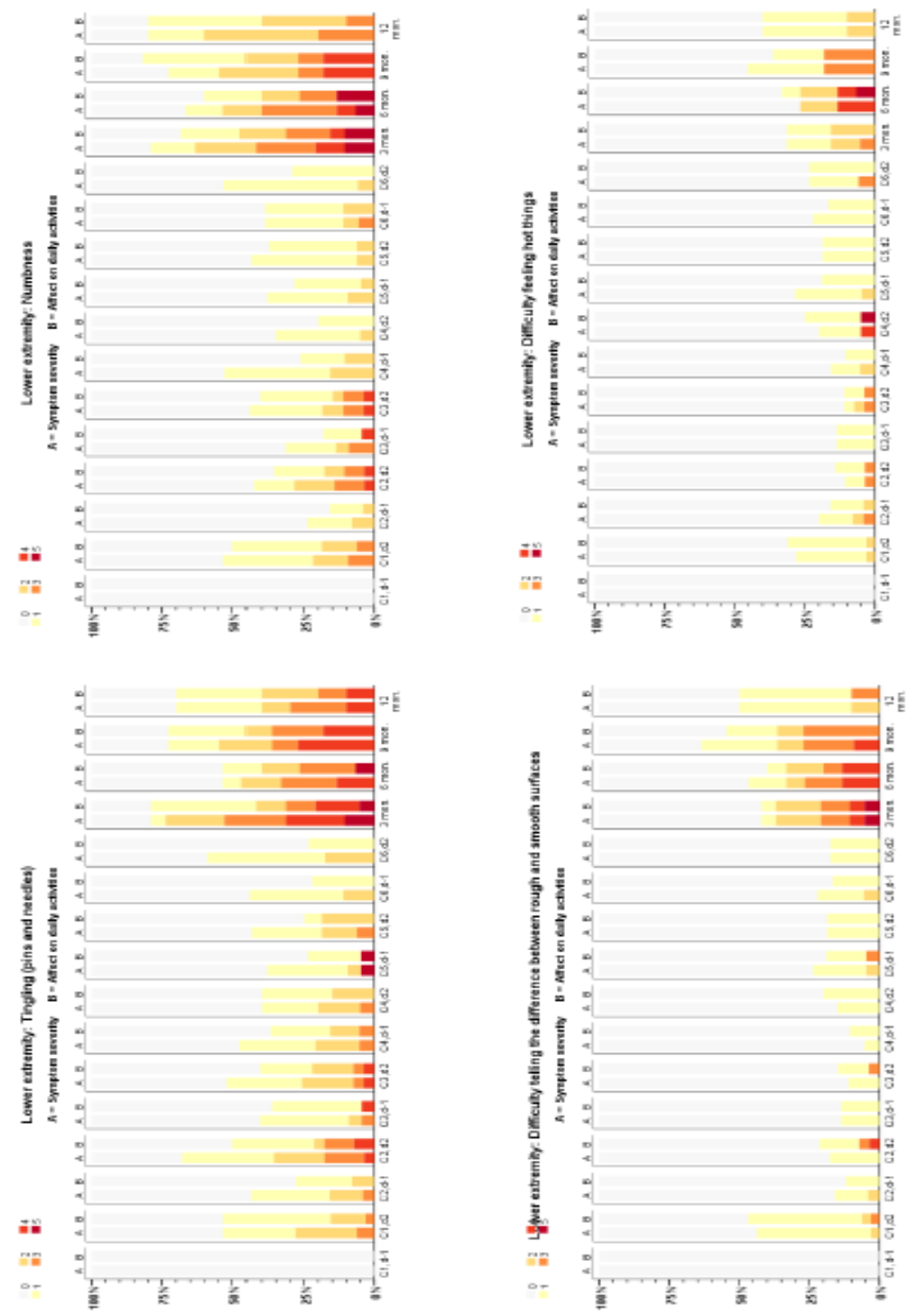

Figure 10 b. Patient-reported neurotoxic side effects and impact on daily activities in lower extremity (legs $\&$ feet) items. Graded as follows: $0=$ "No side effect", $1=$ "Hardly any" and 5= "Very much". Impact on daily activities: $0=$ "No effects", $1=$ "Hardly bothered at all" and 5= "Extremely bothered". Time axis: cycle number (C No.), day before OXA treatment (d-1) and 2 days (d2) post OXA treatment. 

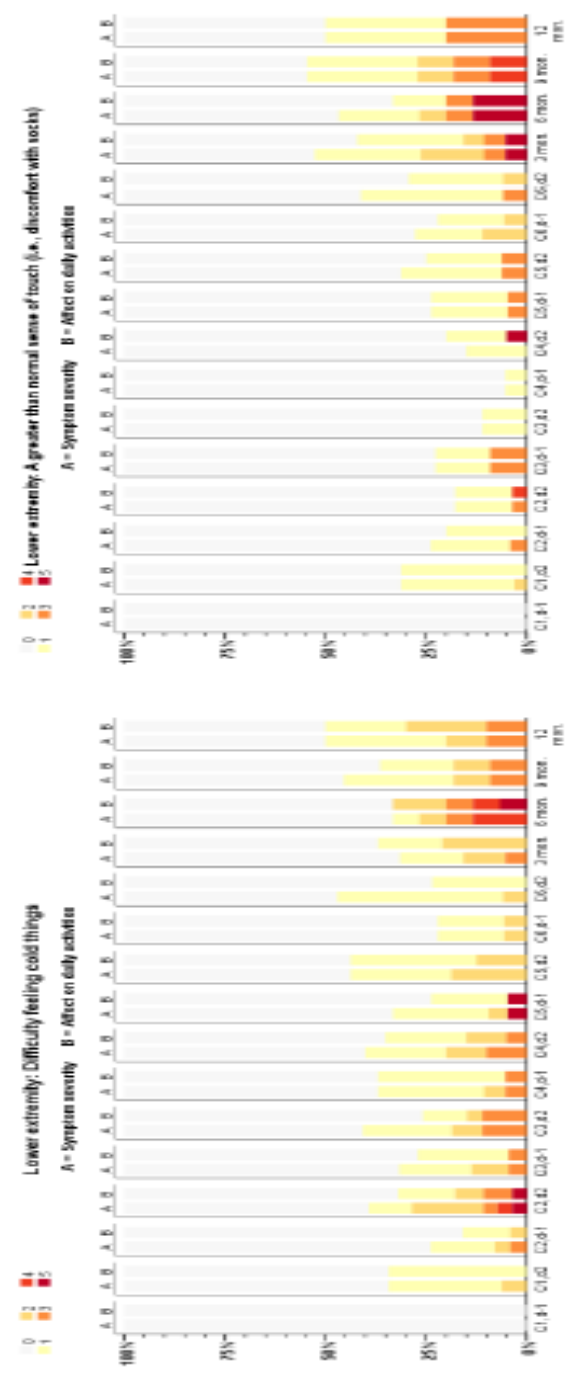

Figure 10 b. Patient-reported neurotoxic side effects and impact on daily activities in lower extremity (legs $\&$ feet) items. Graded as follows: $0=$ "No side effect", $1=$ "Hardly any" and 5= "Very much". Impact on daily activities: $0=$ "No effects", $1=$ "Hardly bothered at all" and $5=$ "Extremely bothered". Time axis: cycle number (C No.), day before OXA treatment (d-1) and 2 days (d2) post OXA treatment. 

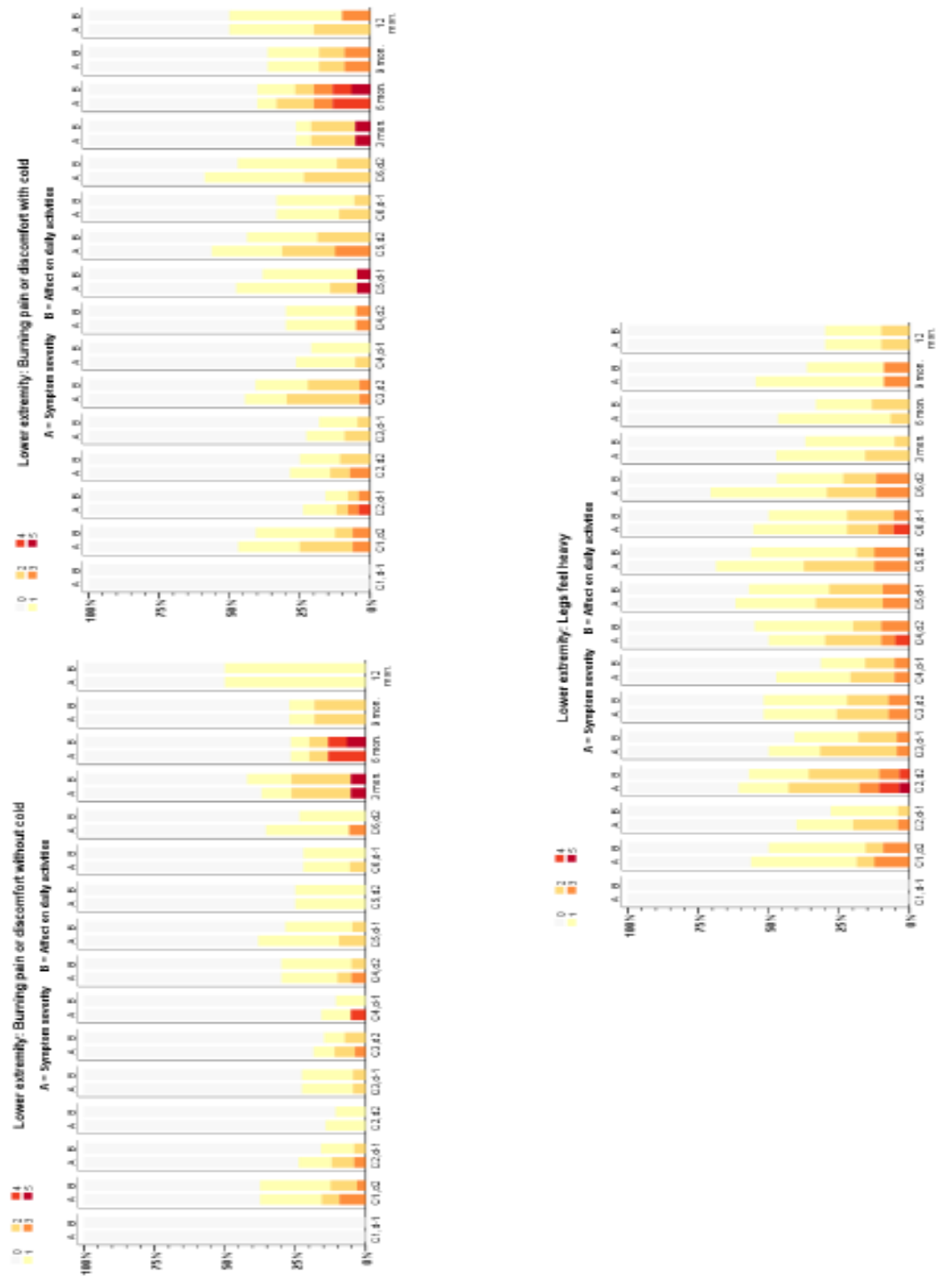

Figure 10 b. Patient-reported neurotoxic side effects and impact on daily activities in lower extremity (legs $\&$ feet) items. Graded as follows: $0=$ "No side effect", $1=$ "Hardly any" and 5= "Very much". Impact on daily activities: $0=$ "No effects", $1=$ "Hardly bothered at all" and 5= "Extremely bothered". Time axis: cycle number (C No.), day before OXA treatment (d-1) and 2 days (d2) post OXA treatment. 

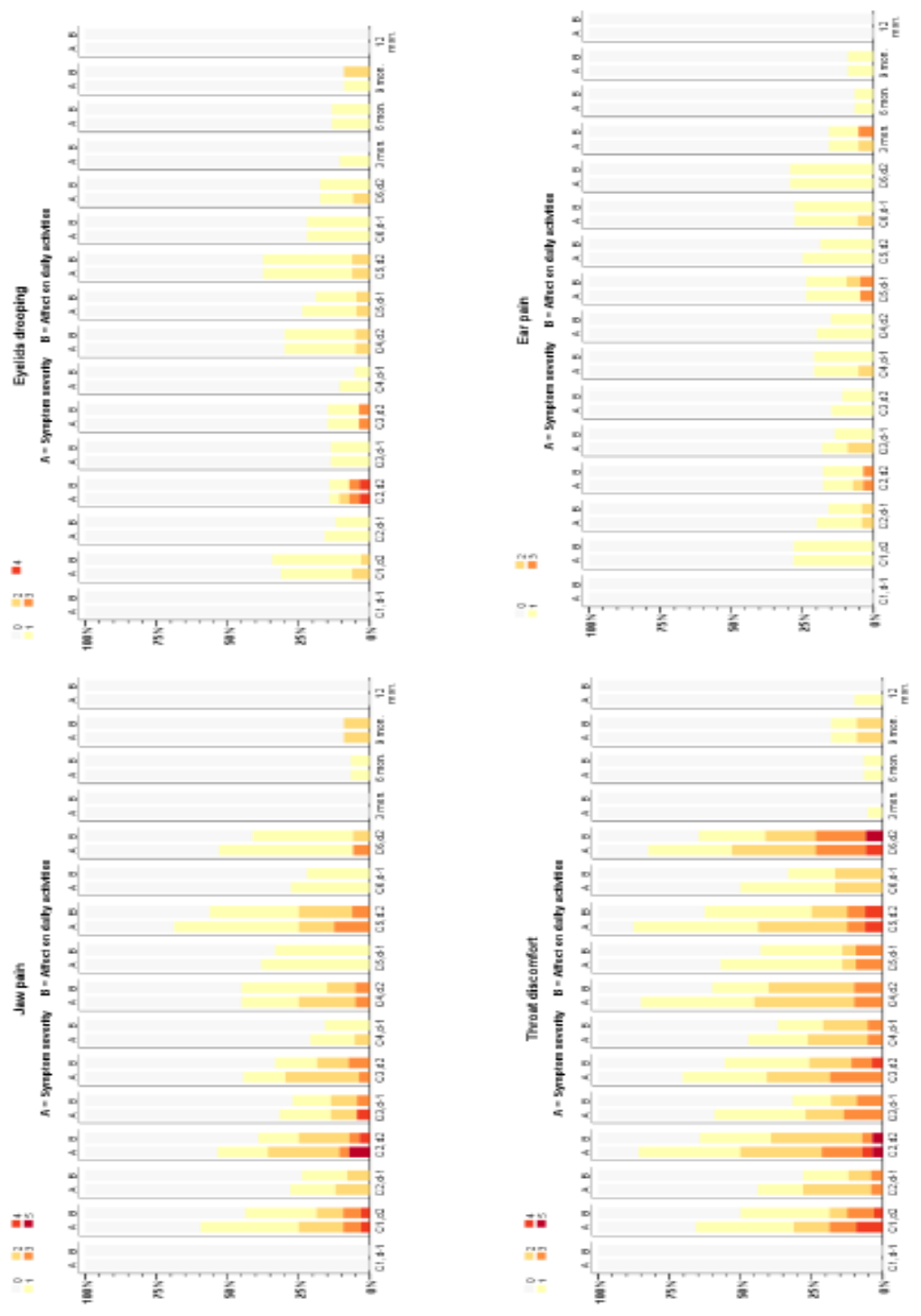

Figure 10 c. Patient-reported neurotoxic side effects and impact on daily activities in oral/facial side effect items. Graded as follows: 0= "No side effect", 1= "Hardly any" and 5= "Very much". Impact on daily activities: $0=$ "No effects", $1=$ "Hardly bothered at all" and 5= "Extremely bothered". Time axis: cycle number (C No.), day before OXA treatment (d-1) and 2 days (d2) post OXA treatment. 


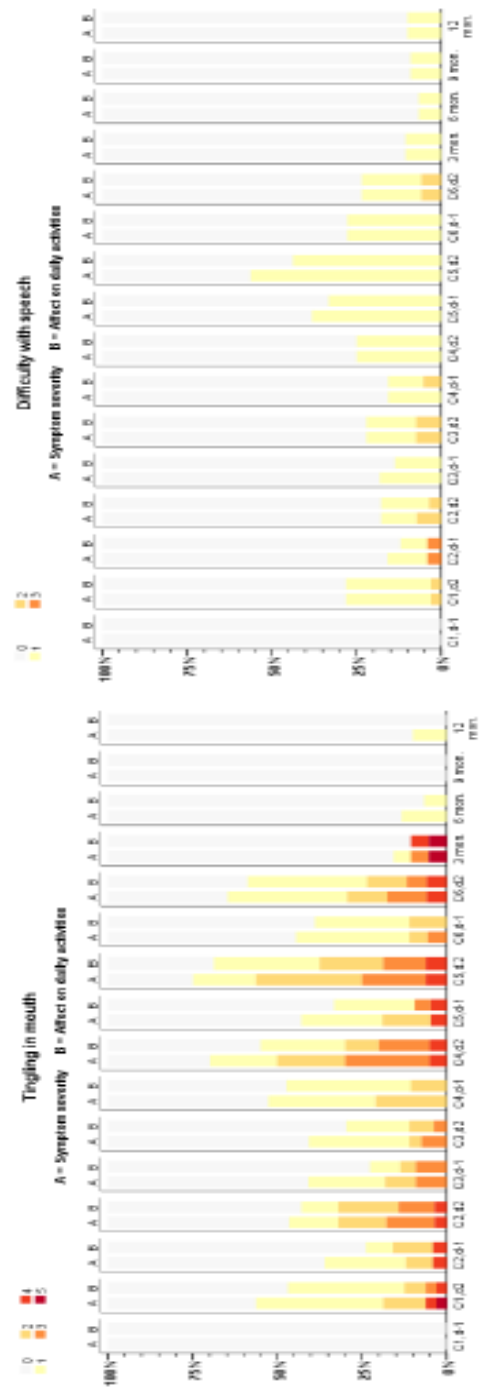

Figure 10 c. Patient-reported neurotoxic side effects and impact on daily activities in oral/facial side effect items. Graded as follows: $0=$ "No side effect", $1=$ "Hardly any" and $5=$ "Very much". Impact on daily activities: $0=$ "No effects", $1=$ "Hardly bothered at all" and 5= "Extremely bothered". Time axis: cycle number (C No.), day before OXA treatment (d-1) and 2 days (d2) post OXA treatment. 

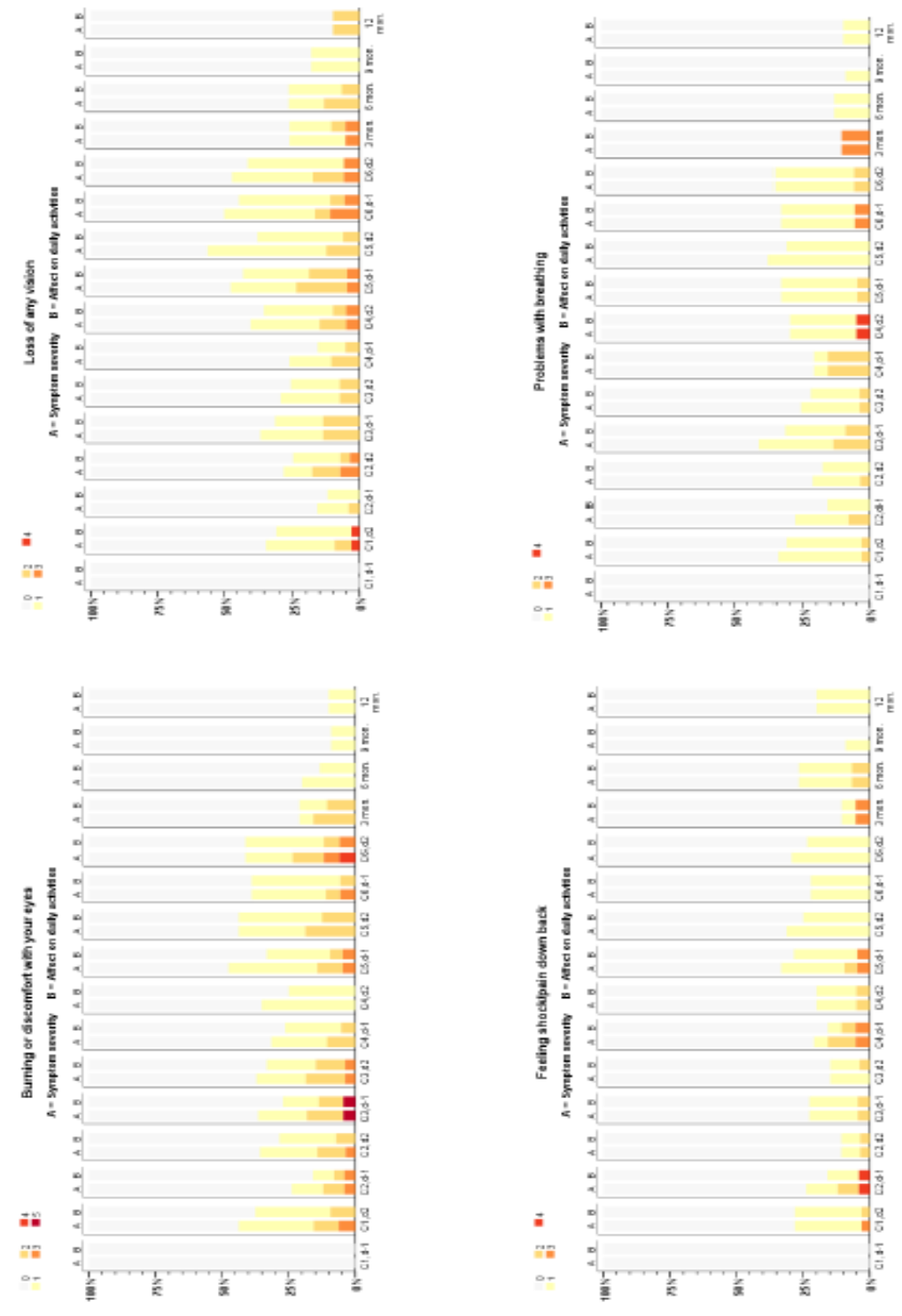

Figure 10 c. Patient-reported neurotoxic side effects and impact on daily activities in oral/facial side effect items. Graded as follows: $0=$ "No side effects", 1= "Hardly any" and 5= "Very much". Impact on daily activities: $0=$ "No effects", $1=$ "Hardly bothered at all" and 5= "Extremely bothered". Time axis: cycle number (C No.), day before OXA treatment (d-1) and 2 days (d2) post OXA treatment. 
The Neurotoxicity Index combining the grades for severity of neurotoxic side effects and their effect on daily activities, and has the potential to measure from 0 to the highest score 870.

Gender distribution in follow-up (male/female): 3 months (55\%/45\%), 6 months (50 $\% / 50 \%), 9$ months $(40 \% / 60 \%$ ) and 12 months (46\%/54\%). No statistically significant differences were noted between genders except for the time point Cycle 6, day 2 ( $p=0,043)$. In Figure 11, the mean of the Neurotoxicity Index is presented over time separated by gender (descriptive data).
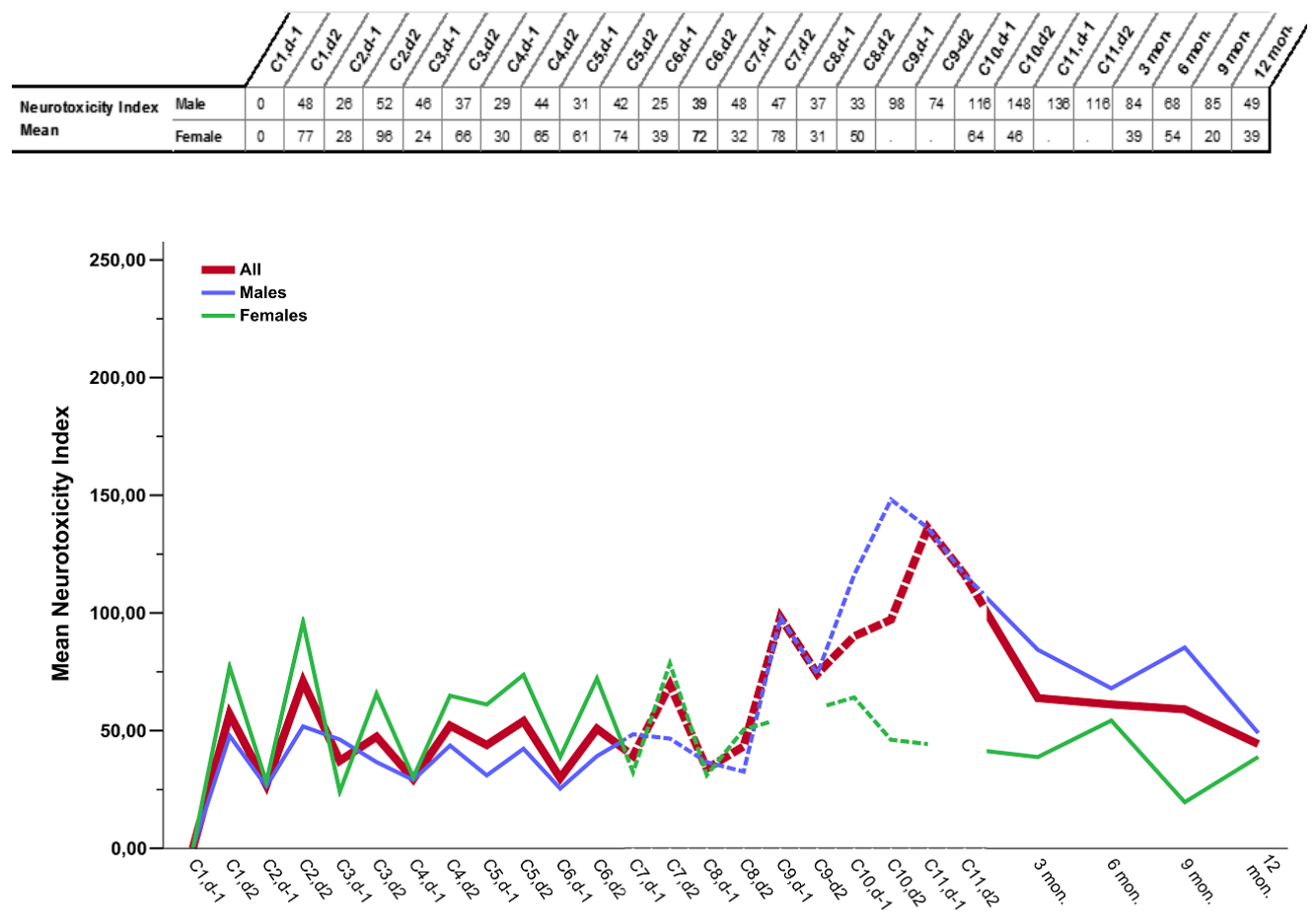

Figure 11. The Neurotoxicity Index (mean) separated by gender (descriptive data). Time axis: cycle number (C No.), day before OXA treatment (d-1) and 2 days (d2) after OXA treatment. Gender distribution in followup (male/female): 3 months (55\%/45\%), 6 months (50\%/50\%), 9 months (40\%/60\%) and 12 months $(46 \% / 54 \%)$. Lines are dashed where there are few patients. 
Results show significant differences in Wilcoxon signed rank test between the baseline data in the Neurotoxicity Index, Cycle 5, day 2 (mean value of end of therapy) $(p=0,008)$ and follow-up at $3(p=0,012), 6(p=0,018), 9(p=0,008)$ and 12 months $(p=0,028)$. No significant differences were found between Cycle 5, day 2 and the follow-up at 3, 6, 9 and 12 months.

For the purpose of this longitudinal design, a mixed effects model for repeated measures illustrates patient-reported outcomes of the Neurotoxicity Index at different time points in Figure 12.

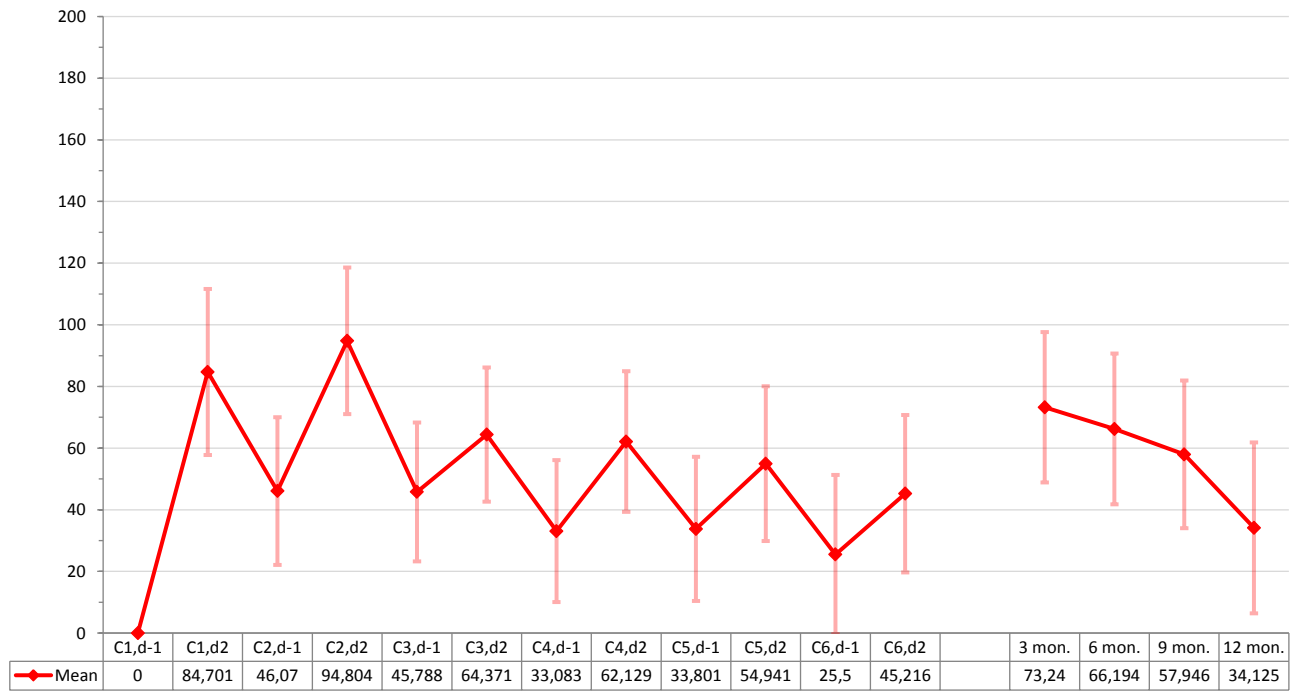

Figure 12. Repeated measures with a mixed effects model illustrate patient-reported outcomes of the Neurotoxicity Index at different time points. The index is presented as mean with a $95 \%$ confidence interval adjusted for covariates (age, gender and OXA dose per cycle). 
The summary of results shows a high prevalence of patient-reported neurotoxic side effects and impact on daily activities. The side effects changed in character and body location over time, and the most frequently assessed side effects during OXA treatment were cold-precipitated tingling in the upper extremities and mouth/throat. Patients' physical, psychological, emotional and social lives were affected, e.g. family roles, hobbies, social activities and the ability to work. Patients endured side effects early in the treatment phase, but after one year post treatment they had learned to live with neurotoxicity and discomfort. After one year, their daily lives were mostly affected by numbness and tingling in the legs but also tingling in the upper extremities. Patients endured and adapted to side effects in their daily lives, and developed strategies to minimise them, for example by avoiding activities or changing past habits to meet universal and health-deviation selfcare needs (Figure 13).

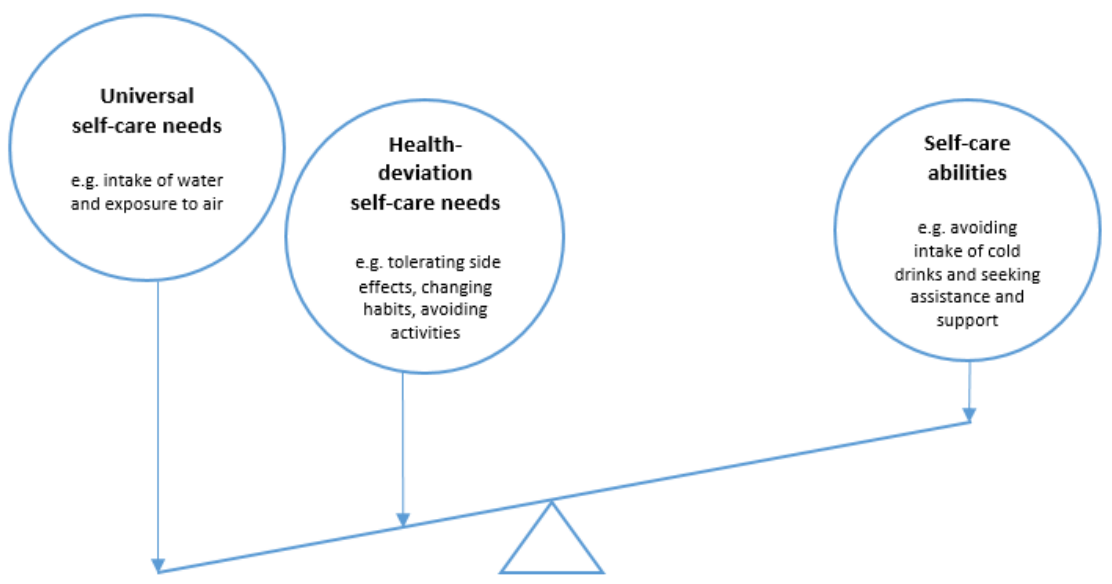

Figure 13. Experience of neurotoxic side effects and self-care abilities to meet universal and health deviation self-care needs. Figure inspired by Orem (2001). 
Capacity and strategies for self-care included support and help from family members and avoiding activities. In relation to the theoretical framework, it is on a partly compensatory level. Patients reprioritised activities, and used strategies to mitigate unpleasant feelings. In other words, patients endured and coped with their side effects in different ways, developing self-care strategies to restore normality. Patients who had symptoms when the therapy ended experienced feelings of sadness and discomfort, as they had thought that symptoms would disappear when the OXA-chemotherapy ended. At the end of the treatment, patients perceived it had been difficult to talk about their side effects, and they had not known where to contact the healthcare provider. Supportive and educative nursing care is needed both in the short and long term.

Synthesised results in relation to the theoretical framework, illustrated in Figure 14.

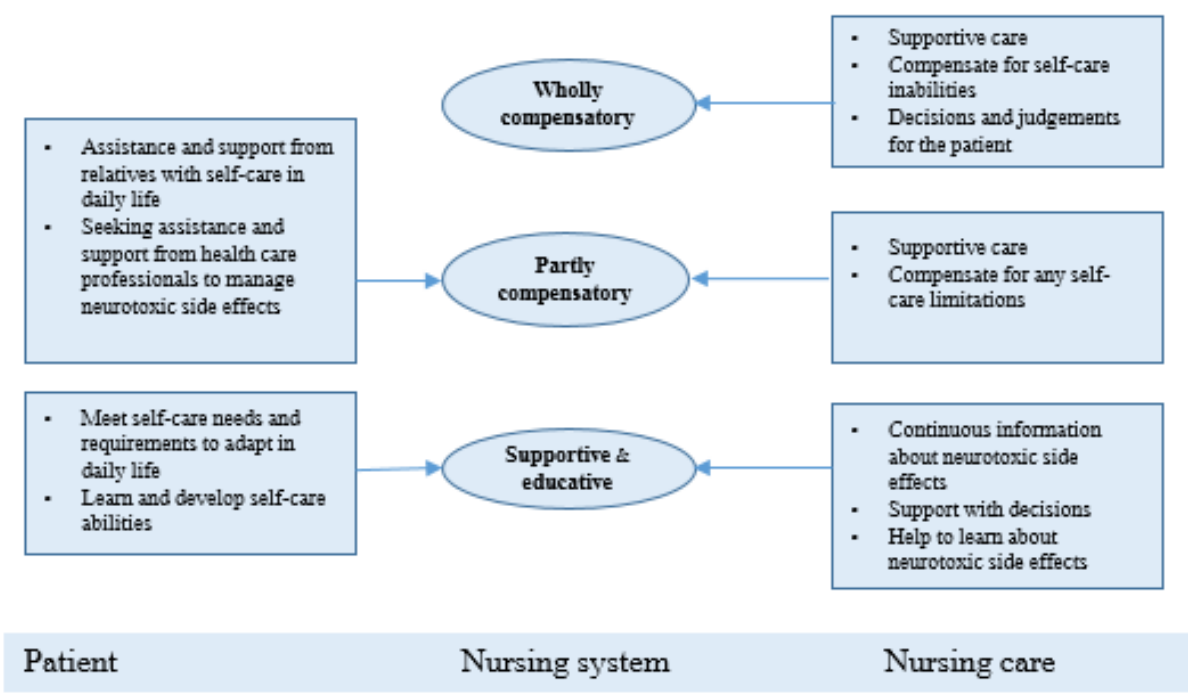

Figure 14. Patient with neurotoxic side effects, influenced by Orem's three nursing systems (Orem, 2001). 


\section{DISCUSSION}

\section{Discussion of results}

\section{Patient perspectives on neurotoxic side effects and impact on daily life}

The main focus in this thesis was to explore OXA-induced neurotoxic side effects in patients with CRC, and expand current knowledge about the influence of these effects on patients' daily lives. The thesis focuses on patients' perceptions and patient-reported outcomes of neurotoxic side effects.

The main results in the thesis show that patients reported and experienced considerable and multifaceted neurotoxic side effects, which had an important impact on their daily activities. Literature searches have so far shown that no previous studies in the CRC population have evaluated longitudinal real-time reported outcomes of neurotoxic side effects or their impact on daily activities (IV), which also probably makes the longitudinal interview study unique (II+III).

Trajectories on neurotoxicity showed that the side effects changed in character and location in the body over time. The most frequently assessed neurotoxic side effect during OXA treatment was cold-precipitated tingling in the upper extremities and mouth/throat (IV). At the beginning of the chemotherapy, the patients endured the neurotoxic side effects in the hope they would be cured, and their survival instinct was predominant (II). This is in agreement with previous research (Arndt et al. 2004, Chao et al. 2015, Chen et al. 2012, Drageset et al. 2016). Patients reported neurotoxic side effects one year after OXA treatment, mainly numbness and tingling in the legs, which affected their daily lives (IV). These results are in agreement with a study by Tofthagen (2010b) where numbness also was reported by the patients and interfered with the daily life (Tofthagen 2010b). Experiences of neurotoxicity depended on the patient's specific life situation. At first glance it seemed to be only physical and functional, but it also affected the patient's social life and roles (II+III). 
Patients experienced interference with activities in their daily lives. Family roles, hobbies, social activities and the ability to work were affected. They reprioritised activities, and used strategies to reduce the unpleasant feeling (II+III). A number of factors affect how patients perceive their health, e.g. motivation, coping strategies, access to healthcare systems, social support, individual values and health behaviours (Bowling 2002, GonzalezSaenz de Tejada et al. 2016). Psychological distress is reported as a negative factor in terms of how patients with CRC perceive their health (Aminisani et al. 2017, Mosher et al. 2017). The results also indicated that positive thinking about the future was an important issue in terms of managing the situation (III). This is in agreement with earlier studies on coping processes and cancer (Chen et al. 2012, Pama et al. 2017).

The patients with family and small children at home had problems coping with the situation (II+III). Their responsibility for their family led to considerable difficulties in daily life. Retired patients and those who lived alone seemed to adapt more easily because they were able to modify their situation and take more time, and these findings are similar to an earlier study (Tan et al. 2015). Common strategies for coping with neurotoxic side effects in daily life involved avoiding triggering difficult situations (II+III). Support from family members or life partners was common. Earlier studies have noted that partners and social support play an important role in restoring normality during the cancer trajectory, and our findings seem to be similar (Forsberg and Cedermark 1996, Madsen and Handberg 2018, Sjovall et al. 2011, Stuhlfauth et al. 2017).

The specific, individual challenges involved in the neurotoxic side effects forced the participating patients to adjust in order to reduce and minimise the impact on their daily lives. Patients customised these adjustments to the specific situation in each specific context (II+III). Previous studies have shown that difficulty in carrying out daily activities is a predictor of the use of healthcare services, specifically in elderly people (Dunlop et al. 1997, Mor et al. 1994). The patients in this thesis were forced to use family members as assistants to manage daily activities (II+III). Daily activity is necessary for everyday care and also important in terms of an independent life (Catt et al. 2017, Mlinac et al. 2016, Okamoto et al. 2012). Making adjustments to life, avoiding triggering difficult situations and trying to be independent of family could cause psychological distress, which is known to be a negative factor in terms of how CRC patients perceive their state of health (Aminisani et al. 2017, Mosher et al. 2016, Mosher et al. 2017). 
The patients included in this thesis reported neurotoxic side effects and an impact on their daily activities (IV). A contradictory result noted by Paul et al. (2016) is that a minority of patients with CRC experienced problems in their daily lives 2 years after diagnosis. The focus in this particular trial involved disease-related factors and data on treatment outcomes. Neurotoxicity was not studied. Previous qualitative research is sparse on patients' experiences of chemotherapy-induced neurotoxic side effects (Bennett et al. 2012, Tanay et al. 2017), further evidence that the findings in this thesis contribute new knowledge and insights (II+III).

There is a discrepancy between the perspectives of patients and healthcare professionals in terms of neurotoxicity as a side effect. The documentation in the patients' medical records indicated that patients felt well and felt really good except for the neurotoxicity (I), yet the patients in study II and III had reported neurotoxicity and changes to their habits and lifestyle and also reported that the neurotoxic side effects had affected them emotionally. Cold sensitivity was documented in 39 patients' (64\%) medical records (I), but the patient- reported outcomes show that the majority of the included patients in study IV reported cold sensitivity. Numbness was documented in one third of the patients (I), but in the patient-reported outcomes it was more common (IV). This discrepancy is in agreement with previous studies showing that patients reported significantly greater neurotoxic side effects than were reported by healthcare professionals, and retrospective assessments show a lower severity of neurotoxicity (Alberti et al. 2014, Cirillo et al. 2009, Coolbrandt et al. 2011).

This thesis involved a homogenous patient population with CRC which was undergoing adjuvant postoperative OXA treatment. The different prevalence of neurotoxicity in existing studies, could be explained by the use of mixed cohorts (curative and palliative intentions), cross-sectional designs and retrospective assessments (Briani et al. 2014, Hsieh et al. 2016, Kidwell et al. 2012, Park et al. 2012, Park et al. 2013). On the other hand, a study by Rohrl et al. (2016) investigated the symptom burden of CRC patients with curative versus palliative chemotherapy, and no significant differences were found between the two groups. Regardless of the treatment intention, patients experienced many symptoms (Rohrl et al. 2016). 
Results from the meta-analysis by Seretny et al. 2014, show that neurotoxicity falls over time, and approximately one-third of patients can expect to have chronic neurotoxicity six months or more post chemotherapy (Seretny et al. 2014). While the severity of neurotoxicity can improve after OXA discontinuation, a study show that more than half of the patients still had side effects at one year after discontinuation (Kim et al. 2018). The results from study IV seem to be similar, and patients still reported neurotoxicity after one year. This longitudinal progression of neurotoxicity (IV) also seem to differ from earlier results (Argyriou et al. 2014, Beijers et al. 2014). The results (IV) showed a higher prevalence of neurotoxicity, in contrast to earlier studies. Earlier studies results showed partly resolved neurotoxicity in about $40 \%$ of the patients and after 6-8 months completely resolved neurotoxicity one year after OXA treatment (Argyriou et al. 2014, Beijers et al. 2014).

The prevalence of side effects can be lower when data are collected from healthcare professionals and there is considerable inter-rater variability as is known from earlier research (Alberti et al. 2014, Brewer et al. 2016, Haryani et al. 2017, Le-Rademacher et al. 2017). From the one year time point (IV) only thirteen questionnaires were available (nine reported neurotoxicity), and it is not possible to draw significant conclusions.

There may be an advantage that the patients in the study (IV) were observed and doseadjusted to a greater extent. However, a study by Iveson et al (2018) showed that 3months of OXA-containing adjuvant chemotherapy was non-inferior to 6-months of the same treatment for patients with stage II (high-risk) and stage III CRC and was associated with reduced neurotoxicity and improved health-related quality of life. Shorter treatment duration leads to similar survival outcomes with better health-related quality of life (Iveson et al. 2018). 
According to the gender distribution during the study period, no statistically significant differences were noted between genders except for one time point (IV). The results show significant differences between baseline data, and nine of the patients had not returned to baseline after one year. Seven (78\%) of them were males (IV). Results from Bakogeorgos and Georgoulias 2017, show that sex (female), are a suspected risk factor (Bakogeorgos and Georgoulias 2017). It is not possible to draw significant conclusions, but one speculation could be that females in this cohort reported more side effects and were dose-adjusted more during treatment, and had fewer side effects post OXA treatment.

In their assessments, the patients reported scores of up to 148 on the Neurotoxicity Index (IV), and the Neurotoxicity Index has the potential to measure up to 870. An earlier study coined the metaphor "background noise" to illustrate the essence of neurotoxicity in everyday life. Neurotoxic side effects may be in the background and not always the central focus (Bakitas 2007). It could be speculated that a Neurotoxicity Index up to 148 indicates a background noise, as noted by Bakitas. Neurotoxic side effects could be overshadowed by other symptoms. We may rather discuss symptoms that we can put into action more easily. A previous cross-sectional study on patients with CRC reported numbness/tingling in the hands and feet as a highly prevalent symptom in relation to a range of other symptoms (Pettersson et al. 2014). However, even if the Neurotoxicity Index was relatively low, the qualitative interviews showed that neurotoxicity interfered with the patients' daily lives in different ways. 


\section{Neurotoxic side effects and self-care}

Three out of four studies (II-IV) in this thesis relied on patients' perceptions and patientreported outcomes of neurotoxic side effects. Early assessment and detection of neurotoxic side effects are important in terms of reducing and eliminating chronic neurotoxic side effects later on. Patient-reported outcomes in real time, as used in this thesis, could be a valuable form of individualised monitoring. Current research (Majithia et al. 2016) indicates a need for patient-oriented evidence of long-term follow-up of neurotoxic side effects in terms of underestimated side effects and assessment of how they function. According to the International Classification of Functioning, Disability and Health (ICF), the functioning or disability of an individual takes place in a specific context which involves dynamic interaction between environmental and individual factors (WHO 2001). Orem also states that self-care can be influenced by a range of factors (age, gender, environment, family, healthcare system). The patients are not isolated from their environments. Environments can affect lives in different directions, both positively and negatively (Orem 2001).

Actions for managing neurotoxicity are limited (Cheng et al. 2015, Kuriyama and Endo 2018, Majithia et al. 2016). Hyper acute neurotoxic side effects can be predictors of OXAinduced chronic neurotoxicity (Argyriou et al. 2008, Tanishima et al. 2017). Preventing chronic neurotoxicity depends on the dosage and the length of the OXA treatment, and therefore it is important to monitor the patients (Gebremedhn et al. 2018). It is also important that self-care activities are undertaken at the supportive and educational level (Orem 2001), making patients aware of the importance of reporting side effects. Patients with OXA-induced neurotoxic side effects may need support from family members, and health care in both the short and long term in order to maintain their health (II+III). There is considerable involvement in self-care interventions in patients with cancer, which stimulate understanding of the side effects of treatment. Being supported and educated (Orem 2001) may reduce distress and improve perceptions of confidence and control. Interventions which improve self-care and self-management in long-term care planning (Boger et al. 2015, Chodosh et al. 2005, Hammer et al. 2015, McCorkle et al. 2011) support patients in managing symptoms during the treatment phase (Henoch et al. 2018, Tofthagen et al. 2016, Tofthagen et al. 2013b). 
Self-care interventions can improve patients' involvement in their care (Jorgensen et al. 2015, Kidd et al. 2008, Kidd et al. 2009, Richard and Shea 2011), but more interventions that can be applied in the patients daily activities is needed (Boland et al. 2018). The patients in this thesis undertook self-care at the partly compensatory level (Orem 2001) by adjusting their daily lives, and by seeking support and assistance from family members and others (II+III).

A study by Smith et al. (2014) noted that many nurses were unaware of which drugs were neurotoxic. The survey indicated that nurses caring for patients with neurotoxicity wanted more education about available assessment options and treatments (Smith et al. 2014). There are a number of different tools, and consensus needs to be established on a gold standard for promoting optimal assessment strategies (McCrary et al. 2017). Identifying side effects early in treatment, including effective reporting and assessment, may be a way of addressing neurotoxicity (Moore et al. 2015). Assessment in real time could be a solution to identify patients in early stage of treatment.

Patient reported information and PROMs include patients' descriptions of their experiences and also quantified reports of perceived health (Foskett-Tharby et al. 2017). Screening for chemotherapy-induced neurotoxic side effects using ePRO-systems, and monitoring by mobile phones, could help identify high-risk patients in need of further evaluation and healthcare intervention. Screening for side effects using mobile-phone technology could also help identify patients requiring further evaluation and healthcare intervention (Dickinson et al. 2014, Drott et al. 2016, Halleberg Nyman et al. 2017, Langius-Eklof et al. 2017, Maher 2013).

Structured assessment can support healthcare professionals in being supportive and providing education. It can also make it easier to follow the progression of neurotoxicity and give continuous information, as well as providing supportive care and intervention both during and after OXA treatment. It can aid the dialogue on treatment decisions, support patients in adapting their everyday lives and improve knowledge about neurotoxic side effects both in the short and longer perspective. The nurse's responsibility is to support patients with cancer in promoting self-care to maintain health (Orem 2001). 
Wickham (2007) suggested that nurses need more information about how to plan and implement skilled care of patients at risk of perceived or chemotherapy-induced neurotoxicity (Wickham 2007). Nurses play an important role in patient-reported outcomes and in assessing neurotoxic side effects, and effective identified symptom follow-up can reduce prevalence, severity and distress (Fox et al. 2017, Kolb et al. 2018).

From a patient perspective, the quality of supportive care can be considered a result of the extent to which needs and side effects are addressed (Tantoy et al. 2016). Some patients had difficulty addressing their side effects and unmet needs, so that their psychosocial health may have been affected (Ross et al. 2002) and they may have had a poorer quality of life (Santin et al. 2015). At the end of the treatment, patients experienced difficulty talking about their side effects, and did not know where to contact the healthcare provider (II+III). A study by Muntlin Athlin et al (2018) show that patients with cancer want to take part in the decisions, but they need to strive for support from health professionals to regain control. Nurses in cancer care need to support patients to provide personcentred care (Muntlin Athlin et al. 2018). The patients included in this thesis reported neurotoxic side effects and an impact on their daily activities (IV) and managed their side effects in different ways, making use of self-care strategies to restore normality (II+III). Patients with OXA-induced neurotoxic side effects may need support both in the short and long term in order to maintain their health (II+III).

Structured, real-time assessment of neurotoxicity can encourage nurses to be supportive and provide person-centred care. It might be important to follow the progression of side effects and fulfilled person-centred interventions and supportive care both during and after OXA treatment. It can aid the dialogue on treatment decisions, support patients in adapting their everyday lives and improve knowledge about neurotoxic side effects both in the short and longer perspective. And according to the National Healthcare program for cancer rehabilitation, supportive care over time is important. The goal is that all patients with cancer, along with their relatives, should be given the opportunity for rehabilitation based on their unique situation, needs and individual resources, which can change during the process. Cancer rehabilitation involves a holistic view in terms of seeing the whole person in a specific context (National Healthcare Program Cancer Rehabilitation 2014). 
Studies have shown that the incidence of OXA-induced neurotoxic side effects impact patients' health-related quality of life (Jones et al. 2015, Miaskowski et al. 2017, Stefansson et al. 2016, Tofthagen et al. 2013a). Physical exercise is recommended in the National Healthcare program for cancer rehabilitation as a primary goal, to increase well-being during and after cancer treatment. For patients with neurotoxic side effects, exercise may be more difficult or impossible due to difficulty controlling the body and balance difficulties. This can result in risk of injuries, and training may need to be carried out with instructions and support given. Positive effects of an exercise program on chemotherapy induced neurotoxicity have been reported. Patients need support to improve safety and compliance (Piringer et al. 2018, Zimmer et al. 2018). Findings from the interview study (III) showed that the patients had doubts about their ability to manage the side effects and about their future. The patients experienced a strange feeling in their bodies and reprioritised or avoided activities as a result of the neurotoxic side effects. They had a desire to start walking and exercising again, but they haven't been able to. They expressed imbalance and that they often felt unsafe (III).

The diagnosis and treatment of CRC have an important impact on patients' health as the results shows (II-VI). Patients have to cope with a number of physical, psychological and social consequences (Andrykowski et al. 2008, Harrison et al. 2011, Jorgensen et al. 2015, Ward Sullivan et al. 2018). Supportive care should be supplied both during and after treatment, and should aim to achieve the best possible health in terms of the individual patient's daily life. Supportive care aims to minimise symptoms and side effects to improve health (Weis and Geiser, 2014, Hellbom et al. 2011). A study by Drury et al. (2017) described support and communication as key issues in survivorship care of patients with CRC. If support and communication are inadequately addressed it may affect the patients' well-being and health (Drury et al. 2017). Patients managed their side effects in different ways, making use of self-care strategies to restore normality, and reprioritising activities to reduce the feeling of discomfort (II+III). Patients who had symptoms after discontinuation experienced feelings of sadness, as they had thought symptoms would disappear when chemotherapy ended. At the end of the treatment, patients experienced difficulty talking about their side effects, and did not know where to contact the healthcare provider (II+III). 
Patients often strive for normality, but it is not a possible and a realistic goal for all patients. A systematic review and meta-synthesis show that unexpected symptoms can have a negative effect on patients who need to be better prepared for long-term symptoms. Clear communication from professionals may help patients to cope more efficiently (Bennion and Molassiotis 2013). Effective strategies for giving patients understandable information about their care is important in cancer care, and nurses need to identify patients' health literacy level (Wittenberg et al. 2018). This is consistent with core competencies for nursing, involving the importance of person-centred care towards safe care and involvement, clear communication, as well as clear and careful documentation (Swedish Society of Nursing). Patient-centred care is important and essential component of quality in cancer care. Patient-centred care is best assessed by patients' self-reports and experiences (Harrison et al. 2009, Zucca et al. 2014). Tailored supportive care is needed throughout the cancer trajectory and must be based on these patients' self-care abilities.

The main results of this thesis show that patients reported and experienced considerable multifaceted neurotoxic side effects, and that these impacted on their everyday activities. Patients reprioritised activities, and used self-care strategies to mitigate unpleasant feelings to restore normality (II-III). Maybe it is still as a professor complained at one point, "to listen to patient's experience is 1000 times better than not even dare to ask". That patients learn to live with the neurotoxic side effects does not mean that we as professionals, can ignore these problems. Patients who had symptoms when the therapy ended experienced feelings of sadness and discomfort, as they had thought that symptoms would disappear when the OXA-chemotherapy ended. Neurotoxic side effects may extend the periods of sickness, affect the working ability and prolong suffering for patients. This places new demands on the rehabilitation for cancer care. 


\section{Methodological considerations}

This thesis is based on four studies using both qualitative and quantitative methods. Different research methods were used to collect and interpret data on the neurotoxicity phenomenon in order to strengthen the results (Patton 2015, Polit and Beck 2016). The longitudinal methods provide an important basis for the thesis in terms of exploring OXAinduced neurotoxic side effects in patients with $\mathrm{CRC}$, and expand current knowledge about its influence on patients' daily lives. A number of methodological strengths and weaknesses need to be taken into consideration.

\section{Study I}

The research for this study began with an investigation of medical records. Inclusion criteria meant that the pilot study used a relatively small number of patients' medical records, but the findings provide valuable knowledge of existing documentation over a limited period. This retrospective study, which explored medical records documented during 2009-2010, gave a variety of information in terms of the data corpus. Patients who had been admitted at the beginning of 2009 had more extensive post-treatment information in their medical records than patients treated at the end of 2010. A predetermined protocol was developed to investigate the documentation of patients' neurotoxic side effects, influenced by the OANQ questionnaire. The protocol was tested on five medical records, and identified neurotoxic side effects sufficiently. Using a protocol, and testing it before it is used, contributes to the strength and feasibility of a study (Polit and Beck, 2016).

Another aspect to consider is that the documentation in the medical records is a secondary source and does not involve patients' own words/experiences; it represents the perceptions of nurses and physicians in terms of oxaliplatin-induced neurotoxicity. How health professionals manage the documentation and what they write in the record will affect the outcome of this study (Polit and Beck, 2016). 
The summative content analysis used in the thesis requires evidence of validity, which affects credibility. Internal consistency (credibility) shows that the evidence in the text is consistent with the description and interpretation. Subjecting the analysis and findings to peer-debriefing made them more trustworthy (Lincoln and Guba 1985, Polit and Beck 2016).

\section{Studies II-III}

These interview studies have a prospective design (interviewed when side effects occur) and have advantages compared to retrospective studies, which could be influenced by informants' failure to recall situations (Farrall 2006, Murray et al. 2009, Holland et al. 2004). In these studies, a purposeful and consecutive sampling strategy was used. The first ten patients who assessed neurotoxic side effects were asked to participate. The sample size of ten was chosen because of the amount of data these longitudinal interviews were expected to generate. More females were included in the study at baseline, a consequence of the purposeful and consecutive sampling strategy. However, the gender distribution at baseline could have affected the findings. These gender differences in terms of the occurrence of side effects were not acknowledged, and there was no mention of them in the literature. The participants were varied in terms of age and marital status.

The interview guide was tested on the first patient, to confirm that it was appropriate, and the data from this pilot interview were included in the analysis. No patients declined to be interviewed, even though the interviews continued for 12 months after treatment. This probably indicated a need to share their experiences of neurotoxic side effects and the impact on their daily lives. The interviews were rich and informative, presenting detailed information about neurotoxicity and its impact on daily life. One of the participating patients had a sensory impairment, so the interviews were very short but informative. The quality of the interviews strengthens their credibility (Lincoln and Guba 1985). 
In longitudinal study III, repeated interviews were conducted in order to improve understanding of the neurotoxicity phenomenon over time (Farrall 2006, Murray et al. 2009, Holland et al. 2004). This study overcame any failure to recall situations by providing opportunities to talk about neurotoxic side effects when they actually occurred and while they were affecting daily activities. The patients had the chance to talk about the same phenomenon repeatedly, and if experiences had changed as a result of contextual processes, these changes could be verbalised. As the interviews were repeated, the researcher developed a relationship with the patients over time, which could have influenced data collection and interpretation. This influence could be both positive and negative (Farrall 2006, Murray et al. 2009, Holland et al. 2004). The interviews were analysed thematically. Alternative analysis methods like phenomenology were discussed at the start of the project, but thematic analysis was chosen. Thematic analysis can be adapted to existing data and provides both a description and interpretation. Thematic analysis is a flexible qualitative method, and can be applied across a range of epistemological approaches.

Internal consistency (credibility) shows that the evidence in the text is consistent with the description and interpretation. In order to improve the validity of the findings, the analysis was subjected to peer-debriefing, and was continuously scrutinised by a co-researcher. Any discrepancies were resolved through discussion (Lincoln and Guba 1985, Braun and Clarke 2006). Braun and Clarke (2006) present a 15-point checklist of criteria for good thematic analysis, and these criteria were followed in an attempt to improve quality and trustworthiness. Nowell et al.'s (2017) six phases establishing trustworthiness during each phase of thematic analysis over time were also followed. More than one researcher was involved in the analysis during the initial stage and throughout the process to strengthen the results (Nowell et al. 2017). 


\section{Study IV}

For this prospective, quantitative, longitudinal, multicentre study, patients were recruited from four hospitals (two university hospitals and two regional ones). Recruiting patients was a challenge. During the recruitment period, parallel studies were recruiting from the same patient population, and there were also study-stop periods due to staff shortages. The sample size was therefore restricted. These patients undergo difficult treatment, and experience psychological stress, so taking part in a longitudinal study like this during and after treatment can be overwhelming. Seen from this perspective, the sample size is acceptable. Larger numbers of patients and longer follow-up periods will provide opportunities to counterbalance atypical values, but large samples cannot ensure accuracy. A large sample is nevertheless preferable to a small one (Polit and Beck, 2016).

The small sample size in the study may limit the generalizability of the study, but this longitudinal study defines the trajectory of neurotoxicity over time. In terms of selection bias, no statistical differences were found in age or gender between the participating patients and the patients who declined to participate.

To reduce selection bias and sampling error, patients were included on the basis of the inclusion and exclusion criteria. It should be taken into consideration that there may be a risk that patients who were positive about the mobile phone system, participated to a greater extent. More males were included in the study (61\%), and few patients were included with an educational level lower than high school (11\%).

To prevent attrition bias and ensure low dropout rates, a reminder was send out to the patients' mobile phones at $4 \mathrm{pm}$. The patients had only one day to answer the questions, and only one reminder was sent out. There might have been a higher response rate in the follow-up post treatment if it was possible to have more than a day to answer the questions. One possible explanation for the high response rate during ongoing treatment is the Hawthorne effect, in the sense that patients answered the questionnaire more intensely and received more feedback from the healthcare professionals (McCambridge et al. 2014). There may also be an advantage that the patients in the study were observed and dose-adjusted to a greater extent, which resulted in fewer experienced and reported side effects. 
The response rate was relatively high (76\%) during ongoing treatment, but in the followup period the response rate decreased. Patients who did not answer the questionnaire after one year post treatment were contacted by telephone, and the majority transpired that they had not responded to the questionnaire because they had not experienced neurotoxicity. On the other hand, the response rate was $70 \%$ in total over the period, and the mobile phone-based system ensured that no internal data were missing. The lower response rate after treatment may have led to under or over-estimation of outcomes as a result of participants withdrawing from the study, dying or experiencing a recurrence of the disease (McGrath-Lone et al. 2016, Polit and Beck 2016). It is a major limitation that only thirteen of the patients responded to the questionnaire after one year. But according to the ethical guidelines, the patients were informed that they could decline to participate or could withdraw from the study at any time without explanation or consequences for their future care.

Confounding factors, such as alcohol consumption, smoking habits, vitamin $\mathrm{B}_{12}$ deficiency or other diseases assessed at baseline, may have changed over the follow-up period, which could have affected longitudinal outcomes of neurotoxicity (reduced sensitivity). Another confounder we did not study is the patient's body weight. Obesity and body mass index (BMI) over 30 may increase the risk of neurotoxic side effects (CoxMartin et al. 2017).

Study IV relied on patient-reported outcome data and did not include any objective assessments of neurological examinations or measurements of nerve function. This could be seen as a limitation, but this thesis focuses on patients' perceptions and their reported outcomes of neurotoxic side effects. Another limitation is that only one questionnaire was used in the assessment, but the questionnaire contained a great deal of specific items. The patients also answered two more questionnaires during the study period (Health related Quality of life $=$ Fact-G and Sense of coherence $=$ SOC $)($ Cella and Tulsky 1993, Cella et al. 1993, Eriksson and Lindstrom 2005), but these results are not presented in this thesis. 
There are a number of established scales for assessing chemotherapy-induced neurotoxic side effects, and the OANQ by Leonard was used because it contained OXA-specific items. The OANQ was therefore appropriate, and was chosen because it had been developed to assess OXA-induced neurotoxic side effects both during and after treatment, and was sensitive to variation in the side effects over time. The validity and reliability of the Swedish version of the OANQ were tested, and the questionnaire indicated strong content validity. Test-retest reliability of the Swedish version of the OANQ, administered through a patient-reported mobile-phone system, indicated that the OANQ was stable (Gustafsson et al. 2016). Validity testing of the paper version of the OANQ had been previously evaluated in a comparative analysis with FACT/GOG Ntx, and both instruments assessed similar constructs (Driessen et al. 2012). More psychometric testing would be desirable in larger study populations.

Real-time identification of side effects may seem a complex form of intervention for encouraging early detection of chemotherapy-induced neurotoxic side effects, as it includes effective reporting and assessment (Moore et al. 2015). The contextual factors were different in the hospitals and may have affected the outcomes (e.g. how each physician decided to reduce the dose). The cut-off limit for dose reduction or stopping treatment was decided by the physician responsible for the treatment. The graded information from the patients on neurotoxic side effects and their impact on daily activities was visualised and made available in graph form (on the mobile phone-based system). 


\section{Clinical implications}

Early detection of neurotoxic side effects is required in order to identify patients and to be able to prevent chronic neurotoxicity. Further evaluation and healthcare intervention will be important in terms of meeting patients' needs, strengthening the patients' self-care abilities and improve health. Individualised care, based on repeated real-time assessments during and after chemotherapy, could be a way to improve communication. These assessments help visualise patient-reported side effects and symptoms. Making use of ePRO systems in the cancer care setting, such as mobile-phone technology, could improve communication between patients and healthcare professionals. Incorporating structured assessment into medical records could support healthcare professionals in documenting and following the progression of neurotoxic side effects and ultimately taking action.

\section{Future research}

OXA-induced neurotoxic side effects remain an important and prominent burden for CRC patients in their daily lives. This thesis has generated new research questions, and the scientific focus in future should be to explore further the correlations between health related quality of life, sense of coherence and these patient-reported outcomes. As patients had considerable support from their relatives in coping with their daily lives, it would be of interest to study relatives' perspectives. Other future research could involve the study of different information and communication strategies for healthcare professionals prior to, during and post OXA treatment. Interventions should focus on a patient's experiences of neurotoxicity and on communications for encouraging its early detection. Evaluating the use of mobile phone-based systems in everyday care would also be valuable. 


\section{CONCLUSIONS}

The results from the medical record study showed that a free description of the degree of neurotoxic side effects was given in the patients' medical records, and no formal assessment had been made. Side effects were reported in the documentation in terms of their relationship to well-being, and were interpreted in terms of minimising neurotoxic side effects.

The results and findings of this thesis show that the patients in this prospective study, which covered the entire treatment period, had high prevalence of neurotoxic side effects during OXA treatment. The results show that the neurotoxic side effects affect the patient's daily activities in different ways, including physical, psychological, emotional and social e.g. family roles, hobbies, social activities and the ability to work. Patients adapt to side effects, and develop strategies for minimising them in their daily lives, for example by avoiding activities or changing past habits. Patients coped with and managed their side effects in different ways, making use of self-care strategies to restore normality, and reprioritising activities to reduce the feeling of discomfort. Patients who had symptoms after discontinuation experienced feelings of sadness and discomfort, as they had thought symptoms would disappear when chemotherapy ended.

At the end of the treatment, patients experienced difficulty talking about their side effects, and did not know where to contact the healthcare provider. One year post treatment, the patients had learned to live with the side effects, and they had become part of their daily life. The neurotoxic side effects changed character and localisation over time. After one year, patients were largely experiencing numbness and tingling in the legs, which affected their daily lives. These results should be taken into account when patients are informed about treatment, and in the dialogue about the benefits and risks associated with chemotherapy. 


\section{SVENSK SAMMANFATTNING}

Forskningsprojektet är inriktat på neurotoxiska biverkningar vid cytostatikabehandling för att motverka återinsjuknande, hos patienter med tjock- och ändtarmscancer med fokus på patientperspektivet.

Samtliga patienter har i projektet behandlats med läkemedlet oxaliplatin efter kirurgi. I projektet har patienter graderat neurotoxiska biverkningar samt påverkan på dagliga aktiviteter under pågående och efter avslutad cytostatika behandling. Ett mobiltelefon system har använts för att erhålla svar i realtid. Upprepade patientintervjuer har genomförts avseende neurotoxiska biverkningar och påverkan på det dagliga livet.

Alla 46 patienter hade neurotoxiska biverkningar under pågående cytostatika behandling. Det var 9 patienter som rapporterade neurotoxiska biverkningar ett år efter avslutad behandling. Patienterna hade biverkningar som domningar och stickningar i benen, som påverkade deras dagliga aktiviteter. Två intervjustudier med 35 upprepade intervjuer med 10 patienter, visade att patienternas dagliga och sociala liv var påverkat. De anpassade sig och hade strategier för att minimera biverkningarna i det dagliga livet, exempelvis genom att undvika aktiviteter eller ändra tidigare vanor. Ett år efter avslutad behandling hade patienterna lärt sig leva med biverkningarna.

Patienterna kände sig ledsna och besvikna, eftersom de haft tankar om att biverkningarna skulle försvinna efter avslutad cytostatikabehandling. De hade föreställningar om att livet skulle bli som vanligt igen. När behandlingen var avslutad upplevde patienterna svårigheter att veta vem i vården de skulle kontakta för att berätta om biverkningarna. Eftersom en stor andel patienter med oxaliplatinbehandling är i risk att utveckla långvariga och kroniska neurotoxiska symtom, är det av betydelse att sjukvården identifierar dessa besvär både under och efter avslutad cytostatika behandling.

I projektet har också en granskning av 61 journaler genomförts och resultatet visade ett behov av förbättrade elektroniska journalsystem för möjlighet till mer strukturerade mätningar och dokumentation av symtom för att följa dess progress över tid. 
Resultaten från studierna poängterar vikten av individanpassad vård för patienter med tjock- och ändtarmscancer, för att minska eller undvika kroniska neurotoxiska biverkningar. Resultaten kan användas när patienter informeras om fördelar och risker med cytostatikabehandling.

Att patienter lär sig leva med biverkningarna innebär inte att man kan förbise dessa problem. De kan förlänga sjukperioder, påverka arbetsförmåga och innebära ett förlängt lidande för patienterna. Detta ställer krav på rehabiliteringen för cancersjukvården. 


\section{ACKNOWLEDGEMENTS}

My deepest thanks to the patients in the studies for giving of your time and sharing of your experiences.

I would also like to express my gratitude to all of you who have contributed in various ways to this thesis. Special thanks to:

Professor Carina Berterö, my main supervisor. Thank you for invited me to the project and for introducing me to the world of nursing research. You have generously shared your expertise and knowledge. Thanks for you believed in me and inspired me to continue working with research.

Associate professor Hans Starkhammar, my co-supervisor. It has been an honor to work with you. You have generously shared your great knowledge, always treated me with respect and always contributed to a positive learning environment. Thanks for all the laughs and humorous approach, when I really needed it.

Professor Karin Kjellgren, my co-supervisor. You have always contributed with great scientific knowledge and valuable aspects. Thanks for all the cooperation and for all the friendly support.

Professor Sussanne Börjeson, my co-supervisor. Thanks for the introduction to the project and for collaboration.

Victoria Fomichov, the best Statistician and co-author, not just extremely competent but also friendly, funny and a pleasure to work with. Thank you for all your tremendous patience with all my questions.

Maria Wilhelmsson, Elin Gustafsson and Emma Litström, my co-authors. Thanks for the friendship and good cooperation both within the academic and clinical work. 
The management and staff at the oncology clinics, who always been so friendly and shown interest in this project and gave me access to the patients. A special thanks to Maria Albertsson, Charlotte Bratthäll, Anders Johnsson, Jakob Eberhard, Helga Hagman, Ursula Scheibling and also thanks to Anna-Karin Ax, Britt-Marie Persfalk, Helén Jung, Britt Strand, Katarina Sjövall, Anki Hultman, Linda Jakobsson and Linda Dahlquist.

A special thanks to Gun Skire and Lars-Erik Fredhammar. Thanks for all the good cooperation and for all support related to the mobile phone based system, both in the start as well during the ongoing project.

Thanks also to Henrik Green, for all wise perspectives and your kindness. Looking forward to learning more about pharmacogenetics.

The management and staff at the surgery clinic in Linköping. My deepest thanks to Conny Wallon, Per Sandström, Oliver Gimm, Bärbel Jung, Olof Hallböök, Ewa Öhrling, Kristin Ek and Britt-Marie Johansson. Thanks for all the support that you always believed in me and for all the encouraging words during this period.

A special thanks to Anna Lindhoff Larsson, Anette Jönsson, Linda Bergdahl, Jessica Carlsson, Sara Hossainy, Anton Larnebratt, Pernilla Svanäng, Marie Stenlund, Karolina Härle and Lillemor Sjöberg. You have always contributed with so much positive energy, it has been very valuable.

The management team, senior researchers and doctoral students at the Division of Nursing Science. Thanks for interesting discussions on seminars. A special thanks to Elisabeth Welin, Inger Hallberg, Susanna Ågren, Helen Marklund and also thanks to Christina Andreae, Katarina Pihl Lesnovska, Nana Waldréus, Ulrica Lovén Wickman, Maria Liljeroos and Lisa Hjelmfors.

My deepest thanks to the excellent colleagues, researchers and great friends; Rikard Wärdig, Carina Wennerholm, Carina Hjelm, Lena Näsström (former colleague) and Sara Bergstrand. It has meant a lot to have you near me, during this period. I have appreciated all laugh together enormously. 
A special thanks also to Carina Hellqvist, a good friend, listener and excellent doctoral student. And also thanks to my former colleague and good friend Jenni Fock, it is always a pleasure to meet you, wise woman.

A special thanks to all colleagues in Division of Nursing, especially Karin Steel, Charlotte Waldeck, Ing-Marie Byström and Marie Danielsson. Thanks also to Mahin Kiwi for all encouraging words, and a lot of nice times together in the Office late evenings and weekends.

Thanks to lovely friends; Malin, Karolin, Lina, Jessica, Lisa, Mia and Elisabeth. Looking forward to more dinner parties, training, golf, and other fun things together in the future.

Thanks to Roger and Kristina that taken care of the kids when I've had to do interviews far away on short notice. And also for all help with the hockey trainings, it has been great in times of much work.

A warm and sincere thanks to the world's best Grandma, Birgitta. Thanks for all love and support.

Big warm thanks to my brother Martin. Thank you for drawing the picture on the front page of the thesis. Thanks also to Isabelle, Douglas, Ellie and Minna.

My warmest thanks to my wonderful parents Dennis and Helen. You're just the best, and give everything a daughter can wish for. You have always believed in me, thanks for all love and support.

Thank you to my wonderful family, Jens, Max and My.

You always makes me in a positive mood. I am so grateful to have all of you in my life. Jens, thanks for all your love, patience and never-ending support.

Thanks to all of you!<smiles>CCC[14CH2]C1C=C1</smiles> 
The studies were financially supported by:

-Swedish Cancer Society

-Medical Research Council of Southeast Sweden (FORSS)

-Division of Nursing Science, Linköping University

-LFOU Grants, County Council of Östergötland

-Department of Surgery, Linköping University Hospital

-Lions, Linköping University

-Swedish Society of Nursing 


\section{REFERENCES}

Acquadro, C. (2009) Linguistic validation manual for patient-reported outcomes (PRO) instruments, Mapi Research Institute, Lyon.

Acquadro, C. (2012) Linguistic validation manual for health outcome assessments, MAPI Institute, France.

Ajani, J.A., Welch, S.R., Raber, M.N., Fields, W.S. \& Krakoff, I.H. (1990)

Comprehensive criteria for assessing therapy-induced toxicity. Cancer Invest, 8(2), 147-59.

Albers, J.W., Chaudhry, V., Cavaletti, G. \& Donehower, R.C. (2014) Interventions for preventing neuropathy caused by cisplatin and related compounds. Cochrane Database Syst Rev, (3), CD005228.

Alberti, P., Rossi, E., Cornblath, D.R., Merkies, I.S., Postma, T.J., Frigeni, B., Bruna, J., Velasco, R., Argyriou, A.A., Kalofonos, H.P., Psimaras, D., Ricard, D., Pace, A., Galie, E., Briani, C., Dalla Torre, C., Faber, C.G., Lalisang, R.I., Boogerd, W., Brandsma, D., Koeppen, S., Hense, J., Storey, D., Kerrigan, S., Schenone, A., Fabbri, S., Valsecchi, M.G., Cavaletti, G. \& Group, C.I.-P. (2014) Physicianassessed and patient-reported outcome measures in chemotherapy-induced sensory peripheral neurotoxicity: two sides of the same coin. Ann Oncol, 25(1), 257-64.

Aminisani, N., Nikbakht, H., Asghari Jafarabadi, M. \& Shamshirgaran, S.M. (2017) Depression, anxiety, and health related quality of life among colorectal cancer survivors. J Gastrointest Oncol, 8(1), 81-88.

Andre, T., Boni, C., Mounedji-Boudiaf, L., Navarro, M., Tabernero, J., Hickish, T., Topham, C., Zaninelli, M., Clingan, P., Bridgewater, J., Tabah-Fisch, I., de Gramont, A. \& Multicenter International Study of Oxaliplatin/5Fluorouracil/Leucovorin in the Adjuvant Treatment of Colon Cancer, I. (2004) Oxaliplatin, fluorouracil, and leucovorin as adjuvant treatment for colon cancer. N Engl J Med, 350(23), 2343-51. 
Andre, T., Boni, C., Navarro, M., Tabernero, J., Hickish, T., Topham, C., Bonetti, A., Clingan, P., Bridgewater, J., Rivera, F. \& de Gramont, A. (2009) Improved overall survival with oxaliplatin, fluorouracil, and leucovorin as adjuvant treatment in stage II or III colon cancer in the MOSAIC trial. J Clin Oncol, 27(19), 3109-16.

Andre, T., Iveson, T., Labianca, R., Meyerhardt, J.A., Souglakos, I., Yoshino, T., Paul, J., Sobrero, A., Taieb, J., Shields, A.F., Ohtsu, A., Grothey, A., Sargent, D.J. \& for the, I.S.C. (2013) The IDEA (International Duration Evaluation of Adjuvant Chemotherapy) Collaboration: Prospective Combined Analysis of Phase III Trials Investigating Duration of Adjuvant Therapy with the FOLFOX (FOLFOX4 or Modified FOLFOX6) or XELOX (3 versus 6 months) Regimen for Patients with Stage III Colon Cancer: Trial Design and Current Status. Curr Colorectal Cancer Rep, 9, 261-269.

Andrykowski, M.A., Lykins, E. \& Floyd, A. (2008) Psychological health in cancer survivors. Semin Oncol Nurs, 24(3), 193-201.

Argyriou, A.A., Kyritsis, A.P., Makatsoris, T. \& Kalofonos, H.P. (2014) Chemotherapy-induced peripheral neuropathy in adults: a comprehensive update of the literature. Cancer Manag Res, 6, 135-47.

Argyriou, A.A., Polychronopoulos, P., Iconomou, G., Chroni, E. \& Kalofonos, H.P. (2008) A review on oxaliplatin-induced peripheral nerve damage. Cancer Treat Rev, 34(4), 368-77.

Argyriou, A.A., Zolota, V., Kyriakopoulou, O. \& Kalofonos, H.P. (2010) Toxic peripheral neuropathy associated with commonly used chemotherapeutic agents. J BUON, 15(3), 435-46.

Arndt, V., Merx, H., Stegmaier, C., Ziegler, H. \& Brenner, H. (2004) Quality of life in patients with colorectal cancer 1 year after diagnosis compared with the general population: a population-based study. J Clin Oncol, 22(23), 4829-36.

Attal, N., Bouhassira, D., Gautron, M., Vaillant, J.N., Mitry, E., Lepere, C., Rougier, P. \& Guirimand, F. (2009) Thermal hyperalgesia as a marker of oxaliplatin neurotoxicity: a prospective quantified sensory assessment study. Pain, 144(3), 245-52.

Avan, A., Postma, T.J., Ceresa, C., Avan, A., Cavaletti, G., Giovannetti, E. \& Peters, G.J. (2015) Platinum-induced neurotoxicity and preventive strategies: past, present, and future. Oncologist, 20(4), 411-32. 
Baek, K.K., Lee, J., Park, S.H., Park, J.O., Park, Y.S., Lim, H.Y., Kang, W.K., Cho, Y.B., Yun, S.H., Kim, H.C., Lee, W.Y. \& Chun, H.K. (2010) Oxaliplatininduced chronic peripheral neurotoxicity: a prospective analysis in patients with colorectal cancer. Cancer Res Treat, 42(4), 185-90.

Baier, P., Ihorst, G., Wolff-Vorbeck, G., Hull, M., Hopt, U. \& Deschler, B. (2016) Independence and health related quality of life in 200 onco-geriatric surgical patients within 6 months of follow-up: Who is at risk to lose? Eur J Surg Oncol, 42(12), 1890-1897.

Bakitas, M.A. (2007) Background noise: the experience of chemotherapy-induced peripheral neuropathy. Nurs Res, 56(5), 323-31.

Bakogeorgos, M. \& Georgoulias, V. (2017) Risk-reduction and treatment of chemotherapy-induced peripheral neuropathy. Expert Rev Anticancer Ther, 17(11), 1045-1060.

Beijers, A., Mols, F., Dercksen, W., Driessen, C. \& Vreugdenhil, G. (2014a) Chemotherapy-induced peripheral neuropathy and impact on quality of life 6 months after treatment with chemotherapy. J Community Support Oncol, 12(11), 401-6.

Beijers, A.J., Mols, F. \& Vreugdenhil, G. (2014b) A systematic review on chronic oxaliplatin-induced peripheral neuropathy and the relation with oxaliplatin administration. Support Care Cancer, 22(7), 1999-2007.

Beijers, A.J., Mols, F., Tjan-Heijnen, V.C., Faber, C.G., van de Poll-Franse, L.V. \& Vreugdenhil, G. (2015) Peripheral neuropathy in colorectal cancer survivors: the influence of oxaliplatin administration. Results from the population-based PROFILES registry. Acta Oncol, 54(4), 463-9.

Bennett, B.K., Park, S.B., Lin, C.S., Friedlander, M.L., Kiernan, M.C. \& Goldstein, D. (2012) Impact of oxaliplatin-induced neuropathy: a patient perspective. Support Care Cancer, 20(11), 2959-67.

Bennion, A.E., Molassiotis, A. (2013) Qualitative research into the symptom experiences of adult cancer patients after treatments: a systematic review and meta-synthesis. Support Care Cancer, 21(1), 9-25.

Blake, H. (2008) Innovation in practice: mobile phone technology in patient care. $\mathrm{Br} J$ Community Nurs, 13(4), 160, 162-5. 
Boger, E., Ellis, J., Latter, S., Foster, C., Kennedy, A., Jones, F., Fenerty, V., Kellar, I. \& Demain, S. (2015) Self-Management and Self-Management Support Outcomes: A Systematic Review and Mixed Research Synthesis of Stakeholder Views. PLoS One, 10(7), e0130990.

Boland, L., Bennett, K. \& Connolly, D. (2018) Self-management interventions for cancer survivors: a systematic review. Support Care Cancer, 26(5), 1585-1595.

Borjeson, S., Starkhammar, H., Unosson, M. \& Bertero, C. (2012) Common Symptoms and Distress Experienced Among Patients with Colorectal Cancer: A Qualitative part of Mixed Method Design. Open Nurs J, 6, 100-7.

Bowling, A. (2002) Research methods in health: investigating health and health services, Open University Press, Buckingham ; Philadelphia.

Braun, V. \& Clarke, V. (2006) Using thematic analysis in psychology. Qual Res Psychol, 3(2), 77-101.

Braun, V. \& Clarke, V. (2013) Successful qualitative research : a practical guide for beginners, SAGE, Los Angeles.

Breugom, A.J., Swets, M., Bosset, J.F., Collette, L., Sainato, A., Cionini, L., GlynneJones, R., Counsell, N., Bastiaannet, E., van den Broek, C.B., Liefers, G.J., Putter, H. \& van de Velde, C.J. (2015) Adjuvant chemotherapy after preoperative (chemo)radiotherapy and surgery for patients with rectal cancer: a systematic review and meta-analysis of individual patient data. Lancet Oncol, 16(2), 200-7.

Brewer, J.R., Morrison, G., Dolan, M.E. \& Fleming, G.F. (2016) Chemotherapyinduced peripheral neuropathy: Current status and progress. Gynecol Oncol, 140(1), 176-83.

Briani, C., Argyriou, A.A., Izquierdo, C., Velasco, R., Campagnolo, M., Alberti, P., Frigeni, B., Cacciavillani, M., Bergamo, F., Cortinovis, D., Cazzaniga, M., Bruna, J., Cavaletti, G. \& Kalofonos, H.P. (2014) Long-term course of oxaliplatin-induced polyneuropathy: a prospective 2-year follow-up study. $J$ Peripher Nerv Syst, 19(4), 299-306.

Brislin, R.W. (1970) Back-translation for cross-cultural research. J Cross Cult Psychol, 1(3), 185-216.

Brown, H. \& Prescott, R. (2006) Applied Mixed Models in Medicine, Wiley, Chichester. 
Bujko, K., Glimelius, B., Valentini, V., Michalski, W. \& Spalek, M. (2015)

Postoperative chemotherapy in patients with rectal cancer receiving preoperative radio(chemo)therapy: A meta-analysis of randomized trials comparing surgery +/- a fluoropyrimidine and surgery + a fluoropyrimidine +/- oxaliplatin. Eur $J$ Surg Oncol, 41(6), 713-23.

Cappelleri, J.C. (2014) Patient-reported outcomes : measurement, implementation and interpretation, CRC Press/Taylor \& Francis Group, Boca Raton.

Cassidy, J., Tabernero, J., Twelves, C., Brunet, R., Butts, C., Conroy, T., Debraud, F., Figer, A., Grossmann, J., Sawada, N., Schoffski, P., Sobrero, A., Van Cutsem, E. \& Diaz-Rubio, E. (2004) XELOX (capecitabine plus oxaliplatin): active firstline therapy for patients with metastatic colorectal cancer. J Clin Oncol, 22(11), 2084-91.

Cathomas, R., Koberle, D., Ruhstaller, T., Mayer, G., Rass, A., Mey, U. \& von Moos, R. (2010) Heated (37 degrees C) oxaliplatin infusion in combination with capecitabine for metastatic colorectal carcinoma: can it reduce neuropathy? Support Care Cancer, 18(10), 1263-70.

Catt, S., Starkings, R., Shilling, V. \& Fallowfield, L. (2017) Patient-reported outcome measures of the impact of cancer on patients' everyday lives: a systematic review. J Cancer Surviv, 11(2), 211-232.

Cavaletti, G., Bogliun, G., Marzorati, L., Zincone, A., Piatti, M., Colombo, N., Parma, G., Lissoni, A., Fei, F., Cundari, S. \& Zanna, C. (2003) Grading of chemotherapy-induced peripheral neurotoxicity using the Total Neuropathy Scale. Neurology, 61(9), 1297-300.

Cavaletti, G., Cornblath, D.R., Merkies, I.S., Postma, T.J., Rossi, E., Frigeni, B., Alberti, P., Bruna, J., Velasco, R., Argyriou, A.A., Kalofonos, H.P., Psimaras, D., Ricard, D., Pace, A., Galie, E., Briani, C., Dalla Torre, C., Faber, C.G., Lalisang, R.I., Boogerd, W., Brandsma, D., Koeppen, S., Hense, J., Storey, D., Kerrigan, S., Schenone, A., Fabbri, S., Valsecchi, M.G. \& Group, C.I.-P. (2013) The chemotherapy-induced peripheral neuropathy outcome measures standardization study: from consensus to the first validity and reliability findings. Ann Oncol, 24(2), 454-62. 
Cavaletti, G., Frigeni, B., Lanzani, F., Mattavelli, L., Susani, E., Alberti, P., Cortinovis, D. \& Bidoli, P. (2010) Chemotherapy-Induced Peripheral Neurotoxicity assessment: a critical revision of the currently available tools. Eur J Cancer, 46(3), 479-94.

Cavaletti, G. \& Marmiroli, P. (2015) Chemotherapy-induced peripheral neurotoxicity. Curr Opin Neurol, 28(5), 500-7.

Cella, D.F. \& Tulsky, D.S. (1993) Quality of life in cancer: definition, purpose, and method of measurement. Cancer Invest, 11(3), 327-36.

Cella, D.F., Tulsky, D.S., Gray, G., Sarafian, B., Linn, E., Bonomi, A., Silberman, M., Yellen, S.B., Winicour, P., Brannon, J. \& et al. (1993) The Functional Assessment of Cancer Therapy scale: development and validation of the general measure. J Clin Oncol, 11(3), 570-9.

Chao, Y.H., Wang, S.Y., Hsu, T.H. \& Wang, K.W. (2015) The desire to survive: the adaptation process of adult cancer patients undergoing radiotherapy. Jpn J Nurs Sci, 12(1), 79-86.

Chen, P.Y. \& Chang, H.C. (2012) The coping process of patients with cancer. Eur J Oncol Nurs, 16(1), 10-6.

Cheng, X.L., Liu, H.Q., Wang, Q., Huo, J.G., Wang, X.N. \& Cao, P. (2015)

Chemotherapy-induced peripheral neurotoxicity and complementary and alternative medicines: progress and perspective. Front Pharmacol, 6, 234.

Chodosh, J., Morton, S.C., Mojica, W., Maglione, M., Suttorp, M.J., Hilton, L., Rhodes, S. \& Shekelle, P. (2005) Meta-analysis: chronic disease self-management programs for older adults. Ann Intern Med, 143(6), 427-38.

Cirillo, M., Venturini, M., Ciccarelli, L., Coati, F., Bortolami, O. \& Verlato, G. (2009) Clinician versus nurse symptom reporting using the National Cancer InstituteCommon Terminology Criteria for Adverse Events during chemotherapy: results of a comparison based on patient's self-reported questionnaire. Ann Oncol, 20(12), 1929-35.

Cox-Martin, E., Trahan, L.H., Cox, M.G., Dougherty, P.M., Lai, E.A. \& Novy, D.M. (2017) Disease burden and pain in obese cancer patients with chemotherapyinduced peripheral neuropathy. Support Care Cancer, 25(6), 1873-1879. 
Council of Europe. (1997) Convention for the Protection of Human Rights and Dignity of the Human Being with regard to the Application of Biology and Medicine: Convention on Human Rights and Biomedicine, (Oviedo Convention), European Treaty Series No 164, Strasbourg.

Council for International Organizations of Medical Sciences (CIOMS). (2002)

International ethical guidelines for biomedical research involving human subjects. Geneva.

Coolbrandt, A., Van den Heede, K., Vanhove, E., De Bom, A., Milisen, K. \& Wildiers, H. (2011) Immediate versus delayed self-reporting of symptoms and side effects during chemotherapy: does timing matter? Eur J Oncol Nurs, 15(2), 130-6.

de Gramont, A., Buyse, M., Abrahantes, J.C., Burzykowski, T., Quinaux, E., Cervantes, A., Figer, A., Lledo, G., Flesch, M., Mineur, L., Carola, E., Etienne, P.L., Rivera, F., Chirivella, I., Perez-Staub, N., Louvet, C., Andre, T., Tabah-Fisch, I. \& Tournigand, C. (2007) Reintroduction of oxaliplatin is associated with improved survival in advanced colorectal cancer. J Clin Oncol, 25(22), 3224-9.

de Gramont, A., Figer, A., Seymour, M., Homerin, M., Hmissi, A., Cassidy, J., Boni, C., Cortes-Funes, H., Cervantes, A., Freyer, G., Papamichael, D., Le Bail, N., Louvet, C., Hendler, D., de Braud, F., Wilson, C., Morvan, F. \& Bonetti, A. (2000) Leucovorin and fluorouracil with or without oxaliplatin as first-line treatment in advanced colorectal cancer. J Clin Oncol, 18(16), 2938-47. de Gramont, A., Vignoud, J., Tournigand, C., Louvet, C., Andre, T., Varette, C., Raymond, E., Moreau, S., Le Bail, N. \& Krulik, M. (1997) Oxaliplatin with high-dose leucovorin and 5-fluorouracil 48-hour continuous infusion in pretreated metastatic colorectal cancer. Eur J Cancer, 33(2), 214-9.

Des Guetz, G., Uzzan, B., Morere, J.F., Perret, G. \& Nicolas, P. (2010) Duration of adjuvant chemotherapy for patients with non-metastatic colorectal cancer. Cochrane Database Syst Rev, (1), CD007046.

Dickinson, R., Hall, S., Sinclair, J.E., Bond, C. \& Murchie, P. (2014) Using technology to deliver cancer follow-up: A systematic review. BMC Cancer, 14(1).

Drageset, S., Lindstrom, T.C. \& Underlid, K. (2016) "I just have to move on": Women's coping experiences and reflections following their first year after primary breast cancer surgery. Eur J Oncol Nurs, 21, 205-11. 
Driessen, C.M., de Kleine-Bolt, K.M., Vingerhoets, A.J., Mols, F. \& Vreugdenhil, G. (2012) Assessing the impact of chemotherapy-induced peripheral neurotoxicity on the quality of life of cancer patients: the introduction of a new measure. Support Care Cancer, 20(4), 877-81.

Drott, J., Vilhelmsson, M., Kjellgren, K. \& Bertero, C. (2016) Experiences With a SelfReported Mobile Phone-Based System Among Patients With Colorectal Cancer: A Qualitative Study. JMIR Mhealth Uhealth, 4(2), e66.

Drury, A., Payne, S. \& Brady, A.M. (2017) Cancer survivorship: Advancing the concept in the context of colorectal cancer. Eur J Oncol Nurs, 29, 135-147.

Ducreux, M., Bennouna, J., Hebbar, M., Ychou, M., Lledo, G., Conroy, T., Adenis, A., Faroux, R., Rebischung, C., Bergougnoux, L., Kockler, L., Douillard, J.Y. \& Centers, G.I.G.o.t.F.A.-C. (2011) Capecitabine plus oxaliplatin (XELOX) versus 5-fluorouracil/leucovorin plus oxaliplatin (FOLFOX-6) as first-line treatment for metastatic colorectal cancer. Int J Cancer, 128(3), 682-90.

Dunlop, D.D., Hughes, S.L. \& Manheim, L.M. (1997) Disability in activities of daily living: patterns of change and a hierarchy of disability. Am J Public Health, 87(3), 378-83.

Elashoff, R.M., Li, G. \& Li, N. (2017) Joint modeling of longitudinal and time-to-event data, CRC Press, Boca Raton.

Eriksson, M. \& Lindstrom, B. (2005) Validity of Antonovsky's sense of coherence scale: a systematic review. J Epidemiol Community Health, 59(6), 460-6.

Ewertz, M., Qvortrup, C. \& Eckhoff, L. (2015) Chemotherapy-induced peripheral neuropathy in patients treated with taxanes and platinum derivatives. Acta Oncol, 54(5), 587-91.

Farrall S. (2006) What is qualitative longitudinal research? . Papers in Social Research Methods Qualitative Series, 11.

Ferrier, J., Pereira, V., Busserolles, J., Authier, N. \& Balayssac, D. (2013) Emerging trends in understanding chemotherapy-induced peripheral neuropathy. Curr Pain Headache Rep, 17(10), 364.

Fitzmaurice, G.M., Laird, N.M. \& Ware, J.H. (2011) Applied longitudinal analysis, Wiley, Hoboken, N.J. 
Flatters, S.J.L., Dougherty, P.M. \& Colvin, L.A. (2017) Clinical and preclinical perspectives on Chemotherapy-Induced Peripheral Neuropathy (CIPN): a narrative review. Br J Anaesth, 119(4), 737-749.

Forsberg, C. \& Cedermark, B. (1996) Well-being, general health and coping ability: 1year follow-up of patients treated for colorectal and gastric cancer. Eur J Cancer Care (Engl), 5(4), 209-16.

Foskett-Tharby, R., Hex, N., Chuter, A. \& Gill, P. (2017) Challenges of incentivising patient centred care. Bmj, 359, j4532.

Fox, P., Darley, A., Furlong, E., Miaskowski, C., Patiraki, E., Armes, J., Ream, E., Papadopoulou, C., McCann, L., Kearney, N. \& Maguire, R. (2017) The assessment and management of chemotherapy-related toxicities in patients with breast cancer, colorectal cancer, and Hodgkin's and non-Hodgkin's lymphomas: A scoping review. Eur J Oncol Nurs, 26, 63-82.

Gebremedhn, E.G., Shortland, P.J. \& Mahns, D.A. (2018) The incidence of acute oxaliplatin-induced neuropathy and its impact on treatment in the first cycle: a systematic review. BMC Cancer, 18(1), 410.

Gewandter, J.S., Freeman, R., Kitt, R.A., Cavaletti, G., Gauthier, L.R., McDermott, M.P., Mohile, N.A., Mohlie, S.G., Smith, A.G., Tejani, M.A., Turk, D.C. \& Dworkin, R.H. (2017) Chemotherapy-induced peripheral neuropathy clinical trials: Review and recommendations. Neurology, 89(8), 859-869.

Glimelius, B., Manojlovic, N., Pfeiffer, P., Mosidze, B., Kurteva, G., Karlberg, M., Mahalingam, D., Buhl Jensen, P., Kowalski, J., Bengtson, M., Nittve, M. \& Nasstrom, J. (2018) Persistent prevention of oxaliplatin-induced peripheral neuropathy using calmangafodipir $(\operatorname{PledOx}((\mathrm{R})))$ : a placebo-controlled randomised phase II study (PLIANT). Acta Oncol, 57(3), 393-402.

Gonzalez-Saenz de Tejada, M., Bilbao, A., Bare, M., Briones, E., Sarasqueta, C., Quintana, J.M. \& Escobar, A. (2016) Association of social support, functional status, and psychological variables with changes in health-related quality of life outcomes in patients with colorectal cancer. Psychooncology, 25(8), 891-7.

Grenon, N.N. \& Chan, J. (2009) Managing toxicities associated with colorectal cancer chemotherapy and targeted therapy: a new guide for nurses. Clin J Oncol Nurs, 13(3), 285-96. 
Grisold, W., Cavaletti, G. \& Windebank, A.J. (2012) Peripheral neuropathies from chemotherapeutics and targeted agents: diagnosis, treatment, and prevention. Neuro Oncol, 14 Suppl 4, iv45-54.

Grothey, A (2003) Oxaliplatin-safety profile: neurotoxicity. Semin Oncol 30, 5-13.

Grothey, A. (2006) Recognizing and managing toxicities of molecular targeted therapies for colorectal cancer. Oncology (Williston Park), 20 (14 Suppl 10), 21-8.

Gustafsson, E., Litstrom, E., Bertero, C. \& Drott, J. (2016) Reliability testing of oxaliplatin-associated neurotoxicity questionnaire (OANQ), a pilot study. Support Care Cancer, 24(2), 747-754.

Gurol-Urganci, I., de Jongh, T., Vodopivec-Jamsek, V. \& Atun, R. (2013) Mobile phone messaging reminders for attendance at healthcare appointments. Cochrane Database Syst Rev, (5), CD007458.

Gustavell, T., Langius-Eklof, A., Wengstrom, Y., Segersvard, R. \& Sundberg, K. (2018) Development and Feasibility of an Interactive Smartphone App for Early Assessment and Management of Symptoms Following Pancreaticoduodenectomy. Cancer Nurs. Mar 27.

Gustavsson, B., Carlsson, G., Machover, D., Petrelli, N., Roth, A., Schmoll, H.J., Tveit, K.M. \& Gibson, F. (2015) A review of the evolution of systemic chemotherapy in the management of colorectal cancer. Clin Colorectal Cancer, 14(1), 1-10.

Hallberg, I., Taft, C., Ranerup, A., Bengtsson, U., Hoffmann, M., Hofer, S., Kasperowski, D., Makitalo, A., Lundin, M., Ring, L., Rosenqvist, U. \& Kjellgren, K. (2014) Phases in development of an interactive mobile phonebased system to support self-management of hypertension. Integr Blood Press Control, 7, 19-28.

Halleberg Nyman, M., Frank, C., Langius-Eklof, A., Blomberg, K., Sundberg, K. \& Wengstrom, Y. (2017) Patients' Perspective on Participation in Care With or Without the Support of a Smartphone App During Radiotherapy for Prostate Cancer: Qualitative Study. JMIR Mhealth Uhealth, 5(7), e107.

Haller, D.G., Catalano, P.J., Macdonald, J.S., O'Rourke, M.A., Frontiera, M.S., Jackson, D.V. \& Mayer, R.J. (2005) Phase III study of fluorouracil, leucovorin, and levamisole in high-risk stage II and III colon cancer: final report of Intergroup 0089. J Clin Oncol, 23(34), 8671-8. 
Haller, D.G., Tabernero, J., Maroun, J., de Braud, F., Price, T., Van Cutsem, E., Hill, M., Gilberg, F., Rittweger, K. \& Schmoll, H.J. (2011) Capecitabine plus oxaliplatin compared with fluorouracil and folinic acid as adjuvant therapy for stage III colon cancer. J Clin Oncol, 29(11), 1465-71.

Hammer, M.J., Ercolano, E.A., Wright, F., Dickson, V.V., Chyun, D. \& Melkus, G.D. (2015) Self-management for adult patients with cancer: an integrative review. Cancer Nurs, 38(2), E10-26.

Han, C.H., Kilfoyle, D.H., Hill, A.G., Jameson, M.B. \& McKeage, M.J. (2016) Preventing oxaliplatin-induced neurotoxicity: rationale and design of phase $\mathrm{Ib}$ randomized, double-blind, placebo-controlled, cross-over trials for early clinical evaluation of investigational therapeutics. Expert Opin Drug Metab Toxicol, 12(12), 1479-1490.

Han, Y. \& Smith, M.T. (2013) Pathobiology of cancer chemotherapy-induced peripheral neuropathy (CIPN). Front Pharmacol, 4, 156.

Harrison, J.D., Young, J.M., Price, M.A., Butow, P.N. \& Solomon, M.J. (2009) What are the unmet supportive care needs of people with cancer? A systematic review. Support Care Cancer, 17(8), 1117-28.

Harrison, J.D., Young, J.M., Auld, S., Masya, L., Solomon, M.J. \& Butow, P.N. (2011) Quantifying postdischarge unmet supportive care needs of people with colorectal cancer: a clinical audit. Colorectal Dis, 13(12), 1400-6.

Haryani, H., Fetzer, S.J., Wu, C.L. \& Hsu, Y.Y. (2017) Chemotherapy-Induced Peripheral Neuropathy Assessment Tools: A Systematic Review. Oncol Nurs Forum, 44(3), E111-E123.

Hellbom, M., Bergelt, C., Bergenmar, M., Gijsen, B., Loge, J.H., Rautalahti, M., Smaradottir, A. \& Johansen, C. (2011) Cancer rehabilitation: A Nordic and European perspective. Acta Oncol, 50(2), 179-86.

Henoch, I., Olsson, C., Larsson, M. \& Ahlberg, K. (2018) Symptom Dimensions as Outcomes in Interventions for Patients With Cancer: A Systematic Review. Oncol Nurs Forum, 45(2), 237-249. 
Hershman, D.L., Lacchetti, C., Dworkin, R.H., Lavoie Smith, E.M., Bleeker, J., Cavaletti, G., Chauhan, C., Gavin, P., Lavino, A., Lustberg, M.B., Paice, J., Schneider, B., Smith, M.L., Smith, T., Terstriep, S., Wagner-Johnston, N., Bak, K., Loprinzi, C.L. \& American Society of Clinical, O. (2014) Prevention and management of chemotherapy-induced peripheral neuropathy in survivors of adult cancers: American Society of Clinical Oncology clinical practice guideline. J Clin Oncol, 32(18), 1941-67.

Hoff, P.M., Saad, E.D., Costa, F., Coutinho, A.K., Caponero, R., Prolla, G. \& Gansl, R.C. (2012) Literature review and practical aspects on the management of oxaliplatin-associated toxicity. Clin Colorectal Cancer, 11(2), 93-100.

Holland J, T.R., Henderson S (2004) Feasibility study for a possible qualitative longitudinal study: A discussion paper. Produced for the ESRC.

Hong, J.S., Tian, J. \& Wu, L.H. (2014) The influence of chemotherapy-induced neurotoxicity on psychological distress and sleep disturbance in cancer patients. Curr Oncol, 21(4), 174-80.

Hsieh, H.F. \& Shannon, S.E. (2005) Three approaches to qualitative content analysis. Qual Health Res, 15(9), 1277-88.

Hsieh, Y.L., Chou, L.W., Hong, S.F., Chang, F.C., Tseng, S.W., Huang, C.C., Yang, C.H., Yang, C.C. \& Chiu, W.F. (2016) Laser acupuncture attenuates oxaliplatininduced peripheral neuropathy in patients with gastrointestinal cancer: a pilot prospective cohort study. Acupunct Med, 34(5), 398-405.

Huang, H.Q., Brady, M.F., Cella, D. \& Fleming, G. (2007) Validation and reduction of FACT/GOG-Ntx subscale for platinum/paclitaxel-induced neurologic symptoms: a gynecologic oncology group study. Int J Gynecol Cancer, 17(2), 387-93.

Hung, H.C., Chien, T.W., Tsay, S.L., Hang, H.M. \& Liang, S.Y. (2013) Patient and clinical variables account for changes in health- related quality of life and symptom burden as treatment outcomes in colorectal cancer: a longitudinal study. Asian Pac J Cancer Prev, 14(3), 1905-9.

Husson, O., Vissers, P.A., Denollet, J. \& Mols, F. (2015) The role of personality in the course of health-related quality of life and disease-specific health status among colorectal cancer survivors: A prospective population-based study from the PROFILES registry. Acta Oncol, 54(5), 669-77. 
Iconomou, G., Mega, V., Koutras, A., Iconomou, A.V. \& Kalofonos, H.P. (2004)

Prospective assessment of emotional distress, cognitive function, and quality of life in patients with cancer treated with chemotherapy. Cancer, 101(2), 404-11. Iveson, T.J., Kerr, R.S., Saunders, M.P., Cassidy, J., Hollander, N.H., Tabernero, J., Haydon, A., Glimelius, B., Harkin, A., Allan, K., McQueen, J., Scudder, C., Boyd, K.A., Briggs, A., Waterston, A., Medley, L., Wilson, C., Ellis, R., Essapen, S., Dhadda, A.S., Harrison, M., Falk, S., Raouf, S., Rees, C., Olesen, R.K., Propper, D., Bridgewater, J., Azzabi, A., Farrugia, D., Webb, A., Cunningham, D., Hickish, T., Weaver, A., Gollins, S., Wasan, H.S. \& Paul, J. (2018) 3 versus 6 months of adjuvant oxaliplatin-fluoropyrimidine combination therapy for colorectal cancer (SCOT): an international, randomised, phase 3, non-inferiority trial. Lancet Oncol, 19(4), 562-578.

Jagger, C., Arthur, A.J., Spiers, N.A. \& Clarke, M. (2001) Patterns of onset of disability in activities of daily living with age. J Am Geriatr Soc, 49(4), 404-9.

Jones, D., Zhao, F., Brell, J., Lewis, M.A., Loprinzi, C.L., Weiss, M. \& Fisch, M.J. (2015) Neuropathic symptoms, quality of life, and clinician perception of patient care in medical oncology outpatients with colorectal, breast, lung, and prostate cancer. J Cancer Surviv, 9(1), 1-10.

Jonker, D.J., Spithoff, K., Maroun, J. \& Gastrointestinal Cancer Disease Site Group of Cancer Care Ontario's Program in Evidence-based, C. (2011) Adjuvant systemic chemotherapy for Stage II and III colon cancer after complete resection: an updated practice guideline. Clin Oncol (R Coll Radiol), 23(5), 314-22.

Jordan, B., Jahn, F., Beckmann, J., Unverzagt, S., Muller-Tidow, C. \& Jordan, K. (2016) Calcium and Magnesium Infusions for the Prevention of OxaliplatinInduced Peripheral Neurotoxicity: A Systematic Review. Oncology, 90(6), 299306.

Jorgensen, M.L., Young, J.M. \& Solomon, M.J. (2015) Optimal delivery of colorectal cancer follow-up care: improving patient outcomes. Patient Relat Outcome Meas, 6, 127-38.

Kerckhove, N., Collin, A., Conde, S., Chaleteix, C., Pezet, D. \& Balayssac, D. (2017) Long-Term Effects, Pathophysiological Mechanisms, and Risk Factors of Chemotherapy-Induced Peripheral Neuropathies: A Comprehensive Literature Review. Front Pharmacol, 8, 86. 
Kidd, L., Hubbard, G., O'Carroll, R. \& Kearney, N. (2009) Perceived control and involvement in self care in patients with colorectal cancer. J Clin Nurs, 18(16), 2292-300.

Kidd, L., Kearney, N., O'Carroll, R. \& Hubbard, G. (2008) Experiences of self-care in patients with colorectal cancer: a longitudinal study. $J$ Adv Nurs, 64(5), 469-77.

Kiernan MC, Krishnan AV. (2006) The pathophysiology of oxaliplatin-induced neurotoxicity. Curr Med Chem, 13(24), 2901-7.

Kidwell, K.M., Yothers, G., Ganz, P.A., Land, S.R., Ko, C.Y., Cecchini, R.S., Kopec, J.A. \& Wolmark, N. (2012) Long-term neurotoxicity effects of oxaliplatin added to fluorouracil and leucovorin as adjuvant therapy for colon cancer: results from National Surgical Adjuvant Breast and Bowel Project trials C-07 and LTS-01. Cancer, 118(22), 5614-22.

Kim, S.-H., Kim, W., Kim, J.-H., Ki Woo, M., Baek, J., Kim, S., Hyun Chung, S. \& Kim, H.J. (2018) A Prospective Study of Chronic Oxaliplatin-Induced Neuropathy in Patients with Colon Cancer: Long-Term Outcomes and Predictors of Severe Oxaliplatin-Induced Neuropathy. J Clin Neurol, 14(1), 81-89.

Klasnja, P. \& Pratt, W. (2012) Healthcare in the pocket: mapping the space of mobilephone health interventions. J Biomed Inform, 45(1), 184-98.

Kolb, N.A., Smith, A.G., Singleton, J.R., Beck, S.L., Howard, D., Dittus, K., Karafiath, S. \& Mooney, K. (2018) Chemotherapy-related neuropathic symptom management: a randomized trial of an automated symptom-monitoring system paired with nurse practitioner follow-up. Support Care Cancer, 26(5), 16071615.

Krishna, S., Boren, S.A. \& Balas, E.A. (2009) Healthcare via cell phones: a systematic review. Telemed J E Health, 15(3), 231-40.

Krishnan, A.V., Goldstein, D., Friedlander, M. \& Kiernan, M.C. (2005) Oxaliplatininduced neurotoxicity and the development of neuropathy. Muscle Nerve, 32(1), $51-60$. 
Kuebler, J.P., Wieand, H.S., O'Connell, M.J., Smith, R.E., Colangelo, L.H., Yothers, G., Petrelli, N.J., Findlay, M.P., Seay, T.E., Atkins, J.N., Zapas, J.L., Goodwin, J.W., Fehrenbacher, L., Ramanathan, R.K., Conley, B.A., Flynn, P.J., Soori, G., Colman, L.K., Levine, E.A., Lanier, K.S. \& Wolmark, N. (2007) Oxaliplatin combined with weekly bolus fluorouracil and leucovorin as surgical adjuvant chemotherapy for stage II and III colon cancer: results from NSABP C-07. $J$ Clin Oncol, 25(16), 2198-204.

Kuriyama, A. \& Endo, K. (2018) Goshajinkigan for prevention of chemotherapyinduced peripheral neuropathy: a systematic review and meta-analysis. Support Care Cancer, 26(4), 1051-1059.

Land, S.R., Kopec, J.A., Cecchini, R.S., Ganz, P.A., Wieand, H.S., Colangelo, L.H., Murphy, K., Kuebler, J.P., Seay, T.E., Needles, B.M., Bearden, J.D., 3rd, Colman, L.K., Lanier, K.S., Pajon, E.R., Jr., Cella, D., Smith, R.E., O'Connell, M.J., Costantino, J.P. \& Wolmark, N. (2007) Neurotoxicity from oxaliplatin combined with weekly bolus fluorouracil and leucovorin as surgical adjuvant chemotherapy for stage II and III colon cancer: NSABP C-07. J Clin Oncol, 25(16), 2205-11.

Langius-Eklof, A., Crafoord, M.T., Christiansen, M., Fjell, M. \& Sundberg, K. (2017) Effects of an interactive mHealth innovation for early detection of patientreported symptom distress with focus on participatory care: protocol for a study based on prospective, randomised, controlled trials in patients with prostate and breast cancer. BMC Cancer, 17(1), 466.

Le-Rademacher, J., Kanwar, R., Seisler, D., Pachman, D.R., Qin, R., Abyzov, A., Ruddy, K.J., Banck, M.S., Lavoie Smith, E.M., Dorsey, S.G., Aaronson, N.K., Sloan, J., Loprinzi, C.L. \& Beutler, A.S. (2017) Patient-reported (EORTC QLQCIPN20) versus physician-reported (CTCAE) quantification of oxaliplatin- and paclitaxel/carboplatin-induced peripheral neuropathy in NCCTG/Alliance clinical trials. Support Care Cancer, 25(11), 3537-3544.

Leonard, G.D., Wright, M.A., Quinn, M.G., Fioravanti, S., Harold, N., Schuler, B., Thomas, R.R. \& Grem, J.L. (2005) Survey of oxaliplatin-associated neurotoxicity using an interview-based questionnaire in patients with metastatic colorectal cancer. BMC Cancer, 5, 116.

Lincoln, Y.S. \& Guba, E.G. (1985) Naturalistic inquiry, Sage, Beverly Hills, Calif. 
Madsen, L.S. \& Handberg, C. (2018) Pursuing Normality: Reflections on Cancer Survivorship Care of Lymphoma Survivors. Cancer Nurs. Jan 16.

Maher, E.J. (2013) Managing the consequences of cancer treatment and the English National Cancer Survivorship Initiative. Acta Oncol, 52(2), 225-32.

Majithia, N., Temkin, S.M., Ruddy, K.J., Beutler, A.S., Hershman, D.L. \& Loprinzi, C.L. (2016) National Cancer Institute-supported chemotherapy-induced peripheral neuropathy trials: outcomes and lessons. Support Care Cancer, 24(3), 1439-47.

McCambridge, J., Witton, J. \& Elbourne, D.R. (2014) Systematic review of the Hawthorne effect: new concepts are needed to study research participation effects. J Clin Epidemiol, 67(3), 267-77.

McCann, L., Maguire, R., Miller, M. \& Kearney, N. (2009) Patients' perceptions and experiences of using a mobile phone-based advanced symptom management system (ASyMS) to monitor and manage chemotherapy related toxicity. Eur $J$ Cancer Care (Engl), 18(2), 156-64.

McCorkle, R., Ercolano, E., Lazenby, M., Schulman-Green, D., Schilling, L.S., Lorig, K. \& Wagner, E.H. (2011) Self-management: Enabling and empowering patients living with cancer as a chronic illness. CA Cancer J Clin, 61(1), 50-62.

McCrary, J.M., Goldstein, D., Boyle, F., Cox, K., Grimison, P., Kiernan, M.C., Krishnan, A.V., Lewis, C.R., Webber, K., Baron-Hay, S., Horvath, L., Park, S.B. \& party, I.F.D.w. (2017) Optimal clinical assessment strategies for chemotherapy-induced peripheral neuropathy (CIPN): a systematic review and Delphi survey. Support Care Cancer, 25(11), 3485-3493.

McGrath-Lone, L., Ward, H., Schoenborn, C. \& Day, S. (2016) The effects of cancer research participation on patient experience: a mixed-methods analysis. Eur $J$ Cancer Care (Engl), 25(6), 1056-1064.

Miaskowski, C., Mastick, J., Paul, S.M., Abrams, G., Cheung, S., Sabes, J.H., Kober, K.M., Schumacher, M., Conley, Y.P., Topp, K., Smoot, B., Mausisa, G., Mazor, M., Wallhagen, M. \& Levine, J.D. (2018) Impact of chemotherapy-induced neurotoxicities on adult cancer survivors' symptom burden and quality of life. $J$ Cancer Surviv. 12(2), 234-245. 
Miller, A.B., Hoogstraten, B., Staquet, M. \& Winkler, A. (1981) Reporting results of cancer treatment. Cancer, 47(1), 207-14.

Miltenburg, N.C. \& Boogerd, W. (2014) Chemotherapy-induced neuropathy: A comprehensive survey. Cancer Treat Rev, 40(7), 872-82.

Mirkovic, J., Kaufman, D.R. \& Ruland, C.M. (2014) Supporting cancer patients in illness management: usability evaluation of a mobile app. JMIR Mhealth Uhealth, 2(3), e33.

Mitchell, P.L., Goldstein, D., Michael, M., Beale, P., Friedlander, M., Zalcberg, J., White, S., Thomson, J.A. \& Clarke, S. (2006) Addition of gabapentin to a modified FOLFOX regimen does not reduce oxaliplatin-induced neurotoxicity. Clin Colorectal Cancer, 6(2), 146-51.

Mlinac, M.E. \& Feng, M.C. (2016) Assessment of Activities of Daily Living, Self-Care, and Independence. Arch Clin Neuropsychol, 31(6), 506-16.

Mokkink, L.B., Terwee, C.B., Patrick, D.L., Alonso, J., Stratford, P.W., Knol, D.L., Bouter, L.M. \& de Vet, H.C. (2010) The COSMIN study reached international consensus on taxonomy, terminology, and definitions of measurement properties for health-related patient-reported outcomes. J Clin Epidemiol, 63(7), 737-45.

Mols, F., Beijers, A.J., Vreugdenhil, G., Verhulst, A., Schep, G. \& Husson, O. (2015) Chemotherapy-induced peripheral neuropathy, physical activity and healthrelated quality of life among colorectal cancer survivors from the PROFILES registry. J Cancer Surviv, 9(3), 512-22.

Mols, F., Beijers, T., Vreugdenhil, G. \& van de Poll-Franse, L. (2014) Chemotherapyinduced peripheral neuropathy and its association with quality of life: a systematic review. Support Care Cancer, 22(8), 2261-9.

Moore, G.F., Audrey, S., Barker, M., Bond, L., Bonell, C., Hardeman, W., Moore, L., O'Cathain, A., Tinati, T., Wight, D. \& Baird, J. (2015) Process evaluation of complex interventions: Medical Research Council guidance. Bmj, 350, h1258.

Mor, V., Wilcox, V., Rakowski, W. \& Hiris, J. (1994) Functional transitions among the elderly: patterns, predictors, and related hospital use. Am J Public Health, 84(8), 1274-80.

Mosher, C.E., Winger, J.G., Given, B.A., Helft, P.R. \& O'Neil, B.H. (2016) Mental health outcomes during colorectal cancer survivorship: a review of the literature. Psychooncology, 25(11), 1261-1270. 
Mosher, C.E., Winger, J.G., Given, B.A., Shahda, S. \& Helft, P.R. (2017) A systematic review of psychosocial interventions for colorectal cancer patients. Support Care Cancer, 25(7), 2349-2362.

Muntlin Athlin, A., Browall, M., Wengstrom, Y., Conroy, T. \& Kitson, A.L. (2018) Descriptions of Fundamental Care needs in cancer care - an exploratory study. $J$ Clin Nurs. Jan 2.

Murray, S.A., Kendall, M., Carduff, E., Worth, A., Harris, F.M., Lloyd, A., Cavers, D., Grant, L. \& Sheikh, A. (2009) Use of serial qualitative interviews to understand patients' evolving experiences and needs. BMJ, 339, b3702.

National Board of Health and Welfare (2016) Statistics on Cancer Incidence 2016.

National Cancer Institute (NCI) (2009) Common terminology criteria for adverse events. https://evs.nci.nih.gov/ftp1/CTCAE/CTCAE_4.03_2010-0614_QuickReference 5x7.pdf.

National Cancer Institute (NCI) (2017) Colon Cancer. https://www.cancer.gov/types/colorectal/hp/colon-treatment-pdq/.

National Quality Report from the Swedish Colorectal Cancer Registry (2015) Regional Cancer Center in collaboration.

National Healthcare Program Cancer Rehabilitation (2014).

Nowell, L.S., Norris, J.M., White, D.E. \& Moules, N.J. (2017) Thematic Analysis: Striving to Meet the Trustworthiness Criteria. International Journal of Qualitative Methods, 16(1), 1609406917733847.

Okamoto, I., Wright, D. \& Foster, C. (2012) Impact of cancer on everyday life: a systematic appraisal of the research evidence. Health Expect, 15(1), 97-111.

Orem, D.E., Taylor, S.G. \& Renpenning, K.M. (2001) Nursing : concepts of practice, Mosby, St. Louis, Mo.

Padman, S., Lee, J., Kumar, R., Slee, M., Hakendorf, P., Richards, A., Koczwara, B., Kichenadasse, G., Sukumaran, S., Roy, A., Vatandoust, S. \& Karapetis, C.S. (2015) Late effects of oxaliplatin-induced peripheral neuropathy (LEON)--crosssectional cohort study of patients with colorectal cancer surviving at least 2 years. Support Care Cancer, 23(3), 861-9. 
Pama, M.R., Janse, M., Sprangers, M.A.G., Fleer, J. \& Ranchor, A.V. (2018) Reducing discrepancies of personal goals in the context of cancer: A longitudinal study on the relation with well-being, psychological characteristics, and goal progress. $\mathrm{Br}$ J Health Psychol. 23(1), 128-147.

Park, S.B., Goldstein, D., Krishnan, A.V., Lin, C.S., Friedlander, M.L., Cassidy, J., Koltzenburg, M. \& Kiernan, M.C. (2013) Chemotherapy-induced peripheral neurotoxicity: a critical analysis. CA Cancer J Clin, 63(6), 419-37.

Park, S.B., Lin, C.S. \& Kiernan, M.C. (2012) Nerve excitability assessment in chemotherapy-induced neurotoxicity. $J$ Vis Exp, 26(62).

Patton, M.Q. (2015) Qualitative research \& evaluation methods : integrating theory and practice, SAGE Publications, Inc., Thousand Oaks, California.

Paul, C.L., Cameron, E., Doran, C., Hill, D., Macrae, F., Carey, M.L. \& Sanson-Fisher, R.W. (2016) Experiences of colorectal cancer patients in the 2-years postdiagnosis and patient factors predicting poor outcome. Support Care Cancer, 24(12), 4921-4928.

Petersen, S.H., Harling, H., Kirkeby, L.T., Wille-Jorgensen, P. \& Mocellin, S. (2012) Postoperative adjuvant chemotherapy in rectal cancer operated for cure. Cochrane Database Syst Rev, (3), Cd004078.

Pettersson, G., Bertero, C., Unosson, M. \& Borjeson, S. (2014) Symptom prevalence, frequency, severity, and distress during chemotherapy for patients with colorectal cancer. Support Care Cancer, 22(5), 1171-9.

Piringer, G., Fridrik, M., Fridrik, A., Leiherer, A., Zabernigg, A., Greil, R., Eisterer, W., Tschmelitsch, J., Lang, A., Frantal, S., Burgstaller, S., Gnant, M. \& Thaler, J. (2018) A prospective, multicenter pilot study to investigate the feasibility and safety of a 1-year controlled exercise training after adjuvant chemotherapy in colorectal cancer patients. Support Care Cancer, 26(4), 1345-1352.

Polit, D.F. (2014) Getting serious about test-retest reliability: a critique of retest research and some recommendations. Qual Life Res, 23(6), 1713-20.

Polit, D.F. \& Beck, C.T. (2016) Nursing research : generating and assessing evidence for nursing practice, Wolters Kluwer, Philadelphia. 
Postma, T.J., Aaronson, N.K., Heimans, J.J., Muller, M.J., Hildebrand, J.G., Delattre, J.Y., Hoang-Xuan, K., Lanteri-Minet, M., Grant, R., Huddart, R., Moynihan, C., Maher, J., Lucey, R. \& Group, E.Q.o.L. (2005) The development of an EORTC quality of life questionnaire to assess chemotherapy-induced peripheral neuropathy: the QLQ-CIPN20. Eur J Cancer, 41(8), 1135-9.

Postma, T.J., Heimans, J.J., Muller, M.J., Ossenkoppele, G.J., Vermorken, J.B. \& Aaronson, N.K. (1998) Pitfalls in grading severity of chemotherapy-induced peripheral neuropathy. Ann Oncol, 9(7), 739-44.

Pulvers, J.N. \& Marx, G. (2017) Factors associated with the development and severity of oxaliplatin-induced peripheral neuropathy: a systematic review. Asia Pac J Clin Oncol. 13(6), 345-355.

Rang, H.P., Dale, M.M., Ritter, J.M., Flower, R.J. \& Henderson, G. (2016) Rang and Dale's pharmacology, Churchill Livingstone, London.

Richard, A.A. \& Shea, K. (2011) Delineation of self-care and associated concepts. $J$ Nurs Scholarsh, 43(3), 255-64.

Rohrl, K., Guren, M.G., Miaskowski, C., Cooper, B.A., Diep, L.M. \& Rustoen, T. (2016) No Differences in Symptom Burden Between Colorectal Cancer Patients Receiving Curative Versus Palliative Chemotherapy. J Pain Symptom Manage, 52(4), 539-547.

Ross, L., Boesen, E.H., Dalton, S.O. \& Johansen, C. (2002) Mind and cancer: does psychosocial intervention improve survival and psychological well-being? Eur $J$ Cancer, 38(11), 1447-57.

Santin, O., Murray, L., Prue, G., Gavin, A., Gormley, G. \& Donnelly, M. (2015) Selfreported psychosocial needs and health-related quality of life of colorectal cancer survivors. Eur J Oncol Nurs, 19(4), 336-42.

Schmoll, H.J., Tabernero, J., Maroun, J., de Braud, F., Price, T., Van Cutsem, E., Hill, M., Hoersch, S., Rittweger, K. \& Haller, D.G. (2015) Capecitabine Plus Oxaliplatin Compared With Fluorouracil/Folinic Acid As Adjuvant Therapy for Stage III Colon Cancer: Final Results of the NO16968 Randomized Controlled Phase III Trial. J Clin Oncol, 33(32), 3733-40. 
Schmoll, H.J., Van Cutsem, E., Stein, A., Valentini, V., Glimelius, B., Haustermans, K., Nordlinger, B., van de Velde, C.J., Balmana, J., Regula, J., Nagtegaal, I.D., Beets-Tan, R.G., Arnold, D., Ciardiello, F., Hoff, P., Kerr, D., Kohne, C.H., Labianca, R., Price, T., Scheithauer, W., Sobrero, A., Tabernero, J., Aderka, D., Barroso, S., Bodoky, G., Douillard, J.Y., El Ghazaly, H., Gallardo, J., Garin, A., Glynne-Jones, R., Jordan, K., Meshcheryakov, A., Papamichail, D., Pfeiffer, P., Souglakos, I., Turhal, S. \& Cervantes, A. (2012) ESMO Consensus Guidelines for management of patients with colon and rectal cancer. a personalized approach to clinical decision making. Ann Oncol, 23(10), 2479-516.

Sereno, M., Gutierrez-Gutierrez, G., Gomez-Raposo, C., Lopez-Gomez, M., MerinoSalvador, M., Tebar, F.Z., Rodriguez-Antona, C. \& Casado, E. (2014) Oxaliplatin induced-neuropathy in digestive tumors. Crit Rev Oncol Hematol, 89(1), 166-78.

Seretny, M., Currie, G.L., Sena, E.S., Ramnarine, S., Grant, R., MacLeod, M.R., Colvin, L.A. \& Fallon, M. (2014) Incidence, prevalence, and predictors of chemotherapy-induced peripheral neuropathy: A systematic review and metaanalysis. Pain, 155(12), 2461-70.

Shimozuma, K., Ohashi, Y., Takeuchi, A., Aranishi, T., Morita, S., Kuroi, K., Ohsumi, S., Makino, H., Mukai, H., Katsumata, N., Sunada, Y., Watanabe, T. \& Hausheer, F.H. (2009) Feasibility and validity of the Patient Neurotoxicity Questionnaire during taxane chemotherapy in a phase III randomized trial in patients with breast cancer: N-SAS BC 02. Support Care Cancer, 17(12), 148391.

Sjovall, K., Gunnars, B., Olsson, H. \& Thome, B. (2011) Experiences of living with advanced colorectal cancer from two perspectives - inside and outside. Eur J Oncol Nurs, 15(5), 390-7.

Smith, E.M., Campbell, G., Tofthagen, C., Kottschade, L., Collins, M.L., Warton, C., Ghosh, B., Ronis, D.L., Mallory, G.A. \& Visovsky, C. (2014) Nursing knowledge, practice patterns, and learning preferences regarding chemotherapyinduced peripheral neuropathy. Oncol Nurs Forum, 41(6), 669-79. 
Smith, E.M., Pang, H., Cirrincione, C., Fleishman, S., Paskett, E.D., Ahles, T., Bressler, L.R., Fadul, C.E., Knox, C., Le-Lindqwister, N., Gilman, P.B., Shapiro, C.L. \& Alliance for Clinical Trials in, O. (2013) Effect of duloxetine on pain, function, and quality of life among patients with chemotherapy-induced painful peripheral neuropathy: a randomized clinical trial. JAMA, 309(13), 1359-67.

Smith, E.M., Pang, H., Ye, C., Cirrincione, C., Fleishman, S., Paskett, E.D., Ahles, T., Bressler, L.R., Le-Lindqwister, N., Fadul, C.E., Loprinzi, C., Shapiro, C.L. \& Alliance for Clinical Trials in, O. (2017) Predictors of duloxetine response in patients with oxaliplatin-induced painful chemotherapy-induced peripheral neuropathy (CIPN): a secondary analysis of randomised controlled trial CALGB/alliance 170601. Eur J Cancer Care (Engl), 26(2).

Stefanovic, S., Wallwiener, M., Karic, U., Domschke, C., Katic, L., Taran, F.A., Pesic, A., Hartkopf, A., Hadji, P., Teufel, M., Schuetz, F., Sohn, C., Fasching, P., Schneeweiss, A. \& Brucker, S. (2017) Patient-reported outcomes (PRO) focused on adverse events (PRO-AEs) in adjuvant and metastatic breast cancer: clinical and translational implications. Support Care Cancer, 25(2), 549-558.

Stefansson, M. \& Nygren, P. (2016) Oxaliplatin added to fluoropyrimidine for adjuvant treatment of colorectal cancer is associated with long-term impairment of peripheral nerve sensory function and quality of life. Acta Oncol, 55(9-10), 1227-1235.

Stuhlfauth, S., Melby, L. \& Helleso, R. (2017) Everyday Life After Colon Cancer: The Visible and Invisible Challenges. Cancer Nurs. May 23.

Sundberg, K., Eklof, A.L., Blomberg, K., Isaksson, A.K. \& Wengstrom, Y. (2015) Feasibility of an interactive ICT-platform for early assessment and management of patient-reported symptoms during radiotherapy for prostate cancer. Eur $J$ Oncol Nurs, 19(5), 523-8.

Swedish Society of Nursing. (2018) https://www.swenurse.se/.

Swedish Cancer Society. (2018) https://www.cancerfonden.se/ Swedish colorectal cancer registry.

https://www.socialstyrelsen.se/register/registerservice/nationellakvalitetsregister/ svenskakolorektalcancerregistr. 
Tan, P.Y., Tien Tau, L.C. \& Lai Meng, O.Y. (2015) Living With Cancer Alone? The Experiences of Singles Diagnosed With Colorectal Cancer. J Psychosoc Oncol, 33(4), 354-76.

Tanay, M.A.L., Armes, J. \& Ream, E. (2017) The experience of chemotherapy-induced peripheral neuropathy in adult cancer patients: a qualitative thematic synthesis. Eur J Cancer Care (Engl), 26(5).

Tanishima, H., Tominaga, T., Kimura, M., Maeda, T., Shirai, Y. \& Horiuchi, T. (2017) Hyperacute peripheral neuropathy is a predictor of oxaliplatin-induced persistent peripheral neuropathy. Support Care Cancer, 25(5), 1383-1389.

Tantoy, I.Y., Cataldo, J.K., Aouizerat, B.E., Dhruva, A. \& Miaskowski, C. (2016) A Review of the Literature on Multiple Co-occurring Symptoms in Patients With Colorectal Cancer Who Received Chemotherapy Alone or Chemotherapy With Targeted Therapies. Cancer Nurs, 39(6), 437-445.

Tofthagen, C. (2010a) Surviving chemotherapy for colon cancer and living with the consequences. J Palliat Med, 13(11), 1389-91.

Tofthagen, C. (2010b) Patient perceptions associated with chemotherapy-induced peripheral neuropathy. Clin J Oncol Nurs, 14(3), E22-8.

Tofthagen, C., Donovan, K.A., Morgan, M.A., Shibata, D. \& Yeh, Y. (2013a)

Oxaliplatin-induced peripheral neuropathy's effects on health-related quality of life of colorectal cancer survivors. Support Care Cancer, 21(12), 3307-13.

Tofthagen, C., Gonzalez, L., Visovsky, C. \& Akers, A. (2013b) Self-management of oxaliplatin-related peripheral neuropathy in colorectal cancer survivors.

Chemother Res Pract, 2013, 547932.

Tofthagen, C., Kip, K.E., Passmore, D., Loy, I. \& Berry, D.L. (2016) Usability and Acceptability of a Web-Based Program for Chemotherapy-Induced Peripheral Neuropathy. Comput Inform Nurs, 34(7), 322-9.

Tofthagen, C., McAllister, R.D. \& McMillan, S.C. (2011a) Peripheral neuropathy in patients with colorectal cancer receiving oxaliplatin. Clin J Oncol Nurs, 15(2), $182-8$.

Tofthagen, C.S., McMillan, S.C. \& Kip, K.E. (2011b) Development and psychometric evaluation of the chemotherapy-induced peripheral neuropathy assessment tool. Cancer Nurs, 34(4), E10-20. 
Tofthagen, C., Overcash, J. \& Kip, K. (2012) Falls in persons with chemotherapyinduced peripheral neuropathy. Support Care Cancer, 20(3), 583-9.

Trotti, A., Colevas, A.D., Setser, A., Rusch, V., Jaques, D., Budach, V., Langer, C., Murphy, B., Cumberlin, R., Coleman, C.N. \& Rubin, P. (2003) CTCAE v3.0: development of a comprehensive grading system for the adverse effects of cancer treatment. Semin Radiat Oncol, 13(3), 176-81.

Vatandoust, S., Joshi, R., Pittman, K.B., Esterman, A., Broadbridge, V., Adams, J., Singhal, N., Yeend, S. \& Price, T.J. (2014) A descriptive study of persistent oxaliplatin-induced peripheral neuropathy in patients with colorectal cancer. Support Care Cancer, 22(2), 513-8.

Velasco, R., Bruna, J., Briani, C., Argyriou, A.A., Cavaletti, G., Alberti, P., Frigeni, B., Cacciavillani, M., Lonardi, S., Cortinovis, D., Cazzaniga, M., Santos, C. \& Kalofonos, H.P. (2014) Early predictors of oxaliplatin-induced cumulative neuropathy in colorectal cancer patients. J Neurol Neurosurg Psychiatry, 85(4), 392-8.

Vermeer, N.C., Snijders, H.S., Holman, F.A., Liefers, G.J., Bastiaannet, E., van de Velde, C.J. \& Peeters, K.C. (2017) Colorectal cancer screening: Systematic review of screen-related morbidity and mortality. Cancer Treat Rev, 54, 87-98. Verstappen, C.C., Heimans, J.J., Hoekman, K. \& Postma, T.J. (2003) Neurotoxic complications of chemotherapy in patients with cancer: clinical signs and optimal management. Drugs, 63(15), 1549-63.

Walling, A.M., Weeks, J.C., Kahn, K.L., Tisnado, D., Keating, N.L., Dy, S.M., Arora, N.K., Mack, J.W., Pantoja, P.M. \& Malin, J.L. (2015) Symptom prevalence in lung and colorectal cancer patients. J Pain Symptom Manage, 49(2), 192-202.

Ward Sullivan, C., Leutwyler, H., Dunn, L.B. \& Miaskowski, C. (2018) A review of the literature on symptom clusters in studies that included oncology patients receiving primary or adjuvant chemotherapy. J Clin Nurs, 27(3-4), 516-545.

Wen, F., Zhou, Y., Wang, W., Hu, Q.C., Liu, Y.T., Zhang, P.F., Du, Z.D., Dai, J. \& Li, Q. (2013) $\mathrm{Ca} / \mathrm{Mg}$ infusions for the prevention of oxaliplatin-related neurotoxicity in patients with colorectal cancer: a meta-analysis. Ann Oncol, 24(1), 171-8.

Weis, J. \& Giesler, J.M. (2014) Rehabilitation for cancer patients. Recent Results Cancer Res, 197, 87-101. 
Wickham, R. (2007) Chemotherapy-induced peripheral neuropathy: a review and implications for oncology nursing practice. Clin J Oncol Nurs, 11(3), 361-76.

Wittenberg, E., Ferrell, B., Kanter, E. \& Buller, H. (2018) Health Literacy: Exploring Nursing Challenges to Providing Support and Understanding. Clin J Oncol Nurs, 22(1), 53-61.

Vincenzi, B., Frezza, A.M., Schiavon, G., Spoto, C., Silvestris, N., Addeo, R., Catalano, V., Graziano, F., Santini, D. \& Tonini, G. (2013) Identification of clinical predictive factors of oxaliplatin-induced chronic peripheral neuropathy in colorectal cancer patients treated with adjuvant Folfox IV. Support Care Cancer, 21(5), 1313-9.

Visovsky, C., Meyer, R.R., Roller, J. \& Poppas, M. (2008) Evaluation and management of peripheral neuropathy in diabetic patients with cancer. Clin J Oncol Nurs, 12(2), 243-7.

Wolf, S., Barton, D., Kottschade, L., Grothey, A. \& Loprinzi, C. (2008) Chemotherapyinduced peripheral neuropathy: prevention and treatment strategies. Eur $J$ Cancer, 44(11), 1507-15.

World Health Organization. (1948) Constitution of the World Health Organization. Geneva: World Health Organization.

World Health Organization. (2012) Globocan 2012: Cancer Incidence and Mortality Worldwide. IARC. http://globocan.iarc.fr. Accessed 180423.

World Health Organization. (2014) World Cancer Report 2014, IARC Publication.

World Health Organization. (2011) mHealth: New horizons for health through mobile technologies: based on the findings of the second global survey on eHealth (Global Observatory for eHealth Series. http://www.who.int/goe/publications/goe_mhealth_web.pdf. Accessed 180423.

World Health Organization Classification of Tumours. (2000) International Agency for Research on Cancer (IARC). Pathology and Genetics of Tumours of the Digestive System. IARC Press, Lyon.

World Health Organization. (2001) International Classification of Functioning, Disability and Health: ICF. 
World Medical Association. (2013) Declaration of Helsinki. Ethical Principles for Medical Research Involving Human Subjects, adopted by the 18th WMA General Assembly, Helsinki, Finland, June 1964, latest revision by the WMA General Assembly, Seoul 2013. Ferney-Voltaire, France.

Yothers, G., O'Connell, M.J., Allegra, C.J., Kuebler, J.P., Colangelo, L.H., Petrelli, N.J. \& Wolmark, N. (2011) Oxaliplatin as adjuvant therapy for colon cancer: updated results of NSABP C-07 trial, including survival and subset analyses. J Clin Oncol, 29(28), 3768-74.

Zimmer, P., Trebing, S., Timmers-Trebing, U., Schenk, A., Paust, R., Bloch, W., Rudolph, R., Streckmann, F. \& Baumann, F.T. (2018) Eight-week, multimodal exercise counteracts a progress of chemotherapy-induced peripheral neuropathy and improves balance and strength in metastasized colorectal cancer patients: a randomized controlled trial. Support Care Cancer, 26(2), 615-624.

Zucca, A., Sanson-Fisher, R., Waller, A. \& Carey, M. (2014) Patient-centred care: making cancer treatment centres accountable. Support Care Cancer, 22(7), 1989-97.

Zhang, M.F., Zheng, M.C., Liu, W.Y., Wen, Y.S., Wu, X.D. \& Liu, Q.W. (2015) The influence of demographics, psychological factors and self-efficacy on symptom distress in colorectal cancer patients undergoing post-surgical adjuvant chemotherapy. Eur J Oncol Nurs, 19(1), 89-96. 


\section{Papers}

The papers associated with this thesis have been removed for copyright reasons. For more details about these see:

http://urn.kb.se/resolve?urn=urn:nbn:se:liu:diva-147839 